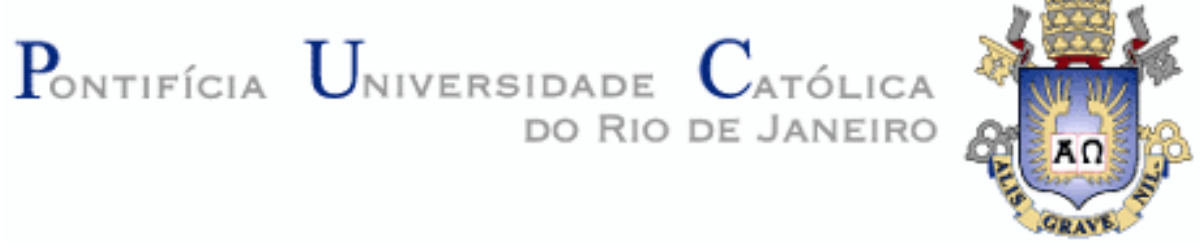

Bruno Farias Dantas

Estimativa do impacto no consumo de energia causado pelo standbydos aparelhos eletroeletrônicos

Dissertação de Mestrado

Dissertação apresentada como requisito parcial para obtenção do título de Mestre pelo Programa de PósGraduação em Metrologia (Área de concentração: Metrologia para Qualidade e Inovação) da PUC-Rio.

Orientador: Prof. Reinaldo Castro Souza Co-orientador: Prof. Rodrigo Flora Calili 
Bruno Farias Dantas

\section{Estimativa do impacto no consumo de energia causado pelo standbydos aparelhos eletroeletrônicos}

Dissertação apresentada como requisito parcial para obtenção do título de Mestre pelo Programa de PósGraduação em Metrologia (Área de concentração: Metrologia para Qualidade e Inovação) da PUC-Rio. Aprovada pela Comissão Examinadora abaixo assinada.

Prof. Reinaldo Castro Souza

Orientador/Presidente

Programa de Pós-Graduação em Metrologia (PósMQVPUC-Rio)

Prof. Rodrigo Flora Calili Co-Orientador Programa de Pós-Graduação em Metrologia (PósMQVPUC-Rio)

Prof. José Eduardo Nunes da Rocha Programa de Pós-Graduação em Metrologia (PósMQVPUC-Rio)

Profa. Claude Cohen Universidade Federal Fluminense

Prof. José Eugenio Leal Coordenador Setorial de Pós-Graduação do

Centro Técnico Científico (PUC-Rio)

Rio de Janeiro, 28 de agosto de 2014 
Todos os direitos reservados. É proibida a reprodução total ou parcial do trabalho sem autorização da universidade, do autor e do orientador.

\section{Bruno Farias Dantas}

Graduado em Marketing e pós-graduado em Gerenciamento de Projetos pela Escola de Negócios da Pontifícia Universidade do Rio de Janeiro (IAG PUC-Rio). Trabalhou nos últimos 10 anos na área de consultoria em projetos no setor elétrico e serviços públicos em parceria com a PUC-Rio. Atualmente atua como diretor administrativo/financeiro na empresa Unicom Comunicação e Promoção, e também como consultor pela PUC-Rio.

Ficha Catalográfica

Dantas, Bruno Farias

Estimativa do impacto no consumo de energia causado pelo standby dos aparelhos eletroeletrônicos / Bruno Farias Dantas ; orientador: Reinaldo Castro Souza ; co-orientador: Rodrigo Flora Calili. - 2014.

92 f. : il. (color.) ; $30 \mathrm{~cm}$

Dissertação (mestrado)-Pontifícia Universidade Católica do Rio de Janeiro, Programa de PósGraduação em Metrologia para a Qualidade e Inovação, 2014.

Inclui bibliografia

1. Metrologia - Teses. 2. Pesquisa de posses e hábitos. 3. Standby. 4. Conservação de energia. I. Souza, Reinaldo Castro. II. Calili, Rodrigo Flora. III. Pontifícia Universidade Católica do Rio de Janeiro. Programa de Pós-Graduação em Metrologia para a Qualidade e Inovação. IV. Título.

CDD: 389.1 
Este trabalho é dedicado à minha família, que me ofereceram a melhor educação que puderam. Ao meu amigo Sergio pela compreensão durante este período. E ao meu orientador Reinaldo, que possibilitou todo o estudo 


\section{Agradecimentos}

Ao meu orientador, Professor Reinaldo Castro Souza, pelo suporte acadêmico necessário para realização deste trabalho e por tantos anos de companheirismo, incentivos e fonte de inspiração.

Ao meu co-orientador, Professor Rodrigo Flora Calili, por toda colaboração técnica, empenho e disponibilidade despendida ao estudo.

À PUC-Rio, pelos auxílios concedidos, sem os quais este trabalho não poderia ter sido realizado.

Aos professores da Banca Examinadora, por contribuírem na formatação final deste trabalho, contribuindo também para sociedade, formação acadêmica e para a comunidade técnica.

A todos os professores do Mestrado e funcionários do Departamento da Metrologia da PUC-Rio, pelos seus esforços, dedicação e empenho para desenvolvimento contínuo do curso e reconhecimento pelas entidades envolvidas. Sem os quais este trabalho não poderia ter sido realizado.

Aos meus colegas de trabalho da PUC-Rio - NEC / IEPUC / ITUC, por tantos anos de convivência e realizações. E que juntos, se esforçaram durante o desenvolvimento do projeto de $\mathrm{P} \& \mathrm{D}$ de posses e hábitos de consumo com a concessionária Ampla e que proporcionou esta dissertação

Meus sinceros agradecimentos à minha família e amigos que de uma maneira indireta também participaram do estudo, permitindo-me medir seus respectivos aparelhos elétricos. 


\section{Resumo}

Dantas, Bruno Farias; Souza, Reinaldo Castro; Calili, Rodrigo Flora. Estimativa do impacto no consumo de energia causado pelo standby dos aparelhos eletroeletrônicos. Rio de Janeiro, 2014. 92p. Dissertação de Mestrado - Programa de Pós-Graduação em Metrologia (Área de concentração: Metrologia para Qualidade e Inovação), Pontifícia Universidade Católica do Rio de Janeiro.

Através da função standby, um aparelho elétrico sai do seu modo de operação principal (em funcionamento); mas permanece ligado assumindo uma função em espera com o objetivo de economizar energia elétrica, até que o consumidor volte a utilizar o equipamento. Nesta dissertação é apresentada a estimativa do consumo de energia com o uso do standby em aparelhos elétricos de utilização doméstica; e o impacto financeiro deste desperdício para a população. $\mathrm{O}$ estudo foi motivado como forma de contribuir para o real entendimento deste consumo e oferecer subsídios que sirvam de alerta; visto que há um aumento da presença da tecnologia standby nos aparelhos existentes, e surgimento de novos equipamentos que possuem um consumo ocioso (quando não estão em funcionamento), podendo este cenário estar indo no caminho contrário às políticas atuais de conservação de energia. Para a estimativa, inicialmente foram utilizadas informações de Pesquisas de Posses e Hábitos de uso (PPH) de aparelhos elétricos para se traçar um panorama da forma como cada aparelho é utilizado sobre o modo de operação standby; em seguida coletaram-se informações de consumo de energia elétrica obtidas através de medições dos próprios equipamentos elétricos, onde foi identificado que o aparelho de TV por assinatura é o grande "vilão" do consumo ocioso em standby. $\mathrm{O}$ último passo foi extrapolar as informações estimadas para uma concessionária local e para o Brasil, e simular o desperdício de energia elétrica com o consumo do standby nos aparelhos elétricos de uso doméstico, chegando-se ao resultado de 1,6 TWh/ano de desperdício alocado aos consumidores residenciais do Brasil, o que representa 1,9\% do volume de vendas de energia no segmento.

\section{Palavras-chave}

Metrologia; Pesquisas de posses e hábitos; Standby; Conservação de energia. 


\section{Abstract}

Dantas, Bruno Farias; Souza, Reinaldo Castro (Advisor); Calili, Rodrigo Flora (Co-advisor). Estimated impact on energy consumption caused by the standby electronic appliances. Rio de Janeiro, 2014. 92p. MSc. Dissertation - Programa de Pós-Graduação em Metrologia (Área de concentração: Metrologia para Qualidade e Inovação), Pontifícia Universidade Católica do Rio de Janeiro.

Through the standby function, an electrical device goes out of your main operation mode (in use); but remains "on", assuming a waiting function to save electricity, until the consumer reuse the equipment. In this dissertation, the estimated power consumption is presented with the use of standby function in electrical appliances from domestic use; and the financial impact of this waste to the population. The study was motivated as a way to contribute to the real understanding of this consumption, and offer subsidies that serve as warning; since there is an increased presence of the standby technology in existing devices, and the emergence of new equipments that has an idle consumption (when not operating), perhaps this scenario may be going against the current policies of energy conservation. To estimate, initially was used information from Electrical Appliances Ownership Survey to draw a picture of how each device is used in standby operation; then collected information about power consumption obtained through measurements of each electrical equipment, where it was identified that cable TV is the biggest "villain" of the idle standby consumption. The last step was to extrapolate the estimates for a local electric utility and Brazil, and simulate the waste of electrical energy consumption in the standby electrical household appliances, coming to the result of $1.6 \mathrm{TWh} /$ year of waste allocated to residential consumers in Brazil, which represents $1,9 \%$ of the energy sales in the segment.

\section{Keywords}

Metrology; Electrical Appliances Ownership Survey; Standby; Energy conservation. 


\section{Sumário}

1 Introdução 16

$\begin{array}{lr}\text { 1.1. Contexto } & 18\end{array}$

1.2. Características do problema 19

1.3. Objetivos 20

2 Standby $\quad 21$

2.1. Definição 21

2.2. Variações do Standby

2.3. Simbologia $\quad 24$

2.4. Estudos internacionais sobre o consumo do standby 25

3 Pesquisa de Posses e Hábitos de uso (PPH) 27

3.1. Breve histórico 28

3.2. Estudo de caso 29

4 Metodologia de pesquisa $\quad 35$

4.1. Identificação da quantidade de horas de funcionamento dos equipamentos elétricos em modos de utilização e standby 35

4.2. Identificação do consumo dos equipamentos elétricos em modos de utilização e standby 43

$\begin{array}{ll}5 \text { Resultados } & 46\end{array}$

5.1. Estimativa do consumo de energia elétrica desperdiçada no Brasil com o uso do standby 58

$\begin{array}{ll}6 \text { Conclusões } & 61\end{array}$

7 Referências bibliográficas $\quad 65$

APENDICE I- Dados da PPH sobre a utilização dos equipamentos elétricos 69 
APENDICE II - Informações sobre medição dos equipamentos elétricos

ANEXO I - Instrumento de coleta de dados para classe residencial

AMPLA (PPH)

ANEXO II - Tabela de estimativa de consumo médio mensal de eletrodomésticos

ANEXO III - Relatório anual de Demonstrações Financeiras da AMPLA (2012) - Número de consumidores

ANEXO IV - Relatório anual de Demonstrações Financeiras da AMPLA (2012) - Volume de vendas

ANEXO V - Anuário Estatístico de Energia Elétrica 2011: Consumo por classe

ANEXO VI - Anuário Estatístico de Energia Elétrica 2011: Consumidores por classe

ANEXO VII - Anuário Estatístico de Energia Elétrica 2013: Tarifa média por classe 


\section{Lista de figuras}

Figura 1: Símbolos de desligamento dos aparelhos eletroeletrônicos 24

Figura 2: Simulador SINPHA $\quad 29$

Figura 3: Polos regionais e municípios que fizeram parte da amostra 30

Figura 4: Curva de carga residencial AMPLA por aparelho elétrico 32

Figura 5: Participação de eletrodomésticos no consumo residencial da

AMPLA 32

Figura 6: Medidor Powersave $\quad 44$

Figura 7: Percentual de aparelhos que são utilizados em modo standby 46

Figura 8: Participação do tempo de utilização dos equipamentos por modo de operação $\quad 47$

Figura 9: Quantidade de horas sobre o funcionamento em standby no ano (dados extrapolados da PPH) 49

Figura 10: Quantidade de horas sobre o funcionamento em standby no ano (x) Posse média de aparelhos

Figura 11: Quantidade de horas sobre o funcionamento em standby no mês ( $\mathrm{x}$ ) Consumo do standby no mês (em kWh)

Figura 12: Consumo mensal (em kWh) dos equipamentos por sua utilização e pelo standby

Figura 13: Consumo mensal (em kWh) do standby em relação ao consumo da utilização dos equipamentos

Figura 14: Percentual de aparelhos que usam standby (x) Participação de funcionamento dos aparelhos em standby $(\mathrm{x})$ Consumo do standby/mês (kWh)

Figura 15: Consumo de energia elétrica desperdiçada na AMPLA com o uso dos equipamentos em modo standby (em GWh)

Figura 16: Posse média de aparelhos que usam standby $(\mathrm{x})$ Consumo mensal do standby de cada aparelho $(\mathrm{x})$ Consumo médio do standby por consumidor 


\section{Lista de tabelas}

Tabela 1: Amostra PPH realizada na AMPLA 30

Tabela 2: Consumo dos aparelhos elétricos em modo standby da PPH 33

Tabela 3: Estimativa de utilização do equipamento dentro do período condensado $0 \mathrm{~h}$ a $6 \mathrm{~h} \quad 40$

Tabela 4: Quantidade de horas de operação dos equipamentos em utilização, e em standby (dados da amostra da PPH) 48

Tabela 5: Informações da AMPLA para extrapolação dos dados da PPH 48

Tabela 6: Quantidade de horas de funcionamento dos aparelhos (dados extrapolados da PPH) $\quad 50$

Tabela 7: Consumo de energia dos equipamentos sobre os modos de operação: em utilização, e em standby 52

Tabela 8: Consumo de energia elétrica desperdiçado na AMPLA com o uso do standby 56

Tabela 9: Consumo médio hipotético do standby por consumidor AMPLA 57

Tabela 10: Consumo médio hipotético do standby por consumidor AMPLA 58

Tabela 11: Consumo médio hipotético do standby por consumidor Brasil 59

Tabela 12: Consumo de energia elétrica desperdiçado no Brasil com o uso do standby

Tabela 13: Dados da PPH sobre a utilização do aparelho de ar condicionado $\quad 69$

Tabela 14: Dados da PPH sobre a utilização do televisor 69

Tabela 15: Dados da PPH sobre a utilização do forno de micro-ondas $\quad 69$

Tabela 16: Dados da PPH sobre a utilização da lavadora de roupas $\quad 70$

Tabela 17: Dados da PPH sobre a utilização do computador 70

Tabela 18: Dados da PPH sobre a utilização da cafeteira elétrica 70

Tabela 19: Dados da PPH sobre a utilização do aparelho de som 70

Tabela 20: Dados da PPH sobre a utilização do rádio elétrico 71

Tabela 21: Dados da PPH sobre a utilização do vídeo cassete 71

Tabela 22: Dados da PPH sobre a utilização do DVD 71

Tabela 23: Dados da PPH sobre a utilização da impressora 71

Tabela 24: Dados da PPH sobre a utilização do vídeo game 72 
Tabela 25: Dados da PPH sobre a utilização do aparelho de TV por assinatura $\quad 72$

Tabela 26: Dados de medição dos condicionadores de ar 73

Tabela 27: Dados de medição dos televisores de LED 73

Tabela 28: Dados de medição dos televisores de LCD 73

Tabela 29: Dados de medição dos televisores CRT 74

Tabela 30: Dados de medição dos fornos de micro-ondas 74

Tabela 31: Dados de medição das lavadoras de roupas 74

Tabela 32: Dados de medição dos computadores 74

Tabela 33: Dados de medição das cafeteiras elétricas $\quad 75$

Tabela 34: Dados de medição dos aparelhos de som $\quad 75$

Tabela 35: Dados de medição dos rádios elétricos 75

Tabela 36: Dados de medição dos aparelhos de vídeo cassete $\quad 75$

Tabela 37: Informações de medição dos aparelhos de DVD 75

Tabela 38: Dados de medição das impressoras 76

Tabela 39: Dados de medição dos aparelhos de vídeo game 76

Tabela 40: Dados de medição dos aparelhos de TV por assinatura 76 


\section{Lista de quadros}

Quadro 1: Aparelhos eletroeletrônicos estudados na PPH 31

Quadro 2: Aparelhos eletroeletrônicos selecionados 


\section{Lista de abreviaturas}

GIZ

BIRD

LED

IDEC

PNE

PPH

IEC

IEEE

INMETRO Instituto Nacional de Metrologia

PBE

OCDE

IEA

MME

PRODIST

Plano Nacional de Energia

Internacional de Eletrotécnica) Energia)

Ministério de Minas e Energia
Deutsche Gesellschaft für Technische Zusammenarbeit

(Agência Alemã de Cooperação Internacional)

Banco Internacional para Reconstrução e Desenvolvimento

Light Emitting Diode (Diodo Emissor de Luz)

Instituto Brasileiro de Defesa do Consumidor

Pesquisa de Posses e Hábitos por uso final

International Electrotechnical Commission (Comissão

Institute of Electrical and Electronics Engineers (Instituto de Engenharias Elétrica e Eletrônica)

Programa Brasileiro de Etiquetagem

Organização para Cooperação e Desenvolvimento Econômico

International Energy Agency (Agência Internacional de

Procedimentos de Distribuição de Energia Elétrica no Sistema Elétrico Nacional 
ANEEL Agência Nacional de Energia Elétrica

PROCEL Programa Nacional de Conservação de Energia Elétrica

SINPHA Sistema de Informação de Posses e Hábitos de Uso de Aparelhos Elétricos

Standby and Off-Mode Energy Losses in New Appliances

SELINA Measured in Shops (Perdas de Energia com Standby e Off-

Mode em Novos Aparelhos medidos em Lojas)

BEU Balanço de Energia Útil 


\section{1 \\ Introdução}

Mais de vinte séculos se passaram desde que o filósofo e matemático grego Tales de Mileto propôs uma primeira explicação para os fenômenos magnéticos - analisando as propriedades de atração e repulsão da pedra magnetita - até à invenção da primeira lâmpada incandescente pelo norteamericano Thomas Edison. A partir desse luminoso ano de 1880 a eletricidade estendeu-se em todas as facetas e atividades do cotidiano.

A eletricidade é uma das formas de energia mais importantes para a sociedade moderna, indispensável ao progresso, garantindo além da produção de bens e serviços, o convívio social dentro dos padrões modernos praticados [1]. Além disso, o uso de energia elétrica é geralmente considerado como um índice de crescimento socioeconômico e industrial para qualquer país [2].

A evolução tecnológica e demográfica assim como a procura de um maior bem-estar e de melhor qualidade de vida, conduzem a humanidade a um avanço cada vez maior do consumo energético, associado a todos os tipos de atividades e tarefas diárias. E por estar tão enraizada nos nossos gestos e tarefas, abdicar da eletricidade nos seria algo impossível. Já não conseguiríamos viver sem iluminação, nem deixar de usufruir dos inúmeros equipamentos elétricos que nos acercam. Seríamos incapazes de passar os dias sem usar televisores, computadores e aparelhos celulares. Não toleraríamos a ausência dos equipamentos elétricos de resfriamento e aquecimento que nos proporcionam o conforto.

A eletricidade se tornou a principal fonte de luz, calor e força utilizada no mundo moderno. Atividades simples como assistir à televisão ou navegar na internet são possíveis porque a energia elétrica chega até a sua casa. Fábricas, supermercados, shoppings e uma infinidade de outros lugares precisam dela para funcionar. Além do que, grande parte dos avanços tecnológicos que alcançamos se deve à energia elétrica [3].

A sua geração, no entanto, é cara, exigindo grandes investimentos e geralmente causando algum impacto ambiental. Por esta razão, conservar energia é fundamental, não apenas como forma de poupar dinheiro, mas 
também combatendo o desperdício e aproveitando a energia de forma racional e inteligente, sem privação do conforto [4].

Atualmente a eletricidade é produzida através da transformação de fontes de energia primárias (carvão, gás natural, petróleo, gasolina, água, vento, sol, biomassa, resíduos). Esta transformação processa-se em diferentes tipos de centrais elétricas, conforme o tipo de energia primária utilizada (centrais hidroelétricas, centrais eólicas, centrais solares, centrais térmicas, centrais núcleares, ...).

Nos dias atuais, o setor elétrico depara-se com importantes problemas e desafios, dentre os quais o esgotamento dos combustíveis fósseis (que representam 57,6\% da matriz energética brasileira [5], a redução das zonas de abastecimento, o maior desenvolvimento industrial que impulsiona o aumento das importações de energia e o crescimento da base de consumidores somados à crescente degradação ambiental.

Em face desta situação, torna-se cada vez mais necessária, a busca de várias alternativas, como por exemplo, a eficiência energética e a produção de energia elétrica utilizando recursos naturais renováveis.

Antes de discutirmos e apoiarmos investimentos bilionários em novas fontes de energia limpa, a eficiência energética aparece como uma alternativa muito mais barata e como seu nome já diz, mais eficiente. Ela poupa recursos naturais, diminui os custos de produção - bens e produtos serão cada vez mais baratos sem prejuízo de suas qualidades - e reduz o investimento em geração de energia, entre outros fatores.

No final de 2010, estudo da Associação Brasileira das Empresas de Serviços de Conservação de Energia [6] e GTZ (agora GIZ) [7] concluiu que o desperdício energético brasileiro chega a $\mathrm{R} \$ 15$ bilhões. Já os números do Banco Mundial (Bird) indicam que se aprendêssemos a usar efetivamente 0 nosso potencial de eficiência energética, economizaríamos mais de $R \$ 4$ bilhões por ano, apenas por racionalizar o uso de nossos recursos [8].

Os nossos hábitos diários, no que se refere ao consumo da energia, refletem-se direta ou indiretamente no meio que nos rodeia (esgotar os recursos; incrementar a produção de resíduos, etc.). É importante que tenhamos consciência deste fato e que urgentemente adquiramos hábitos mais amigos do ambiente. 


\section{1.}

\section{Contexto}

As tentativas de reduzir o consumo de energia proliferam na medida das discussões sobre as alternativas de geração. Se por um lado é preciso definir outras fontes para atender a crescente demanda, por outro deve-se promover o uso racional de energia, reduzindo o consumo de forma eficiente, sem afetar a qualidade dos serviços proporcionados pela eletricidade.

A substituição das lâmpadas incandescentes por fluorescentes nas residências e escritórios, ou as de mercúrio por vapor de sódio na iluminação pública, são exemplos de conservação; Isso sem mencionar as lâmpadas LED, que apesar de serem mais caras que as fluorescentes, são duas vezes mais eficientes, e se comparadas às incandescentes podem ser até oito vezes mais eficientes, além de terem uma vida útil de cinqüenta mil horas (uma lâmpada incandescente possui cerca de 1.000h).

Dentro do contexto de melhor uso da energia deve-se considerar a minimização do consumo do standby. Quando equipamentos eletrônicos ficam ligados em sistema de espera, sem operar, o consumo é muito grande. Segundo o Instituto Brasileiro de Defesa do Consumidor, o IDEC, o consumo mensal de energia de uma residência pode aumentar em até 15\% [9]. Já o Inmetro afirma que cada televisor que esteja utilizando o modo standby pode aumentar o valor da conta de energia elétrica em até $\mathrm{R} \$ 2$ por mês [14].

O Brasil conta com o Plano Nacional de Eficiência Energética, que tem como uma de suas linhas de ações propostas, estudar a possibilidade de estabelecer padrões mínimos ou sistemas de níveis de eficiência energética em modo de espera (standby) para equipamentos de uso final [23]. Porém, esses padrões ainda não foram estabelecidos, dando apenas abertura para ser uma das diretrizes de atuação do Plano. 


\section{2. \\ Características do problema}

A grande quantidade de aparelhos elétricos hoje existentes no mercado torna mais prática a vida de seus consumidores. O "controle remoto" é um dos grandes símbolos das facilidades da vida moderna. Aliados à tecnologia e a necessidade dos usuários de se manterem conectados, observa-se cada vez mais a inserção destes equipamentos dentro dos domicílios.

Com o avanço tecnológico os equipamentos elétricos buscam se tornarem cada vez mais práticos e acessíveis, de forma que o controle remoto de televisão já está sendo substituído por um simples gesto que faça com que o aparelho ligue ou desligue.

A verdade é que equipamentos como TV, DVD, computadores, microondas e máquinas de lavar, caso não sejam desligados diretamente no aparelho (e não no controle remoto) e alguns até mesmo da tomada, continuam consumindo uma energia silenciosa.

Grande parte dos equipamentos de que dispomos hoje em dia pode causar maior impacto no consumo de energia não quando eles estão em uso, mas sim quando estão supostamente desligados.

Estes dispositivos que ao mesmo tempo tornam mais práticos a maioria dos aparelhos e o cotidiano, possuem um consumo de energia associado ao seu modo de "espera" para ser utilizado; Ou seja, o aparelho que não é desligado na tomada, possui um consumo de energia denominado de standby (ou "modo em espera" em português). Formalmente, este consumo já é tido como um problema e é chamado de desperdício de energia do standby.

A preocupação com o consumo de energia é mundial e tem havido esforços em vários países visando uma maior conscientização da população com relação ao gasto de energia e, principalmente, com relação ao gasto de energia de aparelhos em modo standby. Por exemplo, há estudos e plano de ações nos governos dos EUA, Canadá e Austrália que buscam a eficiência energética, não apenas no uso de fontes de energia renováveis, mas também no consumo eficiente dos aparelhos. Essas iniciativas objetivam a redução do consumo de energia em cerca de 75\% no modo standby até 2015 [9].

Entender e poder estimar este consumo dentro dos domicílios é de suma importância para se saber o quanto realmente há de desperdício, e poder criar possíveis soluções que possam mitigar essa situação. 


\section{3.}

\section{Objetivos}

O objetivo dessa dissertação é de se estimar o quanto representa o consumo do standby por aparelho eletrodoméstico e dentro dos domicílios, considerando as informações obtidas através das declarações de posses e hábitos de uso (PPH), e do consumo elétrico identificado através de medidores eletrônicos com memória de massa instalados dentro dos domicílios.

Como objetivo secundário, busca-se dimensionar o quanto representaria a economia de energia caso fosse evitado o desperdício deste tipo de consumo (standby) dentro das residências. 


\section{2 \\ Standby}

A primeira descrição sobre a eletroluminescência, o princípio básico dos LEDs, foi escrita pelo científico Henry Joseph Round em 1907, ao observar que certos semicondutores emitem luz quando uma corrente elétrica passa por eles [10]. Em 1950 foi criado o primeiro controle remoto, o qual realizava o comando por cabos e recebeu o nome de "ossos preguiçosos" [11]; Porém, somente em 1962 o LED comercial foi criado pelo engenheiro Nick Holonyak, que aliado ao desenvolvimento do controle remoto sem fio com utilização de raios infravermelhos no início da década de 80 , teve papel fundamental na permissão do modo de operação em standby e seu uso em larga escala.

\section{1. Definição}

Standby significa em espera, e é um termo oriundo do inglês. A palavra Standby foi designada a uma função muito utilizada em aparelhos eletrônicos. A "grosso modo" quando determinado aparelho fica em standby, significa que ele está ligado, mas não sendo utilizado, com o objetivo de economizar bateria ou energia elétrica.

Sendo assim, o Standby é utilizado para designar o modo de espera da energia elétrica nos aparelhos eletrônicos, por exemplo, computadores, rádios, DVDs, geladeiras, maquinas de lavar, televisores, videogames, celulares e etc. Quando o aparelho fica em standby ele facilita o usuário, pois continua funcionando, porém diminuindo o consumo de energia.

A norma IEC ${ }^{1} 62301$ [12] especifica os métodos de medição do consumo de energia elétrica em modo de espera (standby) e outros modos de baixa potência (off-mode), conforme aplicável. Para benefício dos consumidores e

${ }^{1}$ O International Electrotechnical Commission (IEC) é a organização internacional responsável pela padronização e avaliação da conformidade para todas as tecnologias elétricas, eletrônicas e afins. 
economia ao meio ambiente, esta Norma Internacional fornece um método de teste para determinar o consumo de energia de uma gama de produtos, permitindo medições mais precisas e ajudando a indústria a produzir eletrodomésticos e sistemas que ofereçam um menor consumo de energia quando o produto não está no modo ativo (ou seja, não está realizando uma função primária). Esta norma não especifica os requisitos de segurança. Ela não especifica requisitos mínimos de desempenho nem estabelece limites máximos de potência ou consumo de energia.

\section{2. \\ Variações do Standby}

Várias são as tentativas de se encontrar uma definição completa e abrangente, que torne fácil o entendimento da operação e do consumo energético, quando equipamentos eletroeletrônicos estão operando sob o modo standby. Porém, devido aos diversos avanços tecnológicos, muitos recursos são aplicados nos diferentes equipamentos eletroeletrônicos, dificultando uma singular definição.

Assim, o termo "standby" continua sendo muito confuso. Em alguns produtos ele se refere a um estado de repouso ou "sono", onde o aparelho continua em operação mas sem sua função primária ativa; em outros o standby refere-se ao modo mínimo de energia de um dispositivo, que normalmente é o estado desligado. Com a finalidade de se padronizar o conceito dos modos de operação dos equipamentos, diversas definições são utilizadas para descrever a forma de utilização dos equipamentos no modo standby; encontradas em diversos sites de entidades governamentais, de indústrias ou de pessoas físicas que comentam sobre este assunto. Estabelecem-se de uma maneira geral as seguintes operações existentes:

- Standby ativo: Neste modo o aparelho nunca é desligado, apenas não está desenvolvendo a sua função principal. Como exemplos têm-se um microcomputador que se encontra ligado, mas não está em utilização de nenhuma função. Neste estado o aparelho apresenta aparentes indicações de consumo de energia, seja com a tela ligada ou em repouso. 
- Standby passivo: Quando o aparelho encontra-se desligado de suas funções principais, mas está à espera de algum comando para que seja ligado novamente, em muitos casos através de um controle remoto (mas não necessariamente). A televisão quando é desligada através do controle remoto é um exemplo; O rádio-relógio quando é desligado através de um botão no próprio aparelho, porém continua em funcionamento de um display indicando as horas, é outro exemplo do modo standby passivo. Neste estado o aparelho possui alguma indicação de consumo de energia (seja através de uma luz LED ou display aceso).

- Off-mode: Neste modo o aparelho deve ser desligado no próprio equipamento através de um botão mecânico liga/desliga, mas continuar conectado a uma fonte de energia. A máquina de lavar roupas quando encontra-se desligada e conectada à tomada, é um exemplo de aparelho em off-mode. Neste estado o equipamento não possui nenhuma indicação aparente de consumo (não há display aceso, e nenhuma luz LED, etc) mas pode estar consumindo energia.

Enquanto muitos produtos eletrônicos têm a capacidade de colocar-se em modos de baixo consumo de energia (standby), um número significativo destes produtos desnecessariamente permanecem ligados 24 horas por dia, sete dias por semana, gastando bilhões de dólares em energia por ano. Uma parte significativa do motivo pelo qual isso acontece é que a interface do usuário para os controles destas funções é confusa, inconsistente, ou mesmo ausente. A interface hoje existente para o usuário inclui botões de energia e interruptores, indicadores de energia por diferentes modos de repouso, painéis de controle por software, bem como, símbolos e cores utilizados em todos, e nem sempre padronizados. 


\section{3. \\ Simbologia}

A simbologia da função do standby ainda hoje não encontra-se totalmente consolidada pelo mercado, atribuindo-se símbolos diferentes de acordo com equipamentos e fabricantes distintos. De toda forma, o IEC descreve os símbolos de liga e desliga para os aparelhos eletroeletrônicos através da norma IEC 60417 [13] publicada a partir de 1973; que apresenta os símbolos conforme a Figura 1.

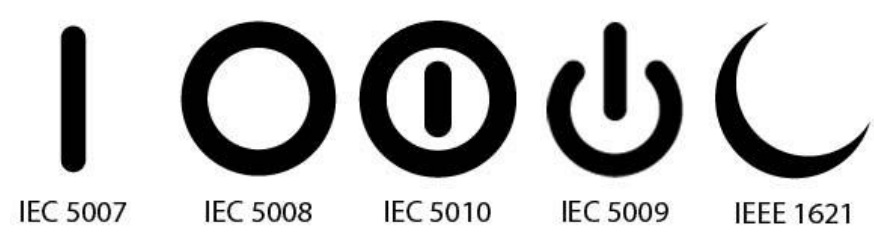

Figura 1: Símbolos de desligamento dos aparelhos eletroeletrônicos [13]

De acordo com a norma; o IEC 5007 é o símbolo para ligar (power on). Aparece em um botão ou em um dos lados dos interruptores tipo gangorra ou chave. Indica que um equipamento está totalmente ligado. A origem do símbolo está no número 1 do sistema binário, ou seja, ligado.

O símbolo para desligar (power off) é o IEC 5008. Ele vem do zero e indica que ao acionar o botão, ou chave, a energia não estará mais correndo pelo sistema.

O símbolo IEC 5010 é usado em botões que alteram o estado do sistema entre ligado e totalmente desligado. Botão liga-desliga (on-off).

O IEC 5009 é o standby. Este símbolo em um botão deveria representar um desligamento parcial do sistema, indicando um estado de baixo consumo de energia. Para a divisão responsável pela padronização do Institute of Electrical and Electronics Engineers, atrávés da norma IEEE 1621, Power Management Controls; aprovada em 2004, ele pode simplesmente indicar "ligar".

A lua crescente, indicaria o modo hibernar ou dormir (sleep). É também uma proposição da IEEE 1621 para substituir o entendimento original do símbolo para standby.

Mesmo com os símbolos definidos, não há uma obrigatoriedade imposta aos fabricantes para a utilização dos mesmos em seus produtos. E apesar dos esforços por tentativas de padronização, o que temos hoje específico para este 
consumo é um selo do Inmetro [14], como parte do Programa Brasileiro de Etiquetagem de classificação de consumo de energia, e que inclui em alguns poucos casos (aparelhos televisores), o consumo do equipamento em modo standby.

\section{4.}

\section{Estudos internacionais sobre o consumo do standby}

Distintos estudos indicam que a potência do standby é de 20-60W por casa, em países desenvolvidos. Para os países da $\mathrm{OCDE}^{2}$ este consumo é responsável por cerca de $2 \%$ do consumo total de eletricidade, e a energia gerada equivale a quase $1 \%$ de suas emissões de carbono [15].

Em 2010, foi realizada uma campanha de monitoramento de energia em 12 países geograficamente representativos da UE, com o objetivo de compreender o consumo de energia nos lares para os diferentes tipos de eletrodomésticos e comportamento dos consumidores no que diz respeito a níveis de conforto e levantamento de estilo de vida [16]. A partir das medições realizadas, concluiu-se que o consumo de energia elétrica anual com standby por família é de cerca de $305 \mathrm{kWh}$, ou $11 \%$ do total anual de consumo de energia elétrica por familia (excluindo cargas de aquecimento).

$\mathrm{Na}$ cidade de Halifax no Canadá, quatro varejistas de eletrodomésticos foram estudados juntamente com 75 casas residenciais, amostrando uma ampla gama de eletrodomésticos para serem medidos e analisados. Usando os resultados deste campo, o estudo estimou um consumo médio anual do standby por família de $427 \mathrm{kWh}$, afirmam ainda que este gasto poderia ser minimizado em $59 \%$ se o requisito de potência para o modo em espera de todos os aparelhos fosse reduzido a meta de $1 \mathrm{~W}$ [17].

Outro estudo que investigou o consumo do standby em 10 residências na Califórnia, estimou que a perda de energia com o modo em espera corresponde a 5-26\% do gasto anual destas casas com energia elétrica [18].

$\mathrm{Na}$ Austrália, um estudo de medição de energia em standby de aparelhos elétricos [19], afirma que a potência do standby em muitos aparelhos ainda está bem acima da meta nacional de até $1 \mathrm{~W}$. Verificou-se também, que a diferença

${ }^{2}$ Organização de Cooperação e de Desenvolvimento Económico. É uma organização internacional, composta por 34 países e com sede em Paris, França. A OCDE tem por objetivo promover políticas que visem o desenvolvimento econômico e o bem -estar social de pessoas por todo o mundo. 
entre o valor mínimo e o valor máximo de potência em espera pode ser grande, chegando a mais $22 \mathrm{~W}$ para equipamentos de home theater, por exemplo. A substituição de um aparelho com essa potência para o standby poderia reduzir em $170 \mathrm{kWh}$ o consumo anual de uma casa; isto seria equivalente a economia de US\$32 por ano e 177,7kg de emissões de CO2.

No estudo sobre o uso de energia em espera e seu potencial de economia na China [20], foram pesquisados e medidos através do consumo, os eletrodomésticos em 28 casas urbanas chinesas. A potência do standby combinado para todos os aparelhos foi de cerca de $29 \mathrm{~W}$ por casa. E o consumo do modo em espera destes aparelhos extrapolados para todo o segmento residencial na China, exige o equivalente de saída elétrica de pelo menos seis usinas 500MW.

Na Argentina, a participação do consumo médio de energia standby dentro do consumo total de energia na área residencial metropolitana de Buenos Aires foi estimada em 7,7\% [21]. O estudo mostrou ainda que havia uma média de 12,5 aparelhos que são operados sobre o modo standby por família.

As estimativas das perdas com o standby na literatura científica no entanto, não são tão consistentes segundo Nakagami et al [2], uma vez que existem diferentes modos de espera dos equipamentos quando estão em standby, e a forma de estimativa e análise deste consumo não são padronizadas. A definição sugerida pela Agência Internacional de Energia (IEA) para o consumo sobre o uso do standby, considera a energia mínima consumida quando o aparelho não esteja realizando nenhuma função.

As reduções de consumo alcançadas através da melhor utilização do standby exigem uma colaboração internacional, onde os custos e grandes benefícios conseguidos por tais práticas, seriam distribuídos por todos os países. 


\section{3 \\ Pesquisa de Posses e Hábitos de uso (PPH)}

A Pesquisa de Posses e Hábitos de uso (PPH) é uma pesquisa declaratória que traça um perfil da posse e hábitos de consumo de equipamentos elétricos no setor residencial, com o intuito de avaliar o mercado de eficiência energética nas cinco regiões do Brasil [22]. Essa pesquisa permite o cálculo de uma estimativa do consumo de energia elétrica de uma unidade consumidora, e a elaboração da sua respectiva curva de carga elétrica.

A PPH já é um instrumento amplamente difundido dentro do setor de energia elétrica. As informações obtidas têm sido utilizadas principalmente pelas distribuidoras de energia elétrica e pelo MME [23], seja para conhecer o perfil dos consumidores, para formular estratégias de investimentos em eficiência energética, de gestão de projetos do lado da demanda e o estabelecimento de política energética.

A metodologia adota uma pesquisa quantitativa onde se é aplicado um instrumento de coleta de dados de auditoria energética de posses e hábitos de uso de todos os equipamentos elétricos existentes dentro de residências e comércio. Essas informações coletadas em campo permitem a classificação das posses e consumo sob diversas óticas, fornecendo parâmetros para o estabelecimento de ações por parte das concessionárias, para apoiar a formulação de políticas públicas voltadas para o uso eficiente da energia e alavancar estratégias de gerenciamento da demanda pela Concessionária de energia elétrica.

As Pesquisas de Posses e Hábitos fazem parte dos Procedimentos de Distribuição - PRODIST; que são documentos elaborados pela ANEEL que normatizam e padronizam as atividades técnicas relacionadas ao funcionamento e desempenho dos sistemas de distribuição de energia elétrica [24]. 


\section{1. Breve histórico}

A primeira pesquisa de campo, quantitativa, denominada "Pesquisa de Posse de Eletrodomésticos e Hábitos de uso - PPH", na classe residencial, em âmbito nacional, teve a coordenação da Eletrobrás, por meio do PROCEL, e foi realizada em 1988. Esta pesquisa foi realizada na época em 291 municípios em 23 estados brasileiros e no Distrito Federal, contemplando todas as regiões do país e contou com o apoio de 27 concessionárias locais.

Entre os anos de 1997 e 1998, o PROCEL, em parceria com a PUC-Rio, e sob coordenação da Eletrobrás, desenvolveu uma metodologia aplicada aos consumidores residenciais e comerciais atendidos em baixa tensão para apurar as posses de equipamentos e hábitos de uso dos mesmos. Este trabalho foi realizado em 15 estados brasileiros e no Distrito Federal, com a colaboração de 20 concessionárias de energia elétrica.

A partir daí, esta metodologia vem sendo aplicada para acompanhamento e monitoração das posses e hábitos do uso destes equipamentos elétricos em clientes atendidos na baixa tensão. Nos anos de 2004 a 2006 a pesquisa ocorreu com a mesma coordenação e execução da anterior, porém com um escopo mais amplo, abrangendo os seguintes segmentos de consumo: residencial, comercial/industrial (baixa tensão), comercial/industrial (alta tensão) e poderes públicos (alta tensão). Foram contemplados 17 estados e o Distrito Federal, com a participação de 21 concessionárias de energia elétrica.

Atualmente, muitas distribuidoras de Energia Elétrica realizam suas PPHs a partir de suas revisões tarifárias. Através da criação do SINPHA (Sistema de Informações de Posses de eletrodomésticos e Hábitos de consumo) para o Portal PROCEL Info (Figura 2), encontram-se disponíveis indicadores sobre posse de equipamentos e hábitos de consumo de energia do segmento residencial a nível nacional [25].

Neste portal pode-se obter:

- Informações que estão relacionadas ao mercado de eficiência energética, como: estudo, análise e indicadores de dados.

- Acesso de forma eficaz aos dados e a realização de simulações das curvas de carga.

- Informações de PPH dos anos de 1997 e 2004-2006. 


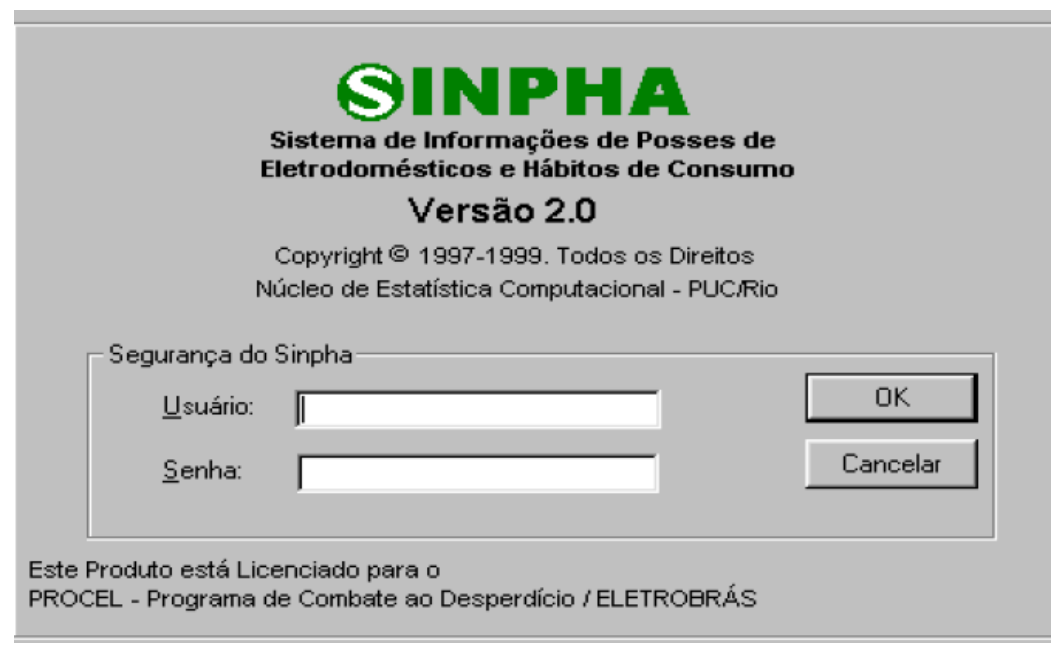

Figura 2: Simulador SINPHA [22]

\section{2. \\ Estudo de caso}

Esta dissertação utilizou-se dos dados obtidos através do projeto de Pesquisa e Desenvolvimento "Desenvolvimento de coeficientes de ajustes das declarações de pesquisas de clientes para a estimativa e simulação do consumo por uso final dos consumidores" [26] desenvolvido pela Pontifícia Universidade Católica do Rio de Janeiro (PUC-Rio), e onde foi estudado, através de Pesquisas de Posses e Hábitos (PPH), o perfil elétrico dos consumidores residenciais da AMPLA.

A concessionária de distribuição de energia elétrica Ampla Energia e Serviços S.A., atende cerca de 2,5 milhões de clientes residenciais, comerciais e industriais em 66 municípios do Rio de Janeiro, que representam 73\% do território do Estado, com a cobertura de uma área de 32.188 km2. A Região Metropolitana de Niterói e São Gonçalo e os municípios de Itaboraí e Magé concentram a maior parte dos clientes da distribuidora, que são, ao todo, sete milhões de pessoas [27].

O Objetivo desse projeto compreendeu o desenvolvimento de coeficientes de ajustes que minimizem as imprecisões das declarações de consumo e a elaboração de uma ferramenta computacional que apresente um modelo de curva de carga de demanda de energia elétrica residencial desagregada por usofinal, a partir de um fator de ajuste das cargas estimadas através de Pesquisas 
de Posses e Hábitos de consumo (PPH) dos consumidores residenciais da AMPLA em relação à curva de carga real do domicílio.

Para o levantamento dessas informações de consumo e carga, foram realizadas pesquisas de campo em toda área de concessão da AMPLA, e são estes dados que servirão de subsídios para esta dissertação. A Tabela 1 apresenta a amostra pesquisada na concessionária a ser estudada:

Tabela 1: Amostra PPH realizada na AMPLA [26]

\begin{tabular}{|c|c|}
\hline $\begin{array}{c}\text { Faixa de } \\
\text { consumo (kWh) }\end{array}$ & $\begin{array}{c}\text { Amostra } \\
\text { AMPLA }\end{array}$ \\
\hline 0 a 80 & 217 \\
\hline 81 a 150 & 525 \\
\hline 151 a 220 & 548 \\
\hline 221 a 400 & 596 \\
\hline $400+$ & 198 \\
\hline Total & 2084 \\
\hline
\end{tabular}

A amostra representativa da pesquisa atendeu todos os polos regionais da empresa. Através do mapa do Rio de Janeiro (Figura 3), pode-se ver os municípios que participaram do estudo.

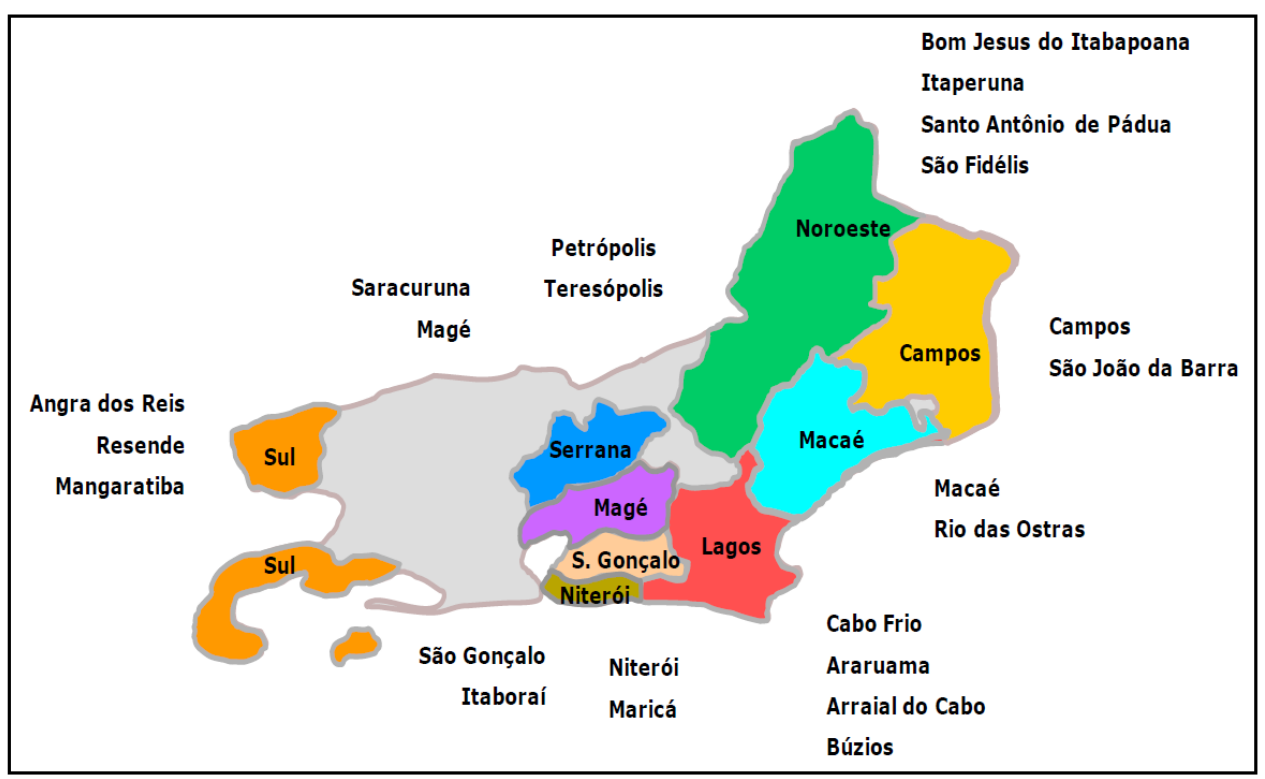

Figura 3: Polos regionais e municípios que fizeram parte da amostra [26] 
O instrumento de coleta de dados, ou seja, o questionário que foi aplicado nesta pesquisa encontra-se no ANEXO I. Esse questionário é composto por seis módulos: Caracterização do domicílio, Posses e hábitos de uso de lâmpadas, Posses e hábitos de uso dos principais aparelhos elétricos, Posses e hábitos de uso de outros aparelhos elétricos, Outras informações sobre equipamentos elétricos e Identificação do consumidor.

Posses e Hábitos de uso é o tópico principal do instrumento de coleta de dados e busca identificar em detalhes os perfis de uso dos principais aparelhos elétricos de um domicílio, que são: lâmpadas (iluminação), refrigerador, freezer, condicionador de ar, televisor e chuveiro elétrico. E em menos detalhes outros aparelhos de menor consumo, como aparelhos de som, máquina de lavar roupa, ferro de passar roupa entre outros.

A seguir no Quadro 1, estão apresentados todos os aparelhos que foram estudados na pesquisa, ou seja; Foi identificada a posse de todos, e para uma grande parte foi identificado também o hábito de uso (incluindo a informação de utilização do equipamento em standby) e modelo do mesmo.

Quadro 1: Aparelhos eletroeletrônicos estudados na PPH [26]

\begin{tabular}{|c|c|c|}
\hline Aparelho de som & Forno elétrico & Prancha alisadora \\
\hline Ar condicionado & Freezer & Rádio elétrico \\
\hline Aspirador de pó & Grill & Refrigerador \\
\hline Batedeira & Hidromassagem & Secador de cabelo \\
\hline Bomba d’água & Impressora & Televisão \\
\hline Cafeteira elétrica & Lâmpada & TV parabólica \\
\hline Chuveiro elétrico & Liquidificador & TV por assinatura \\
\hline DVD & Máq. costura elétrica & Ventilador de mesa \\
\hline Enceradeira & Máq. lava roupas & Ventilador de pé \\
\hline Exaustor & Máq. Overloque & Ventilador de teto \\
\hline Ferro de passar & Microcomputador & Vídeo cassete \\
\hline Forno de micro-ondas & Panela elétrica & Vídeo game \\
\hline
\end{tabular}

A partir das informações levantadas com a $\mathrm{PPH}$, como produto principal, a pesquisa estima uma curva de carga elétrica de todos os equipamentos estudados a partir das declarações obtidas em campo (Figura 4). Esta curva é estimada pelo sistema computacional desenvolvido pela equipe da PUC-Rio para processar a base de dados de uma PPH. Este sistema fornece estas curvas por cliente, por grupo de clientes, por polos e para a concessionária como um 
todo; e todas estas informações podem ainda ser estratificadas por faixas de consumo.

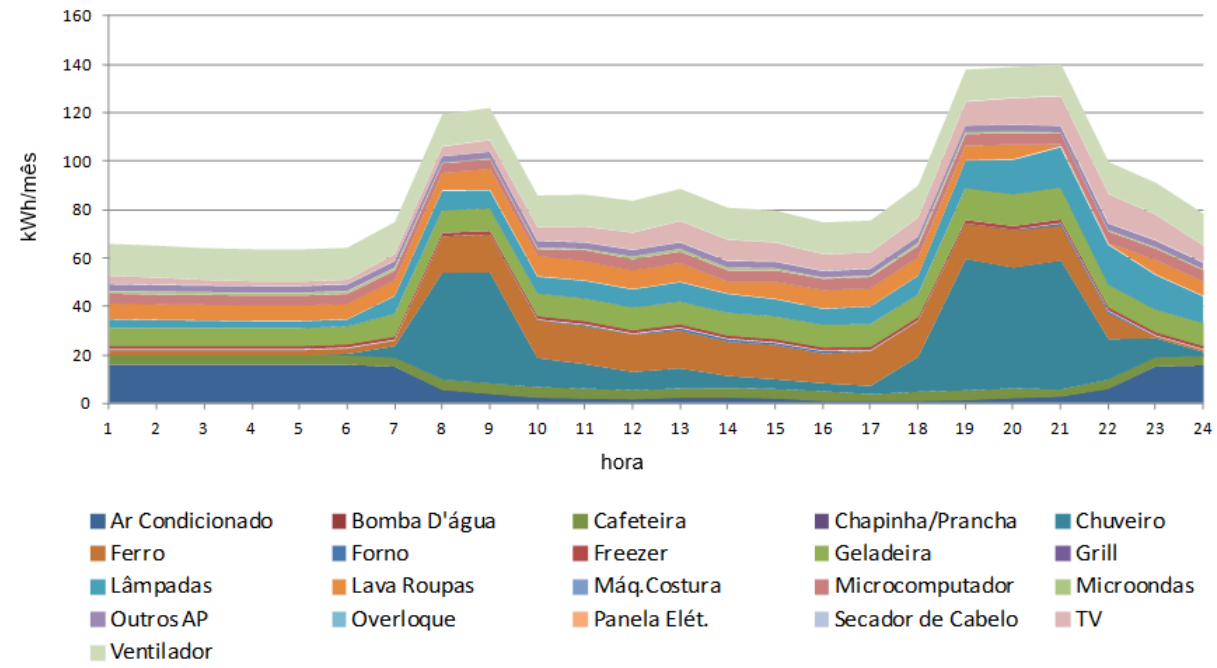

Figura 4: Curva de carga residencial AMPLA por aparelho elétrico [26]

Identifica-se também a participação dos principais aparelhos eletrodomésticos no consumo residencial da AMPLA, conforme apresentado na Figura 5.

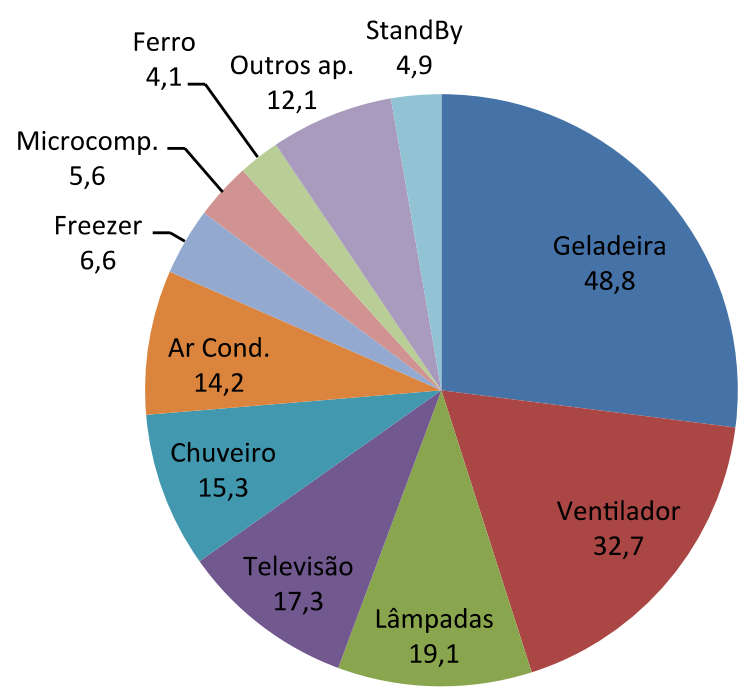

Figura 5: Participação de eletrodomésticos no consumo residencial da AMPLA 
Por fim, a pesquisa estimou a participação do consumo dos eletrodomésticos que operam em modo standby em 4,9\% para a amostra estudada. Para se chegar a estes valores, como há diversos equipamentos eletroeletrônicos utilizados dentro dos domicílios, houve a necessidade de se verificar quais deles realmente operam sob o modo standby. Para isso, foram utilizadas algumas tabelas de consumo estimado em modo em espera por aparelho, fornecidas pelo PROCEL e pelo SELINA ${ }^{3}$ (Standby and Off-Mode Energy Losses In New Appliances Measured in Shops) [28].

Tem-se então na Tabela 2, os aparelhos que compõe na fatia de participação deste consumo na pesquisa, uma vez que o equipamento tivesse sido declarado pelo entrevistado ser utilizado nesta função. $O$ consumo de todos os aparelhos em standby foi então calculado considerando as 24 horas diárias.

Tabela 2: Consumo dos aparelhos elétricos em modo standby da PPH [26]

\begin{tabular}{|c|c|c|c|}
\hline Aparelhos & $\begin{array}{c}\text { Consumo } \\
\text { Standby } \\
\mathbf{( k W h )}\end{array}$ & Aparelhos & $\begin{array}{c}\text { Consumo } \\
\text { Standby } \\
\mathbf{( k W h )}\end{array}$ \\
\hline Aparelho de som & 3,54 & Televisor Convencional & 1,9 \\
\hline Ar condicionado & 1,9 & Televisor LCD & 1,2 \\
\hline DVD & 2,89 & Televisor LED & 0,4 \\
\hline Forno de micro-ondas & 1,91 & Televisor Plasma & 0,3 \\
\hline Impressora & 0,55 & TV por assinatura & 5,42 \\
\hline Microcomputador & 11,45 & Vídeo cassete & 2,52 \\
\hline Rádio elétrico & 1,78 & Vídeo game & 1,26 \\
\hline
\end{tabular}

A partir dos dados da pesquisa, identificaram-se os aparelhos elétricos que farão parte do estudo de medição desta dissertação. A gama de aparelhos selecionada considerou os mesmos aparelhos identificados pela pesquisa que possuíam o modo de operação em standby, e foi acrescida de mais dois aparelhos: a máquina de lavar roupas e a cafeteira elétrica (Quadro 2); uma vez que estes dois equipamentos foram levantados na pesquisa, e após análise

${ }^{3}$ O SELINA se caracterizou pelo desenvolvimento de uma base de dados de uma grande amostra de medições referentes ao consumo de standby e consumo off-mode realizadas em equipamentos eletrônicos domésticos e de escritórios na europa. Oprincipal objetivo deste projeto foi identificar políticas eficazes de transformação do mercado de iniciativas dirigidas a todas as partes interessadas envolvidos na fabricação, distribuição, vendas e operação de aparelhos com perdas no consumo do standby e off-mode. 
verificou-se também um consumo quando não utilizados (porém ligados na tomada).

Quadro 2: Aparelhos eletroeletrônicos selecionados

\begin{tabular}{|c|c|c|}
\hline Aparelho de som & Impressora & Televisão \\
\hline Ar condicionado & Máq. lava roupas & TV por assinatura \\
\hline Cafeteira elétrica & Microcomputador & Vídeo cassete \\
\hline DVD & Rádio elétrico & Vídeo game \\
\hline \multicolumn{3}{|c|}{ Forno de micro-ondas } \\
\hline
\end{tabular}




\section{4 \\ Metodologia de pesquisa}

Para se atingir os resultados estabelecidos no objetivo desta dissertação, foi necessário obter informações de hábito de uso dos equipamentos elétricos de uso doméstico, assim como obter o real consumo dos mesmos referente aos seus respectivos modos de operação: em utilização e em standby. Para tal, buscou-se coletar dados da pesquisa de campo pertencente ao projeto de Pesquisa e Desenvolvimento aplicado na AMPLA, e ainda medir eletronicamente o consumo dos equipamentos objeto do estudo.

Com o hábito de uso dos equipamentos chega-se ao período de utilização dos mesmos, e com o consumo de energia elétrica obtido através da medição é possível estimar os valores do desperdício de cada aparelho, e o montante para a concessionária.

A seguir está explicitada toda a metodologia adotada para o levantamento destas informações.

\section{1. Identificação da quantidade de horas de funcionamento dos equipamentos elétricos em modos de utilização e standby}

O primeiro passo foi o de identificação do tempo de utilização dos equipamentos elétricos entre os dois modos de operação: "em utilização" e "em standby". Para isso, utilizou-se dos dados da Pesquisa de Posses e Hábitos de uso (PPH), diversificando as informações obtidas para cada um dos equipamentos elétricos.

Grupo 1: Para este grupo de equipamentos, foram utilizados os dados que a pesquisa coletou sobre informações de posses, hábitos de uso horário, grau de utilização semanal, sazonalidade de utilização do aparelho de acordo com as estações do ano e utilização do modo standby (ver instrumento de coleta de dados no ANEXO I). Estão neste grupo: Condicionadores de ar. 
A partir do banco de dados da $\mathrm{PPH}$, considerou-se apenas os consumidores que declararam utilizar o(s) equipamento(s) no modo standby, assim obtém-se o total de horas de utilização no ano para cada aparelho, cujo valor é dado por:

$$
u_{a}=\left(d_{v} \times h_{v} \times m_{v}\right)+\left(d_{o p} \times h_{o p} \times m_{o p}\right)+\left(d_{i} \times h_{i} \times m_{i}\right)
$$

Onde:

$u_{a}=$ Quantidade total de horas em utilização, por aparelho, no ano

$d_{v}=$ Quantidade de dias de utilização do aparelho nos meses de verão

$h_{v}=$ Quantidade de horas de utilização diária do aparelho nos meses de verão

$m_{v}=$ Quantidade de meses que compreende a estação verão

$d_{o p}=$ Quantidade de dias de utilização do aparelho nos meses de outono/primavera

$h_{o p}=$ Quantidade de horas de utilização do aparelho nos meses de outono/primavera

$m_{o p}=$ Quantidade de meses que compreende as estações outono/primavera

$d_{i}=$ Quantidade de dias de utilização do aparelho nos meses de inverno

$h_{i}=$ Quantidade de horas de utilização do aparelho nos meses de inverno

$m_{i}=$ Quantidade de meses que compreende a estação inverno

Para a declaração de utilização horária "eventual" ou a não declaração do grau de utilização semanal, foi considerado o tempo de uso habitual do equipamento conforme estimado pelo PROCEL (ANEXO II).

Tem-se através das equações abaixo a quantidade de horas de utilização anual e mensal para o total de aparelhos deste grupo.

$$
\begin{gathered}
U_{a}=\sum_{i=1}^{n} u_{a_{i}} \\
U_{m}=U_{a} \div m_{a}
\end{gathered}
$$

Onde:

$U_{a}=$ Quantidade de horas em utilização, do total de aparelhos, no ano

$U_{m}=$ Quantidade de horas em utilização, do total de aparelhos, no mês

$m_{a}=$ Quantidade de meses que compreende um ano 
Ainda, obtém-se a quantidade média de horas mensais e anuais do aparelho:

$$
\begin{gathered}
U_{a m}=U_{a} \div Q \\
U_{m m}=U_{m} \div Q
\end{gathered}
$$

Onde:

$U_{a m}=$ Quantidade média de horas em utilização, do total de aparelhos, no ano

$U_{m m}=$ Quantidade média de horas em utilização, do total de aparelhos, no mês

$Q=$ Quantidade total de aparelhos

Por fim, chega-se aos valores de operação do(s) aparelho(s) em modo standby através das equações:

$$
\begin{gathered}
s_{a}=h_{a}-u_{a} \\
S_{a}=\sum_{i=1}^{n} s_{a_{i}} \\
S_{m}=S_{a} \div m_{a} \\
S_{a m}=S_{a} \div Q \\
S_{m m}=S_{m} \div Q
\end{gathered}
$$

Onde:

$s_{a}=$ Quantidade total de horas em standby, por aparelho, no ano

$h_{a}=$ Quantidade de horas que compreende um ano (considerando 30 dias $/$ mês)

$S_{a}=$ Quantidade de horas em standby, do total de aparelhos, no ano

$S_{m}=$ Quantidade de horas em standby, do total de aparelhos, no mês

$S_{a m}=$ Quantidade média de horas em standby, do total de aparelhos, no ano

$S_{m m}=$ Quantidade média de horas em standby, do total de aparelhos, no mês

Grupo 2: Para este grupo de equipamentos, foram utilizados os dados que a pesquisa coletou sobre informações de posses, hábitos de uso horário, 
grau de utilização semanal e utilização do modo standby (ver instrumento de coleta de dados no ANEXO I). Estão neste grupo: Televisores.

A partir do banco de dados da $\mathrm{PPH}$, considerou-se apenas os consumidores que declararam utilizar o(s) equipamento(s) no modo standby, assim obtém-se o total de horas de utilização no ano para cada aparelho, cujo valor é dado por:

$$
u_{a}=\left(d_{m} \times h_{d} \times m_{a}\right)
$$

Onde:

$u_{a}=$ Quantidade total de horas em utilização, por aparelho, no ano

$d_{m}=$ Quantidade de dias de utilização do aparelho no mês

$h_{d}=$ Quantidade de horas de utilização diária do aparelho

$m_{a}=$ Quantidade de meses que compreende um ano

Para a declaração de utilização horária "eventual" ou a não declaração do grau de utilização semanal, foi considerado o tempo de uso habitual do equipamento conforme estimado pelo PROCEL (ANEXO II).

Temos através das equações abaixo a quantidade de horas de utilização anual e mensal para o total de aparelhos deste grupo.

$$
\begin{gathered}
U_{a}=\sum_{i=1}^{n} u_{a_{i}} \\
U_{m}=U_{a} \div m_{a}
\end{gathered}
$$

Onde:

$U_{a}=$ Quantidade de horas em utilização, do total de aparelhos, no ano

$U_{m}=$ Quantidade de horas em utilização, do total de aparelhos, no mês

Ainda, obtém-se a quantidade média de horas mensais e anuais do aparelho:

$$
\begin{gathered}
U_{a m}=U_{a} \div Q \\
U_{m m}=U_{m} \div Q
\end{gathered}
$$


Onde:

$U_{a m}=$ Quantidade média de horas em utilização, do total de aparelhos, no ano

$U_{m m}=$ Quantidade média de horas em utilização, do total de aparelhos, no mês $Q=$ Quantidade total de aparelhos

Por fim, chega-se aos valores de operação do(s) aparelho(s) em modo standby através das equações:

$$
\begin{gathered}
s_{a}=h_{a}-u_{a} \\
S_{a}=\sum_{i=1}^{n} s_{a_{i}} \\
S_{m}=S_{a} \div m_{a} \\
S_{a m}=S_{a} \div Q \\
S_{m m}=S_{m} \div Q
\end{gathered}
$$

Onde:

$s_{a}=$ Quantidade total de horas em standby, por aparelho, no ano

$h_{a}=$ Quantidade de horas que compreende um ano (considerando 30 dias $/$ mês)

$S_{a}=$ Quantidade de horas em standby, do total de aparelhos, no ano

$S_{m}=$ Quantidade de horas em standby, do total de aparelhos, no mês

$S_{a m}=$ Quantidade média de horas em standby, do total de aparelhos, no ano

$S_{m m}=$ Quantidade média de horas em standby, do total de aparelhos, no mês

Grupo 3: Para este grupo de equipamentos, a pesquisa coletou informações de posses, hábitos de uso horário (sendo que as horas compreendidas entre 00:00h e 06:00h foram condensadas em um único período), grau de utilização semanal e utilização do modo standby.

Estão neste grupo: Fornos de micro-ondas, Máquinas de lavar roupas, Computadores e Cafeteiras. A metodologia para este grupo foi diversificada por cada equipamento.

A partir do banco de dados da $\mathrm{PPH}$, considerou-se apenas os consumidores que declararam utilizar o(s) equipamento(s) no modo standby, 
assim obtém-se o total de horas de utilização no ano para cada aparelho, cujo valor é dado por:

$$
u_{a}=\left(d_{m} \times h_{d} \times Q \times m_{a}\right)
$$

Onde:

$u_{a}=$ Quantidade total de horas em utilização, por consumidor, no ano

$d_{m}=$ Quantidade de dias de utilização do aparelho no mês

$h_{d}=$ Quantidade de horas de utilização diária do aparelho ${ }^{4}$

$Q=$ Quantidade total de aparelhos

$m_{a}=$ Quantidade de meses que compreende um ano

Referente às declarações de hábito uso dentro do período condensado de 00:00h às 06:00h precisou-se estimar um valor equiparado em horas de utilização dos aparelhos que representasse esse período; Considerou-se então a estimativa diária de uso do PROCEL (ANEXO II), chegando-se proporcionalmente a uma estimativa de uso em 6 horas, conforme apresentado na Tabela 3.

Tabela 3: Estimativa de utilização do equipamento dentro do período condensado $0 \mathrm{~h}$ a $6 \mathrm{~h}$

\begin{tabular}{|l|c|c|c|}
\hline \multicolumn{1}{|c|}{ Aparelho } & $\begin{array}{c}\text { Estimativa de uso } \\
\text { diário em horas } \\
\text { (PROCEL) }\end{array}$ & $\begin{array}{c}\text { Estimativa de uso em } \\
\mathbf{1} \text { hora }\end{array}$ & $\begin{array}{c}\text { Estimativa para o } \\
\text { período consdensado } \\
\text { Oh a } \mathbf{~ h}\end{array}$ \\
\hline Microondas & 0,33 & 0,014 & 0,08 \\
\hline Lavadora de roupas & 1 & 0,042 & 0,25 \\
\hline Computador & 8 & 0,333 & 2,00 \\
\hline Cafeteira & 1 & 0,042 & 0,25 \\
\hline
\end{tabular}

Para a declaração de utilização horária "eventual" ou a não declaração do grau de utilização semanal, foi considerado o tempo de uso habitual do equipamento conforme estimado pelo PROCEL (ANEXO II).

Tem-se através das equações abaixo a quantidade de horas de utilização anual e mensal para o total de aparelhos deste grupo.

${ }^{4}$ Como o forno de micro-ondas é habitualmente utilizado por minutos ou até mesmo segundos, não foi possível identificar pela pesquisa o período de utilização do me smo (a pesquisa não é precisa por minutos, somente por horas); Foi considerado então para cada dia de utilização do aparelho, 0,33 hora, conforme es timado pelo PROCEL (ANEXO II). O mesmo procedimento foi adotado para a cafeteira elétrica, e pelo mesmo motivo, considerou-se para cada dia de utilização, 1 hora, conforme estimado pelo PROCEL. 


$$
\begin{gathered}
U_{a}=\sum_{i=1}^{n} u_{a_{i}} \\
U_{m}=U_{a} \div m_{a}
\end{gathered}
$$

Onde:

$U_{a}=$ Quantidade de horas em utilização, do total de aparelhos, no ano

$U_{m}=$ Quantidade de horas em utilização, do total de aparelhos, no mês

Ainda, obtém-se a quantidade média de horas mensais e anuais do aparelho:

$$
\begin{gathered}
U_{a m}=U_{a} \div Q \\
U_{m m}=U_{m} \div Q
\end{gathered}
$$

Onde:

$U_{a m}=$ Quantidade média de horas em utilização, do total de aparelhos, no ano

$U_{m m}=$ Quantidade média de horas em utilização, do total de aparelhos, no mês

Por fim, chega-se aos valores de operação do(s) aparelho(s) em modo standby através das equações:

$$
\begin{gathered}
s_{a}=h_{a}-u_{a} \\
S_{a}=\sum_{i=1}^{n} s_{a_{i}} \\
S_{m}=S_{a} \div m_{a} \\
S_{a m}=S_{a} \div Q \\
S_{m m}=S_{m} \div Q
\end{gathered}
$$

Onde:

$s_{a}=$ Quantidade total de horas em standby, por aparelho, no ano

$h_{a}=$ Quantidade de horas que compreende um ano (considerando 30 dias $/$ mês) 
$S_{a}=$ Quantidade de horas em standby, do total de aparelhos, no ano

$S_{m}=$ Quantidade de horas em standby, do total de aparelhos, no mês

$S_{a m}=$ Quantidade média de horas em standby, do total de aparelhos, no ano

$S_{m m}=$ Quantidade média de horas em standby, do total de aparelhos, no mês

Grupo 4: Para este grupo de equipamentos, a pesquisa coletou somente as informações de posses e utilização do modo standby.

Estão neste grupo: Aparelho de som, Rádio elétrico, Vídeo cassete, DVD, Impressora, Vídeo game e Equipamento de TV por assinatura.

A partir do banco de dados da $\mathrm{PPH}$, considerou-se apenas os consumidores que declararam utilizar o(s) equipamento(s) no modo standby. Assim obtém-se o total de horas de utilização no ano e no mês, para cada aparelho, e ainda a quantidade média de horas mensais e anuais dos mesmos:

$$
\begin{gathered}
U_{a}=h_{p} \times d_{p} \times m_{a} \times Q \\
U_{m}=h_{p} \times d_{p} \times Q \\
U_{a m}=U_{a} \div Q \\
U_{m m}=U_{m} \div Q
\end{gathered}
$$

Onde:

$U_{a}=$ Quantidade de horas em utilização, do total de aparelhos, no ano

$U_{m}=$ Quantidade de horas em utilização, do total de aparelhos, no mês

$U_{a m}=$ Quantidade média de horas em utilização, do total de aparelhos, no ano

$U_{m m}=$ Quantidade média de horas em utilização, do total de aparelhos, no mês

$h_{p}=$ Quantidade de horas de utilização diária (estimativa PROCEL)

$d_{p}=$ Quantidade de dias de utilização do (estimativa PROCEL)

$m_{a}=$ Quantidade de meses que compreende um ano

$Q=$ Quantidade total de aparelhos

Por fim, chega-se aos valores de operação do(s) aparelho(s) em modo standby através das equações:

$$
S_{a}=\left(h_{d} \times d_{m} \times m_{a} \times Q\right)-U_{a m}
$$




$$
\begin{gathered}
S_{m}=\left(h_{d} \times d_{m} \times Q\right)-U_{m m} \\
S_{a m}=S_{a} \div Q \\
S_{m m}=S_{m} \div Q
\end{gathered}
$$

Onde:

$S_{a}=$ Quantidade de horas em standby, do total de aparelhos, no ano

$S_{m}=$ Quantidade de horas em standby, do total de aparelhos, no mês

$h_{d}=$ Quantidade de horas que compreende um dia

$d_{m}=$ Quantidade de dias que compreende um mês

$S_{a m}=$ Quantidade média de horas em standby, do total de aparelhos, no ano

$S_{m m}=$ Quantidade média de horas em standby, do total de aparelhos, no mês

Todas estas informações foram ainda estratificadas por faixa de consumo de energia elétrica, e podem ser visualizadas no APENDICE I.

\section{2. \\ Identificação do consumo dos equipamentos elétricos em modos de utilização e standby}

Não há na legislação a obrigatoriedade dos fabricantes de informar o gasto de seus equipamentos em operação sobre o modo standby. Porém, alguns fabricantes informam este consumo, no manual do seu produto ou pelos canais de contato da empresa. De toda forma, não há uma identificação padronizada (e de fácil acesso) de consumo do standby para cada um dos tipos de aparelhos eletroeletrônicos existentes no mercado.

Foi desenvolvido para o projeto "Desenvolvimento de coeficientes de ajustes das declarações de pesquisas de clientes para a estimativa e simulação do consumo por uso final dos consumidores" o equipamento Powersave (Figura 6), um medidor capaz de registrar a curva de carga de consumo de um equipamento elétrico para promover a eficiência energética [29]. O equipamento elétrico que se quer medir é ligado no medidor Powersave, que por sua vez é ligado diretamente na tomada fonte de energia elétrica. 

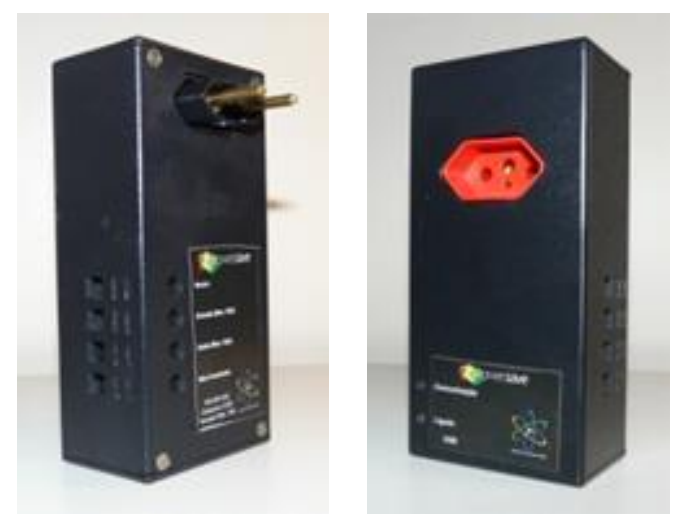

Figura 6: Medidor Powersave [26]

O medidor possui ainda, as seguintes características:

- Permite a leitura em intervalos de tempo de 5 e 15 minutos;

- Memória para leitura durante 41 dias com intervalo de 15 minutos e 14 dias para 5 minutos;

- Leitura de aparelhos com até 50 Ampéres e voltagem de 110 e 220 V;

- Armazena na memória de massa os dados de data, hora, potência máxima $(\mathrm{W})$ do período e consumo no período (kWh);

- Permite a leitura instantânea de data, hora, consumo, potência, tensão, corrente e frequência;

- Permite o ajuste de hora;

- Conexão direta na tomada (10 e $20 \mathrm{~A})$ e por fiação.

- Dimensões de 7,0 x 14,5 x 4,5 ( $\mathrm{LxCxH})$

Esta dissertação utilizou-se dos medidores eletrônicos Powersave para medir os aparelhos elétricos e seus respectivos consumos. O medidor eletrônico foi programado para uma medição de 5 em 5 minutos, e os aparelhos foram medidos ininterruptamente durante um período de 1 hora em que o mesmo encontrou-se em plena utilização, e também 1 hora quando 0 aparelho encontrou-se em modo standby.

E para a identificação do consumo horário em utilização, e do consumo horário em standby dos equipamentos, utilizou-se as equações abaixo:

$$
C H_{u}=\sum_{i=1}^{i=12} C M_{u_{i}}
$$




$$
C H_{S}=\sum_{i=1}^{i=12} C M_{S i}
$$

Onde:

$\mathrm{CH}_{u}=$ Consumo Horário em utilização

$C M_{u}=$ Consumo de 5 minutos em utilização

$\mathrm{CH}_{\mathrm{s}}=$ Consumo Horário em standby

$C M_{s}=$ Consumo de 5 minutos em standby

Durante a medição eletrônica dos aparelhos, foram coletadas também as informações referentes ao tipo/modelo do equipamento, o tamanho/potência do mesmo, a idade aproximada, e sua respectiva marca.

Além do valor horário medido, também foi calculado o "Consumo Equivalente", que considerou o quanto representa a participação do consumo de energia para cada um dos dois modos de operação (em utilização, e em standby) em cada hora de operação do equipamento; Para tanto, foi considerada a quantidade de horas de utilização do aparelho (no mês) em cada modo de operação (segundo as informações advindas da PPH), e calculado proporcionalmente o seu valor dentro de 1 hora, de acordo com a equação abaixo:

$$
\begin{aligned}
& C E_{u}=\left(U_{m m} \div h_{m}\right) \times C H_{u} \\
& C E_{s}=\left(S_{m m} \div h_{m}\right) \times C H_{s}
\end{aligned}
$$

Onde:

$C E_{u}=$ Consumo Equivalente em utilização

$C E_{s}=$ Consumo Equivalente em standby

$U_{m m}=$ Quantidade média de horas em utilização, do total de aparelhos, no mês

$S_{m m}=$ Quantidade média de horas em standby, do total de aparelhos, no mês

$h_{m}=$ Quantidade de horas que compreende um mês

Os dados e as informações de consumo advindas desta etapa de medição, para cada um dos 71 aparelhos que foram medidos e estudados, podem ser visualizados no APÊNDICE ॥.. 


\section{5}

\section{Resultados}

A primeira análise deste estudo se concentrou na identificação do impacto representado pelo hábito de uso dos equipamentos elétricos em cada um dos dois modos de operação: em utilização, e em standby. Pode-se perceber o grande período de tempo em que os aparelhos, mesmo que ligados, não estão sendo utilizados em sua função principal de funcionamento; causando assim desperdício de energia.

$\mathrm{Na}$ Figura 7, verifica-se que o equipamento que é mais operado pelos usuários com sua funcionalidade standby é a TV por assinatura, uma vez que $76,2 \%$ dos aparelhos existentes na amostra da pesquisa operam em modo standby, ficando ligados na tomada constantemente mesmo que não estejam em pleno funcionamento.

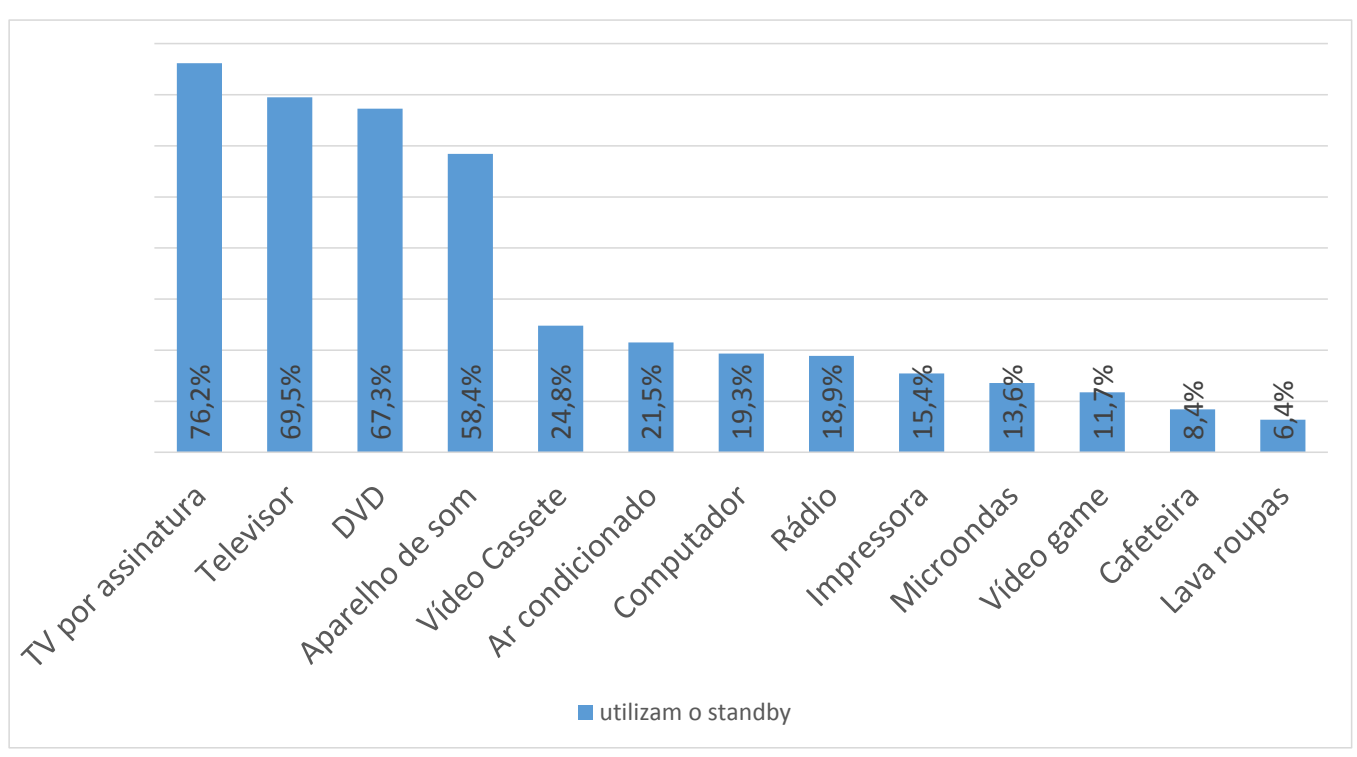

Figura 7: Percentual de aparelhos que são utilizados em modo standby [26] 
Apesar de a TV por assinatura ser o equipamento mais operado sob o modo standby (aparelho que as pessoas menos desligam da tomada), pode-se perceber na Figura 8 que é o forno de micro-ondas o equipamento que tem a maior participação do standby sobre os dois modos de operação, ou seja, ele é o aparelho que fica mais horas em modo standby em relação as horas em modo utilização, 99,3\% do seu período está sob o modo standby.

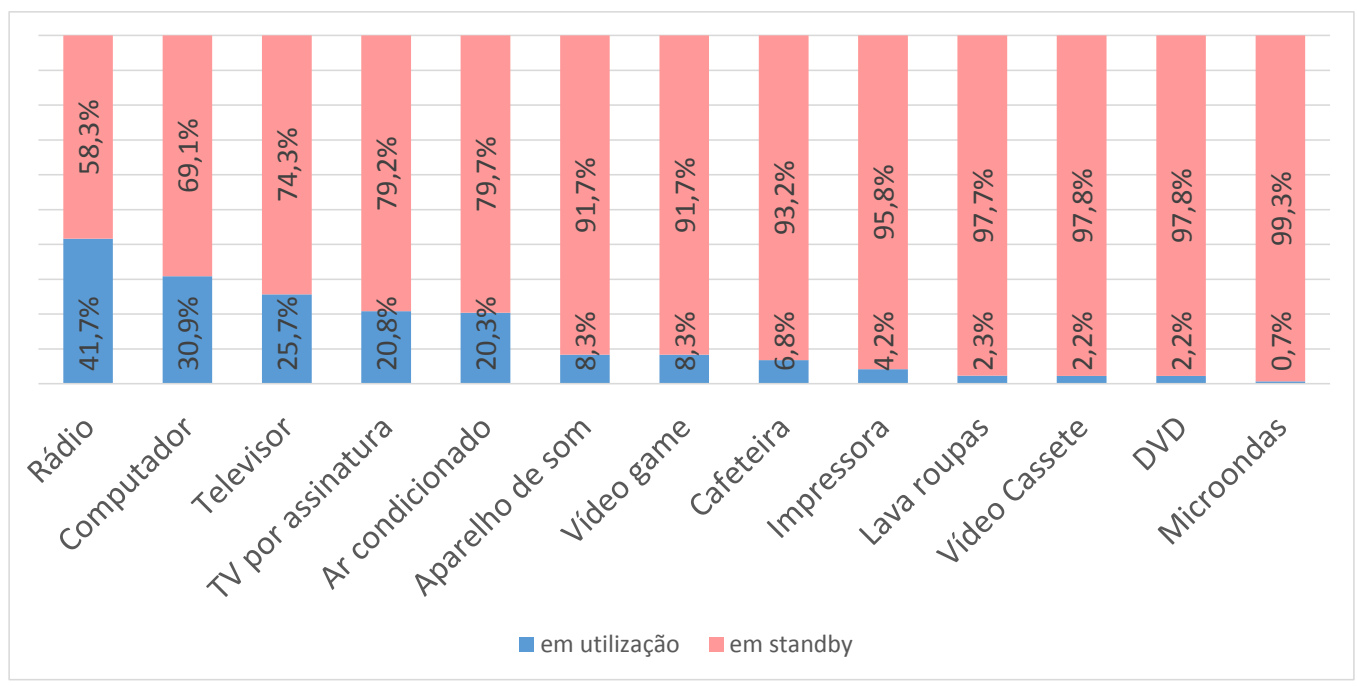

Figura 8: Participação do tempo de utilização dos equipamentos por modo de operação [26] 
$\mathrm{Na}$ Tabela 4 podem ser visualizadas as informações estimadas através da $\mathrm{PPH}$ referentes à operacionalização de todos os equipamentos sobre os dois modos de funcionamento: em utilização e em standby.

Tabela 4: Quantidade de horas de operação dos equipamentos em utilização, e em standby (dados da amostra da PPH)

\begin{tabular}{|c|c|c|c|c|c|c|c|c|c|}
\hline \multirow[b]{2}{*}{ Aparelho } & \multicolumn{3}{|c|}{ Quantidade de aparelhos } & \multicolumn{2}{|c|}{$\begin{array}{l}\text { Quantidade de } \\
\text { horas do aparelho } \\
\text { em UTILIZAÇÃO }\end{array}$} & \multicolumn{2}{|c|}{$\begin{array}{c}\text { Quantidade de } \\
\text { horas do aparelho } \\
\text { em STANDBY }\end{array}$} & \multicolumn{2}{|c|}{$\begin{array}{l}\text { Participação por } \\
\text { modo de operação }\end{array}$} \\
\hline & $\begin{array}{c}\text { Total } \\
\text { amostra }\end{array}$ & $\begin{array}{c}\text { Que } \\
\text { usam o } \\
\text { standby }\end{array}$ & $\begin{array}{c}\text { Que } \\
\text { usam o } \\
\text { standby } \\
\text { (\%) }\end{array}$ & No mês & $\begin{array}{l}\text { média } \\
\text { mensal }\end{array}$ & No mês & $\begin{array}{l}\text { média } \\
\text { mensal }\end{array}$ & $\begin{array}{c}\text { em } \\
\text { utilização }\end{array}$ & $\begin{array}{c}\text { em } \\
\text { standby }\end{array}$ \\
\hline Ar condicionado & 785 & 169 & $21,5 \%$ & 24.761 & 146,5 & 96.919 & 573,5 & $20,3 \%$ & $79,7 \%$ \\
\hline Televisor & 3.936 & 2.735 & $69,5 \%$ & 505.916 & 185,0 & 1.463 .284 & 535,0 & $25,7 \%$ & $74,3 \%$ \\
\hline Microondas & 856 & 116 & $13,6 \%$ & 572 & 4,9 & 82.948 & 715,1 & $0,7 \%$ & $99,3 \%$ \\
\hline Lava roupas & 1.775 & 113 & $6,4 \%$ & 1.906 & 16,9 & 79.454 & 703,1 & $2,3 \%$ & $97,7 \%$ \\
\hline Computador & 1.148 & 222 & $19,3 \%$ & 49.384 & 222,5 & 110.456 & 497,5 & $30,9 \%$ & $69,1 \%$ \\
\hline Cafeteira & 618 & 52 & $8,4 \%$ & 2.534 & 48,7 & 34.907 & 671,3 & $6,8 \%$ & $93,2 \%$ \\
\hline Aparelho de som & 1.530 & 894 & $58,4 \%$ & 53.640 & 60,0 & 590.040 & 660,0 & $8,3 \%$ & $91,7 \%$ \\
\hline Rádio & 773 & 146 & $18,9 \%$ & 43.800 & 300,0 & 61.320 & 420,0 & $41,7 \%$ & $58,3 \%$ \\
\hline Vídeo Cassete & 121 & 30 & $24,8 \%$ & 480 & 16,0 & 21.120 & 704,0 & $2,2 \%$ & $97,8 \%$ \\
\hline DVD & 1.959 & 1.318 & $67,3 \%$ & 21.088 & 16,0 & 927.872 & 704,0 & $2,2 \%$ & $97,8 \%$ \\
\hline Impressora & 713 & 110 & $15,4 \%$ & 3.300 & 30,0 & 75.900 & 690,0 & $4,2 \%$ & $95,8 \%$ \\
\hline Vídeo game & 486 & 57 & $11,7 \%$ & 3.420 & 60,0 & 37.620 & 660,0 & $8,3 \%$ & $91,7 \%$ \\
\hline TV por assinatura & 684 & 521 & $76,2 \%$ & 78.150 & 150,0 & 296.970 & 570,0 & $20,8 \%$ & $79,2 \%$ \\
\hline
\end{tabular}

Através do número de consumidores existentes na área de concessão da AMPLA (ANEXO III) em 2012 (mesmo ano da PPH) e do percentual de consumidores existentes em cada faixa de consumo de energia da estratificação adotada também na PPH; foi feita uma extrapolação dos resultados da amostra do estudo de caso para todo o universo da concessionária (Tabela 5).

Tabela 5: Informações da AMPLA para extrapolação dos dados da PPH

\begin{tabular}{|c|c|c|}
\hline $\begin{array}{c}\text { Faixa de consumo } \\
\text { (kWh) }\end{array}$ & $\begin{array}{c}\text { Número de } \\
\text { consumidores } \\
\text { AMPLA 2012 }\end{array}$ & $\begin{array}{c}\text { Percentual de } \\
\text { consumidores } \\
\text { PPH 2012 }\end{array}$ \\
\hline 0 a 80 & 743.188 & $34,3 \%$ \\
\hline 81 a 150 & 588.709 & $27,1 \%$ \\
\hline 151 a 220 & 371.494 & $17,1 \%$ \\
\hline 221 a 400 & 337.885 & $15,6 \%$ \\
\hline 400+ & 127.277 & $5,9 \%$ \\
\hline Total & 2.168 .553 & $100,0 \%$ \\
\hline
\end{tabular}


A televisão é o equipamento que mais desperdiça horas em standby. $\mathrm{Na}$ Figura 9 observa-se que mais de 15 bilhões de horas são desperdiçadas por ano pelos aparelhos televisores dos consumidores da AMPLA (dados já extrapolados para o universo da concessionária). Corroborando este resultado, verifica-se na Figura 10 que este é também o equipamento de maior posse média entre os estudados, vê-se uma correlação forte entre as horas de funcionamento em standby e a posse média de equipamentos.

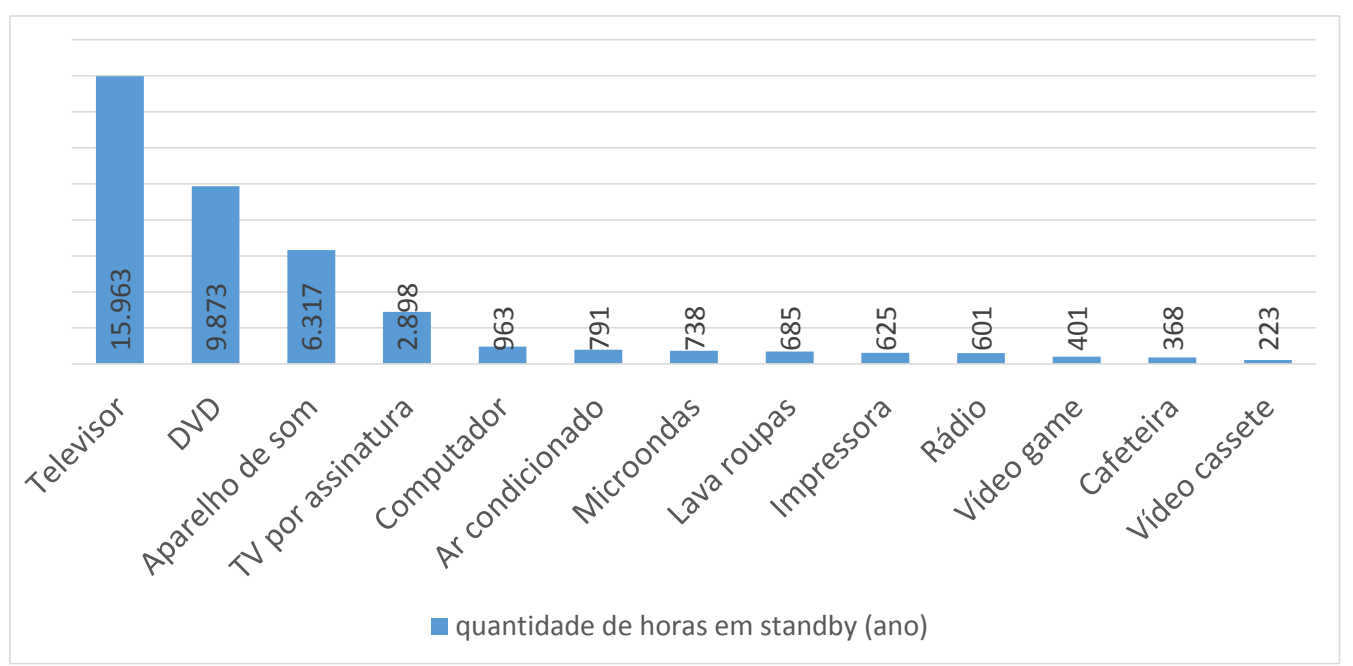

Figura 9: Quantidade de horas sobre o funcionamento em standby no ano (dados extrapolados da PPH)

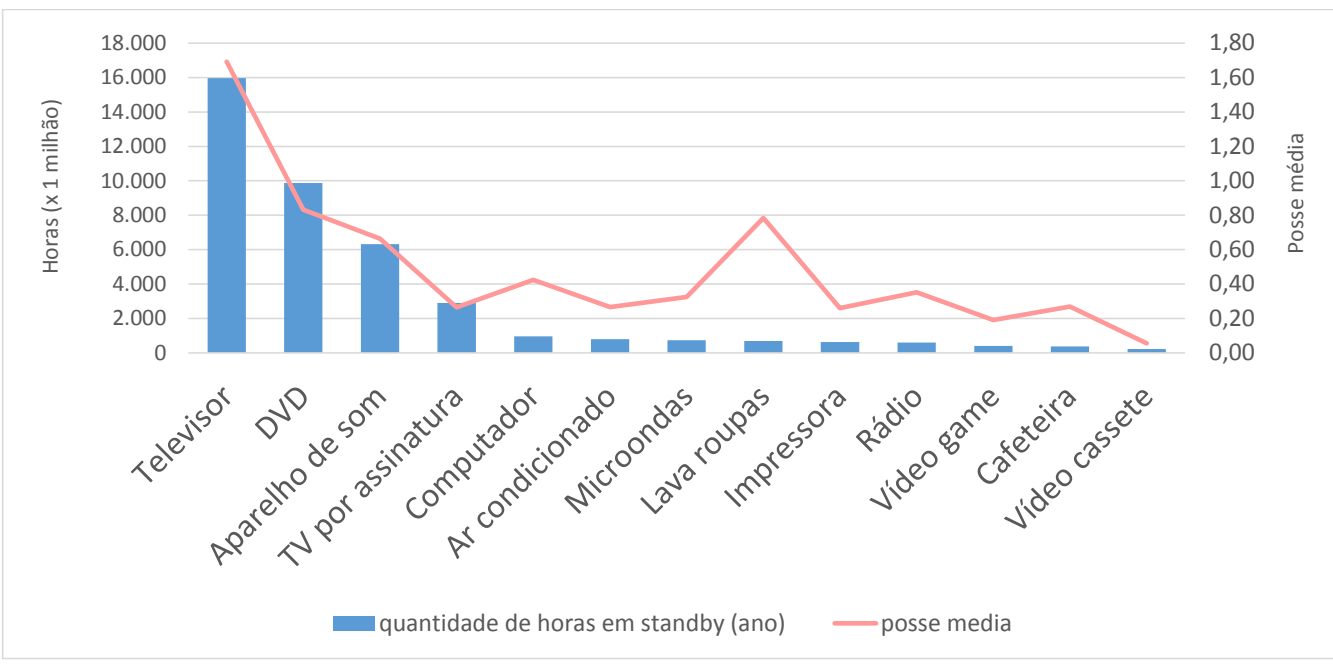

Figura 10: Quantidade de horas sobre o funcionamento em standby no ano (x) Posse média de aparelhos 
Pode ser visualizada na Tabela 6 a quantidade de horas de utilização de todos os equipamentos do estudo considerando todo o universo da PPH (área de concessão da AMPLA), assim como a quantidade de horas desperdiçadas com o funcionamento dos mesmos sobre o modo standby.

Observa-se ainda que apenas na AMPLA, que representa 3,7\% do número de consumidores do Brasil; mais de 15 bilhões de horas são destinadas a um consumo de energia elétrica em desperdício somente com o aparelho de televisão, já que neste período o equipamento encontra-se desligado.

Tabela 6: Quantidade de horas de funcionamento dos aparelhos (dados extrapolados da $\mathrm{PPH}$ )

\begin{tabular}{|l|c|c|c|c|}
\hline \multirow{7}{*}{ Aparelho } & \multicolumn{2}{c|}{$\begin{array}{c}\text { Quantidade de horas de } \\
\text { funcionamento dos } \\
\text { aparelhos (no mês) }\end{array}$} & $\begin{array}{c}\text { Quantidade de horas de } \\
\text { funcionamento dos } \\
\text { aparelhos (no ano) }\end{array}$ \\
\cline { 2 - 5 } & $\begin{array}{c}\text { em utilização } \\
\text { (x 1 milhão) }\end{array}$ & $\begin{array}{c}\text { em standby } \\
\text { (x 1 milhão) }\end{array}$ & $\begin{array}{c}\text { em utilização } \\
\text { (x 1 milhão) }\end{array}$ & $\begin{array}{c}\text { em standby } \\
\text { (x 1 milhão) }\end{array}$ \\
\hline Televisão & 451 & 1.330 & 5.415 & 15.963 \\
\hline DVD & 18 & 823 & 214 & 9.873 \\
\hline Aparelho de som & 45 & 526 & 544 & 6.317 \\
\hline TV por assinatura & 58 & 242 & 690 & 2.898 \\
\hline Computador & 30 & 80 & 355 & 963 \\
\hline Ar condicionado & 11 & 66 & 134 & 791 \\
\hline Microondas & 0,3 & 62 & 4 & 738 \\
\hline Lava roupas & 1 & 57 & 15 & 685 \\
\hline Impressora & 2 & 52 & 20 & 625 \\
\hline Rádio & 32 & 50 & 386 & 601 \\
\hline Vídeo game & 3 & 33 & 31 & 401 \\
\hline Cafeteira & 2 & 31 & 28 & 368 \\
\hline Vídeo cassete & 0,4 & 19 & 4 & 223 \\
\hline
\end{tabular}


Quando analisados os dados de consumo dos equipamentos, começa-se a definir melhor quem são os verdadeiros "vilões" de desperdício de energia no funcionamento em modo standby. Observa-se na Figura 11, que a televisão (campeã em quantidade de horas desperdiçadas), não apresenta um consumo de operação sob a função standby tão alto. Para esta análise, é o aparelho de TV por assinatura que mais consome energia sobre o modo standby.

É interessante observar que os aparelhos que mais quantificam horas para o desperdício de energia sobre o modo standby (Televisão, DVD e o aparelho de som) não apresentaram consumo tão excessivo; Entretanto, os equipamentos que apresentam maior consumo sobre o modo standby são os que apresentaram menor quantidade de horas sobre este modo de funcionamento (aparelho de TV por assinatura, o obsoleto vídeo cassete, e a impressora).

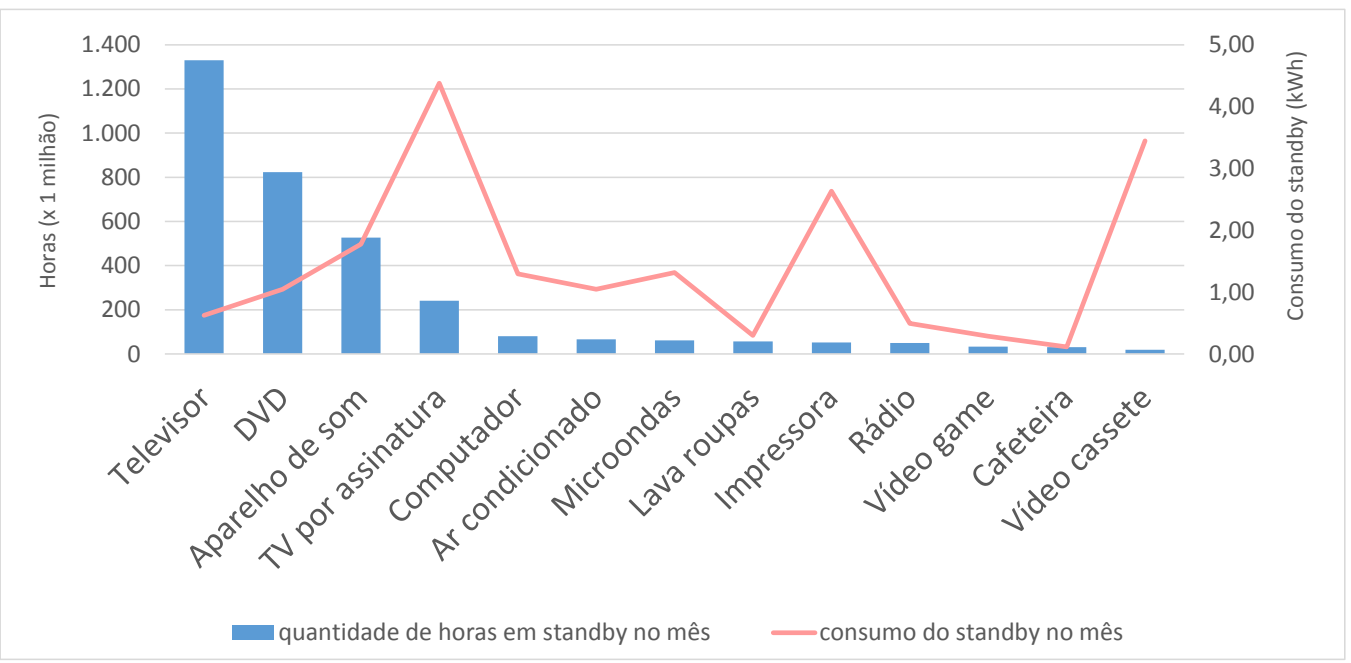

Figura 11: Quantidade de horas sobre o funcionamento em standby no mês (x) Consumo do standby no mês (em kWh) 
Podem ser visualizadas na Tabela 7 as informações de consumo referentes à operacionalização de todos os equipamentos sobre os dois modos de funcionamento: em utilização e em standby.

Tabela 7: Consumo de energia dos equipamentos sobre os modos de operação: em utilização, e em standby

\begin{tabular}{|c|c|c|c|c|c|c|c|c|}
\hline \multirow{3}{*}{ Aparelho } & \multicolumn{8}{|c|}{ Consumo médio estimado } \\
\hline & \multicolumn{2}{|c|}{$\begin{array}{l}\text { Permanente de } 1 \\
\text { hora (kWh) }\end{array}$} & \multicolumn{2}{|c|}{$\begin{array}{l}\text { Equivalente de } 1 \\
\text { hora (kWh) }\end{array}$} & \multicolumn{2}{|c|}{$\begin{array}{c}\text { Equivalente no mês } \\
\text { (kWh) }\end{array}$} & \multicolumn{2}{|c|}{$\begin{array}{c}\text { Equivalente no ano } \\
\text { (kWh) }\end{array}$} \\
\hline & $\begin{array}{c}\text { em } \\
\text { utilização }\end{array}$ & $\begin{array}{c}\text { em } \\
\text { standby }\end{array}$ & $\begin{array}{c}\text { em } \\
\text { utilização }\end{array}$ & $\begin{array}{c}\text { em } \\
\text { standby }\end{array}$ & $\begin{array}{c}\text { em } \\
\text { utilização }\end{array}$ & $\begin{array}{c}\text { em } \\
\text { standby }\end{array}$ & $\begin{array}{c}\text { em } \\
\text { utilização }\end{array}$ & $\begin{array}{c}\text { em } \\
\text { standby }\end{array}$ \\
\hline TV por assinatura & 0,0084 & 0,0077 & 0,0018 & 0,0061 & 1,3 & 4,4 & 15,2 & 52,6 \\
\hline Vídeo Cassete & 0,0087 & 0,0049 & 0,0002 & 0,0048 & 0,1 & 3,4 & 1,7 & 41,4 \\
\hline Impressora & 0,1436 & 0,0038 & 0,0060 & 0,0037 & 4,3 & 2,6 & 51,7 & 31,6 \\
\hline Aparelho de som & 0,0147 & 0,0027 & 0,0012 & 0,0025 & 0,9 & 1,8 & 10,6 & 21,3 \\
\hline Microondas & 1,3894 & 0,0018 & 0,0095 & 0,0018 & 6,8 & 1,3 & 82,1 & 15,8 \\
\hline Computador & 0,0452 & 0,0026 & 0,0140 & 0,0018 & 10,1 & 1,3 & 120,8 & 15,5 \\
\hline DVD & 0,0099 & 0,0015 & 0,0002 & 0,0015 & 0,2 & 1,0 & 1,9 & 12,6 \\
\hline Ar condicionado & 0,8715 & 0,0018 & 0,1773 & 0,0015 & 127,7 & 1,0 & $1.532,2$ & 12,5 \\
\hline Televisor & 0,0755 & 0,0012 & 0,0194 & 0,0009 & 14,0 & 0,6 & 167,5 & 7,5 \\
\hline Rádio & 0,0013 & 0,0012 & 0,0005 & 0,0007 & 0,4 & 0,5 & 4,6 & 5,9 \\
\hline Lava roupas & 0,1081 & 0,0004 & 0,0025 & 0,0004 & 1,8 & 0,3 & 21,9 & 3,6 \\
\hline Vídeo game & 0,0572 & 0,0004 & 0,0048 & 0,0004 & 3,4 & 0,3 & 41,2 & 3,5 \\
\hline Cafeteira & 0,0727 & 0,0002 & 0,0049 & 0,0002 & 3,5 & 0,1 & 42,5 & 1,4 \\
\hline
\end{tabular}


Analisando os consumos mensais de utilização e de standby por equipamento (Figura 12 e Figura 13) ${ }^{5}$, pode-se observar que 5 dos equipamentos possuem o consumo do standby superior ao consumo da utilização dos mesmos, são eles: vídeo cassete, aparelho de DVD, aparelho de som, aparelho de TV por assinatura e o rádio elétrico. Ou seja, estes aparelhos estão consumindo mais energia por estarem "desligados" sobre o modo em standby do que em sua função plena de utilização.
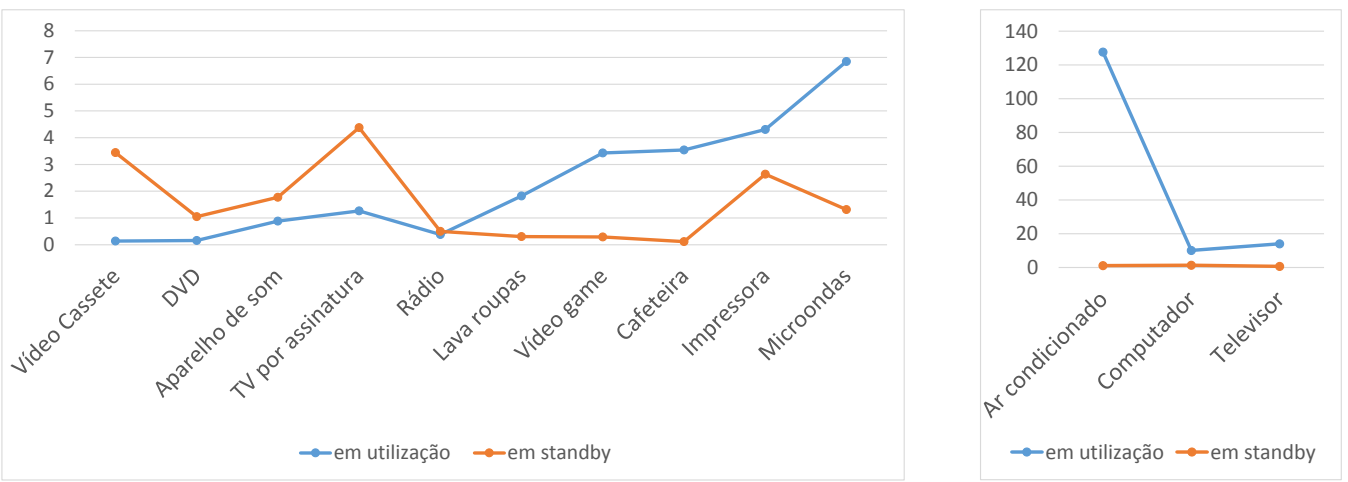

Figura 12: Consumo mensal (em kWh) dos equipamentos por sua utilização e pelo standby
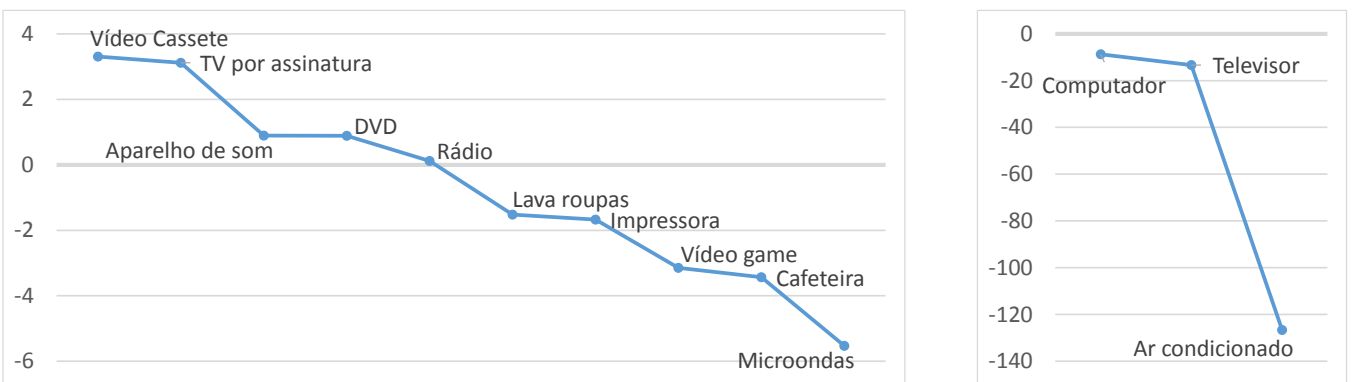

Figura 13: Consumo mensal (em kWh) do standby em relação ao consumo da utilização dos equipamentos

\footnotetext{
${ }^{5}$ Devido a diferença entre os patamares de consumo mensal dos equipamentos elétricos, as figuras foram subdivididas.
} 
Um resumo do estudo apresentado na Figura 14, mostra o aparelho de TV por assinatura como o equipamento que mais é utilizado em modo standby, com $76,2 \%$ dos consumidores que o utilizam nesta função (compreensível já que não é de costume desligar este aparelho da tomada), que possui uma alta participação sobre este consumo, $79,2 \%$ de seu tempo de operação é consumido pelo standby; e que apresentou o mais alto consumo de energia no final do mês também em standby, 4,4 kWh.

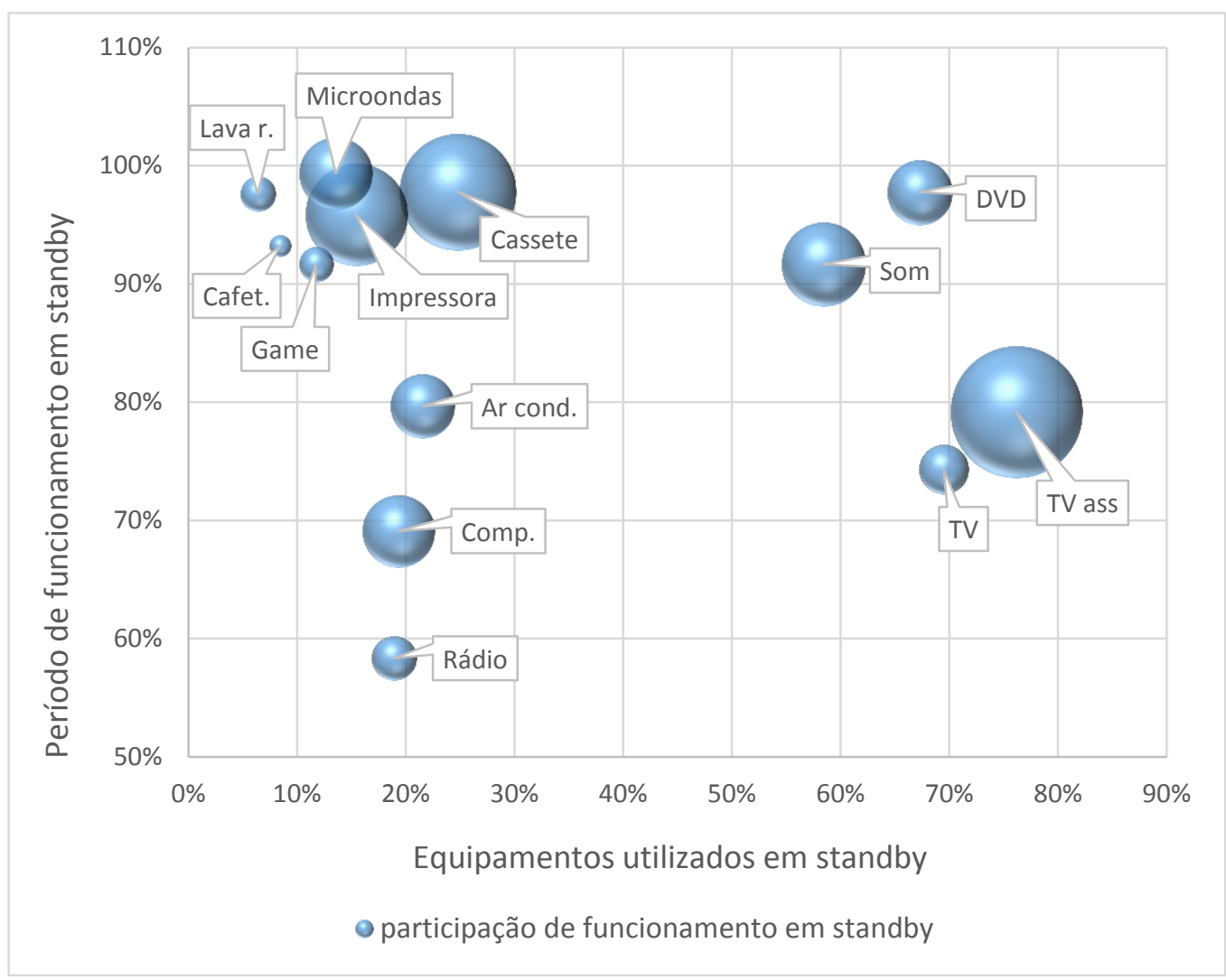

Figura 14: Percentual de aparelhos que usam standby (x) Participação de funcionamento dos aparelhos em standby $(\mathrm{x})$ Consumo do standby/mês (kWh) 
Ao cruzar as informações referentes à quantidade de horas de funcionamento dos equipamentos em standby e o seu respectivo consumo horário também em standby, pode-se observar que é realmente o aparelho de TV por assinatura o equipamento de maior consumo de energia sobre esta função; seguido pela televisão, aparelho de som e o aparelho de DVD. Os demais equipamentos apresentaram um consumo relativamente baixo quando comparados a estes primeiros (Figura 15).

É importante ressaltar que apesar de a TV por assinatura ser o equipamento de maior consumo quando em standby, este aparelho apresenta também funções de operação quando se encontra sobre este modo. De acordo com os fabricantes, estes equipamentos mesmo quando desligados pelo controle remoto são capazes de enviar e receber informações diretamente da empresa fornecedora de seus serviços; como por exemplo o recebimento de emails, atualizações de software, etc. Estas funções podem justificar o alto consumo do equipamento, de qualquer forma este serviço nem sempre é utilizado pelo consumidor final, que por sua vez também não pode optar por não utilizá-lo, o que reduziria por consequência o seu consumo de energia.

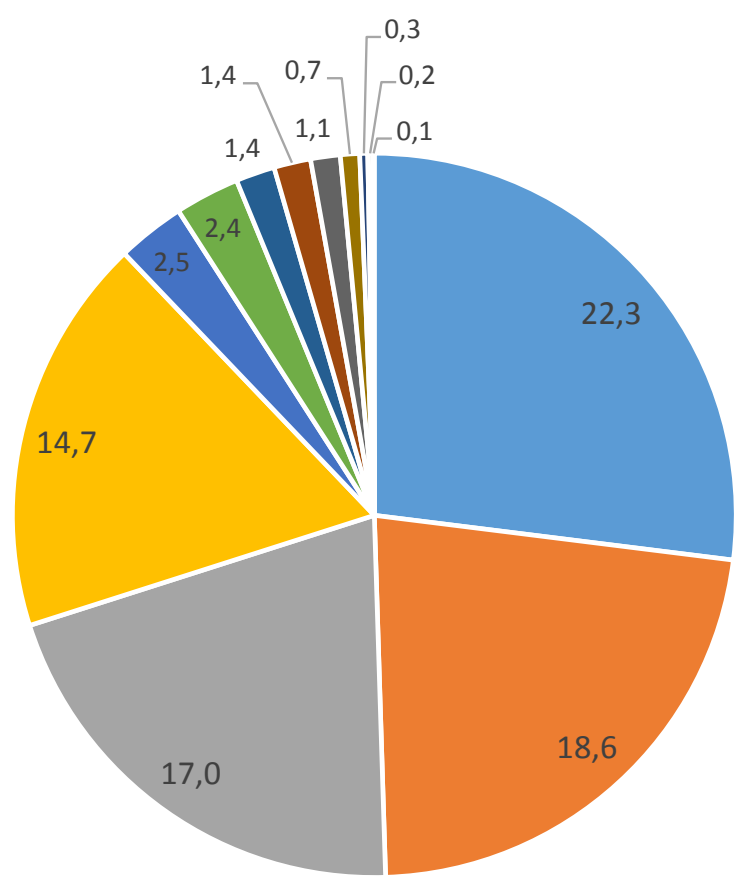

- TV por assinatura

- Televisão

- Aparelho de som

- DVD

- Computador

- Impressora

- Ar condicionado

- Microondas

- Vídeo cassete

- Rádio

- Lava roupas

- Vídeo game

- Cafeteira

Figura 15: Consumo de energia elétrica desperdiçada na AMPLA com o uso dos equipamentos em modo standby (em GWh) 
O resumo apresentado na Tabela 8 , refere-se ao quanto é desperdiçado por mês e por ano com o consumo da energia do standby no universo de consumidores da AMPLA.

Verifica-se que o desperdício gerado com o uso do standby no ano (82,6GWh), é equivalente a 1,9\% do volume de vendas do segmento residencial da concessionária, que foi de 4.332 GWh/ano em 2012 (ANEXO IV). Este número representa ainda, um desperdício de mais de 27 milhões de reais por ano (ANEXO VII).

Tabela 8: Consumo de energia elétrica desperdiçado na AMPLA com o uso do standby

\begin{tabular}{|l|c|c|c|c|}
\hline \multirow{2}{*}{\multicolumn{1}{|c|}{ Aparelho }} & \multicolumn{2}{c|}{ kWh desperdiçado } & \multicolumn{2}{c|}{ GWh desperdiçado } \\
\cline { 2 - 5 } & mês & ano & mês & ano \\
\hline TV por assinatura & 1.855 .632 & 22.267 .590 & 1,86 & 22,3 \\
\hline Televisão & 1.549 .748 & 18.596 .978 & 1,55 & 18,6 \\
\hline Aparelho de som & 1.415 .744 & 16.988 .932 & 1,42 & 17,0 \\
\hline DVD & 1.223 .252 & 14.679 .025 & 1,22 & 14,7 \\
\hline Computador & 208.758 & 2.505 .092 & 0,21 & 2,5 \\
\hline Impressora & 198.755 & 2.385 .062 & 0,20 & 2,4 \\
\hline Ar condicionado & 120.031 & 1.440 .375 & 0,12 & 1,4 \\
\hline Microondas & 113.122 & 1.357 .465 & 0,11 & 1,4 \\
\hline Vídeo cassete & 90.947 & 1.091 .367 & 0,09 & 1,1 \\
\hline Rádio & 59.112 & 709.350 & 0,06 & 0,7 \\
\hline Lava roupas & 24.417 & 293.009 & 0,02 & 0,3 \\
\hline Vídeo game & 14.602 & 175.226 & 0,01 & 0,2 \\
\hline Cafeteira & 5.205 & 62.454 & 0,01 & 0,1 \\
\hline \multicolumn{1}{|c|}{ TOTAL } & $\mathbf{6 . 8 7 9 . 3 2 7}$ & $\mathbf{8 2 . 5 5 1 . 9 2 5}$ & $\mathbf{6 , 9}$ & $\mathbf{8 2 , 6}$ \\
\hline
\end{tabular}


Com a posse média de equipamentos que utilizam o standby da AMPLA e o consumo mensal do standby por aparelho, chega-se ao consumo médio hipotético do standby por consumidor (Tabela 9); onde pode-se observar um consumo que pode ser representado em 3,32 kWh. Ainda, com as informações referentes ao número de consumidores e o volume de venda de energia (ANEXOS III e IV), pode-se deduzir que o consumo médio por consumidor na concessionária é de 166,47 kWh, o que resulta em um percentual de $2 \%$ deste consumo destinado ao standby apenas para estes aparelhos aqui estudados.

Tabela 9: Consumo médio hipotético do standby por consumidor AMPLA

\begin{tabular}{|l|c|c|c|c|c|}
\hline \multicolumn{1}{|c|}{ Aparelho } & $\begin{array}{c}\text { Posse média de } \\
\text { aparelhos }\end{array}$ & $\begin{array}{c}\text { Aparelhos que } \\
\text { usam standby (\%) }\end{array}$ & $\begin{array}{c}\text { Posse média de } \\
\text { aparelhos que } \\
\text { usam o standby }\end{array}$ & $\begin{array}{c}\text { Consumo mensal } \\
\text { standby (kWh) }\end{array}$ & $\begin{array}{c}\text { Consumo médio } \\
\text { mensal de standby } \\
\text { por consumidor } \\
\text { (kWh) }\end{array}$ \\
\hline Televisor & 1,69 & $69,5 \%$ & 1,18 & 0,62 & 0,73 \\
\hline DVD & 0,83 & $67,3 \%$ & 0,56 & 1,05 & 0,59 \\
\hline Lava roupas & 0,78 & $6,4 \%$ & 0,05 & 0,30 & 0,01 \\
\hline Aparelho de som & 0,66 & $58,4 \%$ & 0,39 & 1,77 & 0,69 \\
\hline Computador & 0,42 & $19,3 \%$ & 0,08 & 1,29 & 0,11 \\
\hline Rádio & 0,35 & $18,9 \%$ & 0,07 & 0,50 & 0,03 \\
\hline Microondas & 0,33 & $13,6 \%$ & 0,04 & 1,32 & 0,06 \\
\hline Cafeteira & 0,27 & $8,4 \%$ & 0,02 & 0,11 & 0,00 \\
\hline Ar condicionado & 0,27 & $21,5 \%$ & 0,06 & 1,04 & 0,06 \\
\hline TV por assinatura & 0,27 & $76,2 \%$ & 0,20 & 4,38 & 0,88 \\
\hline Impressora & 0,26 & $15,4 \%$ & 0,04 & 2,63 & 0,11 \\
\hline Vídeo game & 0,19 & $11,7 \%$ & 0,02 & 0,29 & 0,01 \\
\hline Vídeo cassete & 0,05 & $24,8 \%$ & 0,01 & 3,45 & 0,05 \\
\hline & \multicolumn{7}{|l}{} \\
\hline
\end{tabular}

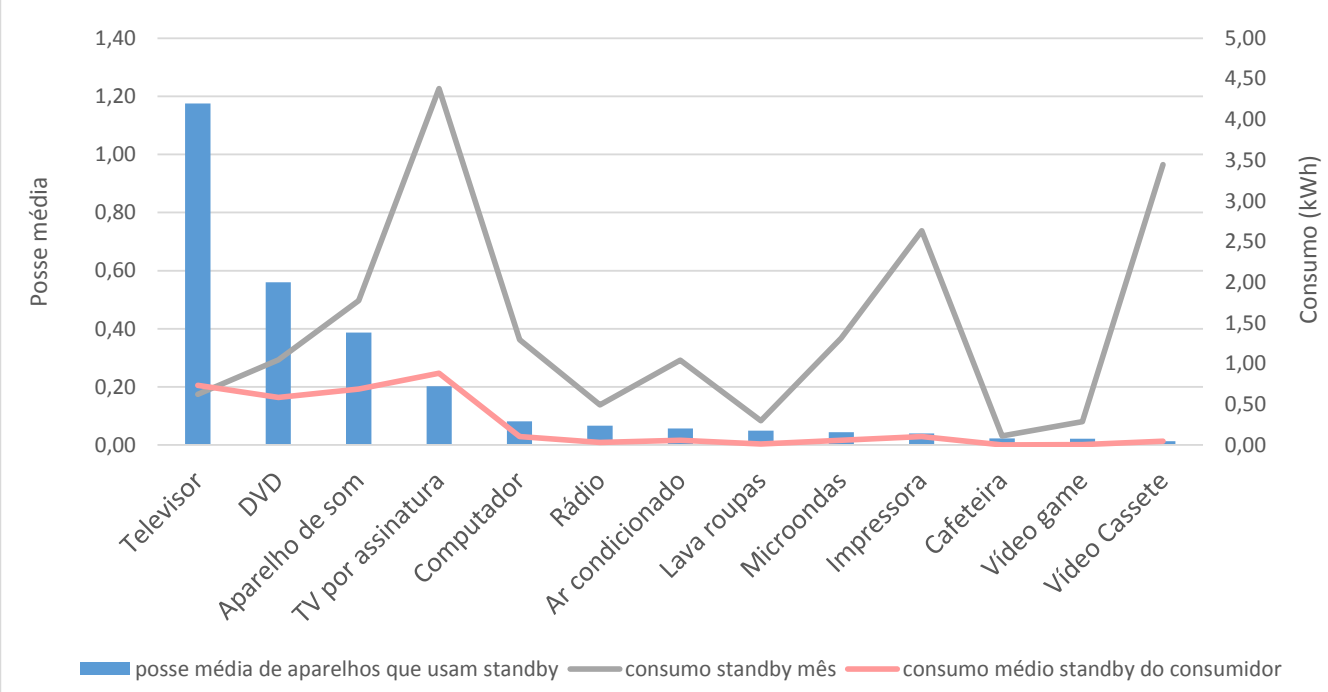

Figura 16: Posse média de aparelhos que usam standby (x) Consumo mensal do standby de cada aparelho $(\mathrm{x})$ Consumo médio do standby por consumidor 
É interessante observar que a participação do standby no consumo médio das residências aumenta conforme a faixa de consumo diminui (Tabela 10). $\mathrm{Na}$ faixa de consumo de até $80 \mathrm{kWh} / \mathrm{mês}$ (que compreende a $34,3 \%$ dos consumidores da AMPLA), o consumo do standby pode representar $7,5 \%$. $O$ consumo médio do domicilio está altamente correlacionado com a renda, e quanto mais pobre o domicílio maior a incidência de aparelhos mais antigos e menos eficientes (caracterizando um maior consumo do standby). E também quanto maior o consumo médio da residência, mais insignificante passa a ser o consumo do standby dos equipamentos elétricos.

Tabela 10: Consumo médio hipotético do standby por consumidor AMPLA

\begin{tabular}{|l|c|c|c|}
\hline \multicolumn{1}{|c|}{ Faixa } & $\begin{array}{c}\text { Consumo médio } \\
\text { por consumidor } \\
\text { (kWh) }\end{array}$ & $\begin{array}{c}\text { Consumo médio } \\
\text { standby por } \\
\text { consumidor (kWh) }\end{array}$ & $\begin{array}{c}\text { Participação do } \\
\text { standby no } \\
\text { consumo médio }\end{array}$ \\
\hline 0 a 80 & 31,8 & 2,4 & $7,5 \%$ \\
\hline 81 a 150 & 114,2 & 2,9 & $2,5 \%$ \\
\hline 151 a 220 & 182,1 & 3,7 & $2,0 \%$ \\
\hline 221 a 400 & 286,7 & 4,8 & $1,7 \%$ \\
\hline $400+$ & 714,0 & 6,2 & $0,9 \%$ \\
\hline
\end{tabular}

\section{1. \\ Estimativa do consumo de energia elétrica desperdiçada no Brasil com o uso do standby}

Com os dados de consumo estimados através deste estudo, foi feito um exercício de extrapolação das informações para o universo de consumidores do Brasil. Para tanto, considerou-se a posse média Brasil dos equipamentos elétricos analisados nesta dissertação. Esta informação foi coletada através da PPH também realizada pela PUC-Rio para todo território nacional no ano de 2005 [30], que é o ano que apresenta a última base de informações a nível nacional.

A área de concessão da AMPLA e o perfil dos seus consumidores, não representa o Brasil e suas diversificadas regiões. Porém, houve a necessidade de utilização da informação do percentual de aparelhos que são operados em 
modo standby, retirada do atual estudo da $A M P L A$, uma vez que não conseguiuse obter esta informação através da pesquisa de PPH para o Brasil.

Outra consideração importante é que em 9 anos que se passaram desde a coleta destas informações, o perfil de consumo, o poder de posse, e a capacidade de pagamento dos consumidores sofreram uma alteração muito forte. Vê-se hoje os consumidores brasileiros com maior capacidade de pagamento e uma maior posse de equipamentos elétricos, o que torna a análise bem conservadora.

Ademais, ao mesmo tempo que os fabricantes avançam com estudos que tornem o consumo do standby cada vez menor, tem-se por outro lado um número cada vez maior de equipamentos que estão utilizando-se deste modo de operação, buscando cada vez mais o conforto e bem estar do consumidor.

De toda forma, como já foi posto, esta extrapolação trata de uma estimativa conservadora, tendo os seus parâmetros baseados nas informações obtidas e estudadas dentro desta dissertação. Observa-se então na Tabela 11, a posse média de aparelhos do Brasil para o ano de 2005 e seus respectivos consumos:

Tabela 11: Consumo médio hipotético do standby por consumidor Brasil

\begin{tabular}{|l|c|c|c|c|c|}
\hline \multicolumn{1}{|c|}{ Aparelho } & $\begin{array}{c}\text { Posse média } \\
\text { BRASIL 2005 }\end{array}$ & $\begin{array}{c}\text { Aparelhos que } \\
\text { usam standby } \\
\mathbf{( \% )}\end{array}$ & $\begin{array}{c}\text { Posse média } \\
\text { de aparelhos } \\
\text { que usam } \\
\text { standby }\end{array}$ & $\begin{array}{c}\text { Consumo } \\
\text { mensal } \\
\text { standby (kWh) }\end{array}$ & $\begin{array}{c}\text { médio mensal } \\
\text { de standby por } \\
\text { consumidor } \\
\text { (kWh) }\end{array}$ \\
\hline Aparelho de som & 0,74 & $58,4 \%$ & 0,43 & 1,77 & 0,77 \\
\hline Televisor & 1,41 & $69,5 \%$ & 0,98 & 0,62 & 0,61 \\
\hline TV por assinatura & 0,17 & $76,2 \%$ & 0,13 & 4,38 & 0,57 \\
\hline Vídeo cassete & 0,32 & $24,8 \%$ & 0,08 & 3,45 & 0,27 \\
\hline DVD & 0,25 & $67,3 \%$ & 0,17 & 1,05 & 0,18 \\
\hline Computador & 0,23 & $19,3 \%$ & 0,04 & 1,29 & 0,06 \\
\hline Impressora & 0,14 & $15,4 \%$ & 0,02 & 2,63 & 0,06 \\
\hline Microondas & 0,30 & $13,6 \%$ & 0,04 & 1,32 & 0,05 \\
\hline Ar condicionado & 0,16 & $21,5 \%$ & 0,03 & 1,04 & 0,04 \\
\hline Rádio & 0,35 & $18,9 \%$ & 0,07 & 0,50 & 0,03 \\
\hline Lava roupas & 0,64 & $6,4 \%$ & 0,04 & 0,30 & 0,01 \\
\hline Vídeo game & 0,09 & $11,7 \%$ & 0,01 & 0,29 & 0,00 \\
\hline Cafeteira & 0,18 & $8,4 \%$ & 0,02 & 0,11 & 0,00 \\
\hline
\end{tabular}


O consumo médio do standby por consumidor no Brasil pode ser representado em 2,65 kWh. Com as informações referentes a número de consumidores e o volume de venda de energia do mercado nacional (dados retirados do anuário estatístico de energia elétrica, vide ANEXOS $\vee$ e $\mathrm{VI}$ ), podese deduzir um desperdício de energia anual com o uso do standby nos equipamentos elétricos da ordem de 1,6 TWh (Tabela 12), ou ainda, 1,9\% de todo o volume de vendas de energia elétrica no segmento residencial no Brasil em 2006 (não foram encontradas informações de 2005, ano em que foi realizada a pesquisa). Pode-se notar que esta estimativa da parcela do consumo de standby no Brasil para o período analisado é a mesma para a distribuidora AMPLA no ano de 2012.

Este número está representado um desperdício de mais de 530 milhões de reais por ano, apenas por serem deixados os equipamentos elétricos residenciais ligados na tomada mesmo que não estejam sendo utilizados. Esta energia caso fosse economizada; representaria $11,8 \%$ da meta do potencial de economia de energia estabelecida por políticas de eficiência energética do Balanço de Energia Útil (BEU) constantes no PNE2030 ${ }^{6}$ [31]; economia esta, que chegaria a 13,6 TWh/ano de potencial de eficiência energética para o setor residencial.

Tabela 12: Consumo de energia elétrica desperdiçado no Brasil com o uso do standby

\begin{tabular}{|l|c|c|c|c|}
\hline \multicolumn{1}{|c|}{ Aparelho } & $\begin{array}{c}\text { Consumo } \\
\text { equivalente do } \\
\text { standby em 1 } \\
\text { hora (kWh) }\end{array}$ & $\begin{array}{c}\text { Total de } \\
\text { aparelhos } \\
\text { Brasil }\end{array}$ & $\begin{array}{c}\text { GWh } \\
\text { desperdiçado } \\
\text { com standby } \\
\text { no mês }\end{array}$ & $\begin{array}{c}\text { GWh } \\
\text { desperdiçado } \\
\text { com standby } \\
\text { no ano }\end{array}$ \\
\hline Aparelho de som & 0,0025 & 21.757 .480 & 38,6 & 463,4 \\
\hline Televisão & 0,0009 & 49.300 .592 & 30,7 & 368,8 \\
\hline TV a cabo & 0,0061 & 6.515 .704 & 28,5 & 342,4 \\
\hline Vídeo cassete & 0,0048 & 3.992 .240 & 13,8 & 165,1 \\
\hline DVD & 0,0015 & 8.463 .534 & 8,9 & 106,3 \\
\hline Computador & 0,0018 & 2.238 .050 & 2,9 & 34,8 \\
\hline Impressora & 0,0037 & 1.086 .831 & 2,9 & 34,3 \\
\hline Microondas & 0,0018 & 2.045 .673 & 2,7 & 32,3 \\
\hline Ar condicionado & 0,0015 & 1.733 .276 & 1,8 & 21,7 \\
\hline Rádio elétrico & 0,0007 & 3.326 .383 & 1,6 & 19,8 \\
\hline Lavadora de roupas & 0,0004 & 2.050 .175 & 0,6 & 7,4 \\
\hline Vídeo game & 0,0004 & 531.144 & 0,2 & 1,8 \\
\hline Cafeteira & 0,0002 & 762.111 & 0,1 & 1,0 \\
\hline \multicolumn{2}{|l|}{ Total de GWh desperdiçados com standby BRASIL } & 133 & 1.599 \\
\hline
\end{tabular}

${ }^{6}$ O Plano Nacional de Energia - PNE 2030 tem como objetivo o planejamento de longo prazo do setor energético do país, orientando tendências e balizando as alternativas de expansão desse segmento nas próximas décadas. 


\section{6 \\ Conclusões}

O modo de operação em standby nos equipamentos eletroeletrônicos hoje, é de fato, um item de conforto para os consumidores finais. Poder ligar e desligar os aparelhos sem precisar se aproximar dos mesmos é uma praticidade muitas vezes indispensável para muitos usuários. Além disto, observa-se a cada dia, um crescimento tecnológico de forma a tornar cada vez mais remoto o acesso, e autonomia aos equipamentos que entram nos domicílios.

Um problema surge exatamente neste ponto, onde equipamentos que operam em modo standby aparecem cada vez mais no mercado, atribuindo assim um consumo de energia "ociosa" aos mesmos, sendo esta, uma energia gasta sem a atividade do aparelho.

Tem havido esforços em vários países visando mitigar o gasto de energia de aparelhos em modo standby. Há estudos e plano de ações que buscam a eficiência energética não apenas no uso de fontes de energia renováveis, mas também no consumo eficiente dos aparelhos. O próprio PNE2030 [31] cita que as maiores oportunidades de redução no consumo de eletricidade em equipamentos eletroeletrônicos, sobretudo nos aparelhos de som e vídeo, estaria na limitação do consumo no modo standby, que aumenta com a posse destes equipamentos.

A não padronização específica para esta função, não permite que o mercado se regularize e que as informações cheguem de forma precisa ao consumidor final, o que poderia lhe trazer argumentos à uma possível economia de energia e anseios na hora da compra dos equipamentos. Devido a isto, se tem hoje aparelhos eletrônicos que mesmo quando desligados e sem o modo standby aparente (como por exemplo uma luz de LED ou relógio), estão consumindo energia somente por estarem ligados à tomada (como é o caso da grande maioria das máquinas de lavar roupas).

O Programa Brasileiro de Etiquetagem, PBE [32]; tem como missão prover confiança à sociedade brasileira nas medições e nos produtos, através da metrologia e da avaliação da conformidade, promovendo a harmonização das relações de consumo, a inovação e a competitividade do País. Porém o mesmo, tem como linhas de ações propostas à este caso, conforme o Plano Nacional de 
Energia 2030, apenas estudar a possibilidade de certificação de estabelecer padrões mínimos ou sistemas de níveis de eficiência energética em espera (standby) para outros equipamentos de uso final, que não somente os televisores; que hoje possuem projeção de penetração que contempla o limite de potência para o standby em $1 \mathrm{~W}$.

A adoção de padrões mais restritos para consumo no modo standby para os equipamentos elétricos cabíveis, e sua certificação obrigatória e não apenas voluntária; são ações adequadas para aumentar a conservação de energia com impactos significativos e bem determinados, podendo resultar na captura de benefícios econômicos para a sociedade e para os consumidores. Índices mínimos de eficiência energética são mecanismos de políticas públicas que restringem a comercialização de produtos não adequados a requerimentos específicos de consumo energético. Esses mecanismos eliminam equipamentos ineficientes do mercado, e assim, promovem a conservação de energia.

Esta dissertação apresentou dados importantes sobre o possível desperdício que está sendo gerado pelo uso de alguns aparelhos em standby. Viu-se que o aparelho de TV por assinatura é o equipamento que mais consome energia em standby dentre os equipamentos elétricos domésticos, com um possível desperdício de 22,3 GWh/ano para área de concessão da concessionária estudada (AMPLA). Observou-se ainda, que 5 equipamentos (vídeo cassete, aparelho de DVD, aparelho de som, aparelho de TV por assinatura e o rádio elétrico) possuem um consumo mensal do standby superior ao consumo da utilização dos mesmos.

Considerando todos os equipamentos estudados, este número está representado em um desperdício de mais de 27 milhões de reais para a AMPLA (ou 1,9\% do volume de vendas do segmento residencial em 2012); podendo chegar a uma grandeza acima dos 530 milhões de reais para o caso Brasil (ou $1,9 \%$ do volume de vendas do segmento residencial em 2006, ano base da pesquisa). Ainda, apenas esta energia economizada de 1,6 TWh anuais/Brasil, representaria $11,8 \%$ da meta do potencial de economia de energia estabelecida por políticas de eficiência energética do Balanço de Energia Útil (BEU) constantes no PNE2030 [31]; economia esta, que chegaria a 13,6 TWh/ano de potencial de eficiência energética para o setor residencial.

De certa forma o estudo aqui analisado e apresentado está sendo bem conservador, uma vez que foram analisados apenas 13 aparelhos eletroeletrônicos de utilização doméstica, mas sabe-se que nos dias de hoje são numerosos os equipamentos que apresentam a tecnologia standby e que sua 
utilização está cada vez maior. Têm-se também os equipamentos que são deixados conectados à tomada por simples praticidade mesmo que não estejam sendo utilizados, como é o caso dos carregadores de carga de celular; Esses aparelhos consomem uma energia mínima quando conectados à tomada sem dar carga a nenhum celular, mas tendo em conta que a posse média de aparelhos celulares no Brasil em 2012 era da ordem de 262 milhões, ou 1,33 celulares por habitante [33], conclui-se que o mínimo consumo de um equipamento pode representar um gigantesco consumo para todo território nacional.

Uma vez analisado este consumo ocioso existente com o standby, buscam-se as alternativas para redução ou até mesmo a eliminação deste desperdício. Meier, Huber e Rosen [34] realizaram um trabalho consistindo na explicação de oportunidades de redução do consumo em standby. Segundo os autores, a explicação inicial era de que a forma que foram projetados os equipamentos eletroeletrônicos permitia um consumo significativo em standby porque alguns componentes permaneciam ligados, desnecessariamente.

A forma mais fácil e simples consiste no desligamento dos equipamentos diretamente da tomada; é claro que esta ação muitas vezes vai contra toda a praticidade que este modo de operação dos equipamentos proporciona. Outra forma de redução deste consumo (e também comum no mercado) está no filtro de linha, que consiste na concentração de várias tomadas em uma régua, com um interruptor único de controle para se desligar os aparelhos elétricos à ele conectados.

Há ainda alguns equipamentos mais modernos que são acoplados às tomadas após serem conectados pelos aparelhos elétricos, e que utilizam também de um controle remoto de encerramento, desligando-se permanentemente todos os aparelhos ao mesmo tempo; cortando assim o consumo do standby de todos os aparelhos, ficando somente com o consumo do standby do próprio equipamento.

Além de uma conscientização da população com o assunto; os fabricantes começam a ter em consideração o consumo de energia em standby. Hoje já existem formas de conceber produtos que conseguem reduzir o consumo em standby em $90 \%$.

Coloca-se como trabalhos futuros, que sejam realizados estudos com o intuito de se representar melhor as amostras medidas por aparelho. Devido a limitação de dados, nesta dissertação foram estudados apenas 13 aparelhos elétricos, mas sabe-se que hoje em dia o mercado apresenta uma gama muito 
maior de equipamentos que possuem esta função; como modem, roteador, máquina de lavar louças, filtro elétrico, telefone, geladeira, etc. Também é importante que seja realizado um estudo com um número maior de equipamentos, o que pode gerar resultados ainda mais expressivos para o setor. Por fim, uma atualização da Pesquisa de Posses e Hábitos de consumo a nível nacional, também seria de suma importância para uma estimativa mais precisa destas informações, já que a última até então realizada (e aqui utilizada) data de 2005. 


\section{Referências bibliográficas}

1 BOA NOVA, A. C. Energia e Classes Sociais no Brasil. São Paulo: Loyola, 1985.

2 SOLANKI, P.S., MALLELA, V.S., ZHOU, C., An investigation of standby energy losses in residential sector: solutions and policies. International Journal of Energy and Environment, 4 (1) (2013).

3 CENTRAIS ELÉTRICAS BRASILEIRAS S. A. - ELETROBRÁS. Na trilha da energia - Importância da Energia Elétrica, Disponível em: < http://www.eletrobras.com/elb/natrilhadaenergia/energia-eletrica/main.asp?Vi ew=\%7BB1E5C97A-39C6-49BE-9B34-9BC51ECC124F\%7D >. Acesso em: 09/01/2014.

4 RODRIGUES, J.R.F., Avaliação da utilização do modo standby em eletrodomésticos e de propostas de soluções mitigadoras para redução do seu consumo energético. Universidade Federal do Paraná - Curitiba, PR, Setembro, 2009.

5 EMPRESA DE PESQUISA ENERGÉTICA - EPE. Balanço Energético Nacional (BEN) 2013: Ano base 2012, Disponível em < https://ben.epe.gov.br/downloads/Relatorio_Final_BEN_2013.pdf >. Acesso em: 02/12/2010.

6 ABESCO, Associação Brasileira das Empresas de Serviços de Conservação de Energia, Disponível em: < http://www.abesco.com.br/datarobot/ >. Acesso em: 09/01/2014.

7 GIZ, Deutsche Gesellschaft fur Internationale Zusammenarbeit GmbH. Disponível em: < http://www.giz.de/en/worldwide/12055.html >. Acesso em: 09/01/2014.

8 AMBIENTE ENERGIA - MEIO AMBIENTE, SUSTENTABILIDADE E INOVAÇÃO. Eficiência energética e meio ambiente, Disponível em: < https://www.ambienteenergia.com.br/index.php/2011/05/eficienciaenergetica-e-meio-ambiente/11412 >. Acesso em: 09/01/2014.

9 INSTITUTO BRASILEIRO DE DEFESA DO CONSUMIDOR - IDEC. Energia desperdiçada, Disponível em: < http://www.idec.org.br/uploads/revistas materias/pdfs/2008-07-ed123-capa-standby.pdf > . Acesso em: 09/01/2014. 
10 INMESOL. Power solutions, Disponível em: < http://www.inmesol.pt/blog/ quem-inventou-o-led >. Acesso em: 09/01/2014.

11 SAN MARTINI, G. Controle remoto faz 50 anos. Observatório da Imprensa, Belluno (Itália), em 19 de setembro de 2006. Disponível em: < http://www.observatoriodaimprensa.com.br/artigos.asp?cod=399MCH001 > Acesso em: 20/01/2014.

12 INTERNATIONAL ELECTROTECHNICAL COMMISSION. IEC 62301: Household Electrical Appliances - Measurement of Standby Power. Suíça, 2011.

13 IEC 60417: Graphical symbols for use on equipment. Suíça, 2005.

14 INSTITUTO NACIONAL DE METROLOGIA, QUALIDADE E TECNOLOGIA INMETRO. Consumidor deve optar por produtos mais eficientes, Disponível em < http://www.inmetro.gov.br/imprensa/releases/consumidor produtos_mais_eficientes.pdf $>$. Acesso em: 05/01/2014.

15 LEBOT, B., MEIER, A.K., ANGLADE, A., Global implications of standby power use. ACEEE Summer Study on Energy Efficiency in Buildings, Washington, DC, 2000.

16 ALMEIDA, A., FONSECA, P., SCHOLMANN, B., FElLBERG, N., Characterization of the household electricity consumption in the EU, Potential energy savings and specific policy recommendations. Energy Build, 43 Elsevier B.V. Portugal, 2011.

17 FUNG, A., AULENBACK, A., FERGUSON, A., UGURSAL, V.I., Standby power requirements of household appliances in Canada. Energy Build, 35 Elsevier B.V. Canadá, 2003.

18 ROSS, J.P., MEIER, A., Measurements of whole-house standby power consumption in California homes. Energy, 27 - Elsevier Science. California, 2002.

19 GUAN, L., BERRILL, T., BROWN, R.J., Measurement of standby power for selected electrical appliances in Australia. Energy Build, 43 - Elsevier B.V. Austrália, 2011.

20 MEIER, A., LIN, J., LIU, J., LI, T., Standby power use in Chinese homes. Energy Build, 36 - Elsevier B.V. China, 2004.

21 TANIDES, C.G., Estimation of standby energy consumption and energy saving potential in argentine households. Energy for Sustainable Development, 12. (4). 2008. 
22 PROCEL INFO - Centro Brasileiro de Informação de Eficiência Energética. Pesquisas de Posses e Hábitos de Consumo de Energia (PPHs), Disponível em: < http://www.procelinfo.com.br/main.asp?View=\{4A5E324FA3B0-482A-B1CD-F75A2A150480\} >. Acesso em 21/01/2014.

23 MINISTÉRIO DE MINAS E ENERGIA - Departamento de Desenvolvimento Energético. Plano Nacional de Eficiência Energética, Disponível em: < http://www.mme.gov.br/mme/galerias/arquivos/PlanoNacEfiEnergetica.pdf $>$. Acesso em: 25/01/2014.

24 AGENCIA NACIONAL DE ENERGIA ELÉTRICA - ANEEL. Procedimentos de Distribuição de Energia Elétrica no Sistema Elétrico Nacional (PRODIST). Disponível em: < http://www.aneel.gov.br/area.cfm?idArea=82 >. Acesso em 21/01/2014.

25 PINHO, J.A.M., Calibração de resultados de pesquisas de posses e hábitos pela medição eletrônica de consumo de eletrodomésticos. Pontifícia Universidade Católica do Rio de Janeiro, RJ, Abirl, 2013.

26 SOUZA, R.C., DANTAS, B.F., MUSAFIR, J.R., VALENÇA, A. \& PINHO, J.A., Desenvolvimento de coeficientes de ajustes das declarações de pesquisas de clientes para a estimativa e simulação do consumo por uso final dos consumidores. Artigo apresentado e publicado nos Anais do XX SENDI (Seminário Nacional de Distribuição de Energia Elétrica), Rio de Janeiro, RJ, Outubro, 2012.

27 PORTAL AMPLA, Ampla Energia e Serviços S.A - Grupo Endesa. Disponível em: http://www.ampla.com. Acessado em 30/01/2013.

28 SILVA, David; RIVIERE, Philippe; CHO, Yiseul; ADNOT, Jerome. Standby and Off-Mode Energy Losses In New Appliances Measured in Shops (SELINA) - Consumption monitoring campaign of standby and off-mode energy losses in new equipments. Mines ParisTech. França, 2010.

29 BRE Brazil Electronics Indústria e Comércio de Produtos Eletrônicos Ltda. Medidor Powersave. Website: < www.powersave.com.br >. Acesso em: 05/01/2014.

30 ELETROBRAS, Departamento de Planejamento e Estudos de Conservação de Energia - Avaliação do Mercado de Eficiência Energética no Brasil. Relatório Pesquisa de Posse e Hábitos de consumo. Ano base 2005. Classe Residencial - Relatório Brasil. Julho 2007.

$31 \mathrm{MME}$, PNE2030. Plano Nacional de Energia 2030. Ministério de Minas e Energia - Secretaria de Planejamento e Desenvolvimento Energético. Disponível em: < http://www.epe.gov.br/PNE/20080512_11.pdf >. Acesso em 17.01.2014. 
32 MDIC, Ministério do Desenvolvimento, Indústria e Comércio Exterior. Programa Brasileiro de Etiquetagem - PBE. Coordenação do InMetro. Disponível em: < http://www2.inmetro.gov.br/pbe/ >. Acesso em 17.01.2014.

33 PNAD2012 - Pesquisa Nacional por Amostra de Domicílios - Síntese de Indicadores, ano base 2012. Instituto Brasileiro de Geografia e Estatística IBGE. Disponível em: < http://www.ibge.gov.br/home/estatistica/populacao/tra balhoerendimento/pnad2012/default_sintese.shtm >. Acesso em: 03/03/2014.

34 MEIER, A.K., HUBER, W., ROSEN, K. Reducing Leaking Electricity to 1 Watt. Berkeley: Lawrence Berkeley National Laboratory: University of California, 1998. 


\section{APENDICE I - Dados da PPH sobre a utilização dos equipamentos elétricos}

Tabela 13: Dados da PPH sobre a utilização do aparelho de ar condicionado

\begin{tabular}{|c|c|c|c|c|c|c|c|c|c|c|}
\hline \multirow{2}{*}{$\begin{array}{c}\text { Faixa de } \\
\text { Consumo } \\
\text { (kWh) }\end{array}$} & \multicolumn{3}{|c|}{ Quantidade de aparelhos } & \multicolumn{3}{|c|}{$\begin{array}{l}\text { Quantidade de horas do } \\
\text { aparelho em UTILIZAÇÃO }\end{array}$} & \multicolumn{3}{|c|}{$\begin{array}{l}\text { Quantidade de horas do } \\
\text { aparelho em STANDBY }\end{array}$} & \multirow{2}{*}{$\begin{array}{c}\text { Período do } \\
\text { aparelho em } \\
\text { standby }\end{array}$} \\
\hline & $\begin{array}{c}\text { Total } \\
\text { amostra }\end{array}$ & $\begin{array}{l}\text { Que usam } \\
\text { o standby }\end{array}$ & $\begin{array}{c}\text { Que usam } \\
\text { o standby } \\
\text { (\%) }\end{array}$ & No mês & No ano & $\begin{array}{l}\text { média } \\
\text { mensal }\end{array}$ & No mês & No ano & $\begin{array}{l}\text { média } \\
\text { mensal }\end{array}$ & \\
\hline 0 a 80 & 19 & 1 & $5,3 \%$ & 24 & 288 & 24 & 696 & 8.352 & 696 & $96,7 \%$ \\
\hline 81 a 150 & 77 & 14 & $18,2 \%$ & 1.837 & 22.038 & 131 & 8.244 & 98.922 & 589 & $81,8 \%$ \\
\hline 151 a 220 & 164 & 32 & $19,5 \%$ & 4.397 & 52.767 & 137 & 18.643 & 223.713 & 583 & $80,9 \%$ \\
\hline 221 a 400 & 319 & 66 & $20,7 \%$ & 8.709 & 104.502 & 132 & 38.812 & 465.738 & 588 & $81,7 \%$ \\
\hline $400+$ & 206 & 56 & $27,2 \%$ & 9.795 & 117.534 & 175 & 30.526 & 366.306 & 545 & $75,7 \%$ \\
\hline Total & 785 & 169 & $21,5 \%$ & 24.761 & 297.129 & 147 & 96.919 & 1.163 .031 & 573 & $79,7 \%$ \\
\hline
\end{tabular}

Tabela 14: Dados da PPH sobre a utilização do televisor

\begin{tabular}{|c|c|c|c|c|c|c|c|c|c|c|}
\hline \multirow{2}{*}{$\begin{array}{c}\text { Faixa de } \\
\text { Consumo } \\
\text { (kWh) }\end{array}$} & \multicolumn{3}{|c|}{ Quantidade de aparelhos } & \multicolumn{3}{|c|}{$\begin{array}{l}\text { Quantidade de horas do } \\
\text { aparelho em UTILIZAÇÃO }\end{array}$} & \multicolumn{3}{|c|}{$\begin{array}{l}\text { Quantidade de horas do } \\
\text { aparelho em STANDBY }\end{array}$} & \multirow{2}{*}{$\begin{array}{c}\text { Período do } \\
\text { aparelho em } \\
\text { standby }\end{array}$} \\
\hline & $\begin{array}{c}\text { Total } \\
\text { amostra }\end{array}$ & $\begin{array}{l}\text { Que usam } \\
\text { o standby }\end{array}$ & $\begin{array}{c}\text { Que usam } \\
\text { o standby } \\
\text { (\%) }\end{array}$ & No mês & No ano & $\begin{array}{l}\text { média } \\
\text { mensal }\end{array}$ & No mês & No ano & $\begin{array}{l}\text { média } \\
\text { mensal }\end{array}$ & \\
\hline 0 a 80 & 292 & 184 & $63,0 \%$ & 33.983 & 407.796 & 185 & 98.497 & 1.181.964 & 535 & $74,3 \%$ \\
\hline 81 a 150 & 816 & 555 & $68,0 \%$ & 109.575 & 1.314 .900 & 197 & 290.025 & 3.480 .300 & 523 & $72,6 \%$ \\
\hline 151 a 220 & 1.012 & 714 & $70,6 \%$ & 132.704 & 1.592 .448 & 186 & 381.376 & 4.576 .512 & 534 & $74,2 \%$ \\
\hline 221 a 400 & 1.308 & 891 & $68,1 \%$ & 159.431 & 1.913 .172 & 179 & 482.089 & \begin{tabular}{|l|}
5.785 .068 \\
\end{tabular} & 541 & $75,1 \%$ \\
\hline $400+$ & 508 & 391 & $77,0 \%$ & 70.223 & 842.676 & 180 & 211.297 & 2.535 .564 & 540 & $75,1 \%$ \\
\hline Total & 3.936 & 2.735 & $69,5 \%$ & 505.916 & 6.070 .992 & 185 & 1.463 .284 & 17.559 .408 & 535 & $74,3 \%$ \\
\hline
\end{tabular}

Tabela 15: Dados da PPH sobre a utilização do forno de micro-ondas

\begin{tabular}{|c|c|c|c|c|c|c|c|c|c|c|}
\hline \multirow{2}{*}{$\begin{array}{c}\text { Faixa de } \\
\text { Consumo } \\
\text { (kWh) }\end{array}$} & \multicolumn{3}{|c|}{ Quantidade de aparelhos } & \multicolumn{3}{|c|}{$\begin{array}{l}\text { Quantidade de horas do } \\
\text { aparelho em UTILIZAÇÃO }\end{array}$} & \multicolumn{3}{|c|}{$\begin{array}{l}\text { Quantidade de horas do } \\
\text { aparelho em STANDBY }\end{array}$} & \multirow{2}{*}{$\begin{array}{c}\text { Período do } \\
\text { aparelho em } \\
\text { standby }\end{array}$} \\
\hline & $\begin{array}{c}\text { Total } \\
\text { amostra }\end{array}$ & $\begin{array}{l}\text { Que usam } \\
\text { o standby }\end{array}$ & $\begin{array}{c}\text { Que usam } \\
\text { o standby } \\
(\%)\end{array}$ & No mês & No ano & $\begin{array}{l}\text { média } \\
\text { mensal }\end{array}$ & No mês & No ano & $\begin{array}{l}\text { média } \\
\text { mensal }\end{array}$ & \\
\hline 0 a 80 & 32 & 3 & $9,4 \%$ & 1 & 16 & 0 & 2.159 & 25.904 & 720 & $99,9 \%$ \\
\hline 81 a 150 & 138 & 13 & $9,4 \%$ & 55 & 665 & 4 & 9.305 & 111.655 & 716 & $99,4 \%$ \\
\hline 151 a 220 & 197 & 24 & $12,2 \%$ & 104 & 1.251 & 4 & 17.176 & 206.109 & 716 & $99,4 \%$ \\
\hline 221 a 400 & 331 & 53 & $16,0 \%$ & 291 & 3.493 & 5 & 37.869 & 454.427 & 715 & $99,2 \%$ \\
\hline $400+$ & 158 & 23 & $14,6 \%$ & 119 & 1.434 & 5 & 16.441 & 197.286 & 715 & $99,3 \%$ \\
\hline Total & 856 & 116 & $13,6 \%$ & 572 & 6.859 & 5 & 82.948 & 995.381 & 715 & $99,3 \%$ \\
\hline
\end{tabular}


Tabela 16: Dados da PPH sobre a utilização da lavadora de roupas

\begin{tabular}{|c|c|c|c|c|c|c|c|c|c|c|}
\hline \multirow{2}{*}{$\begin{array}{c}\text { Faixa de } \\
\text { Consumo } \\
\text { (kWh) }\end{array}$} & \multicolumn{3}{|c|}{ Quantidade de aparelhos } & \multicolumn{3}{|c|}{$\begin{array}{l}\text { Quantidade de horas do } \\
\text { aparelho em UTILIZAÇÃO }\end{array}$} & \multicolumn{3}{|c|}{$\begin{array}{l}\text { Quantidade de horas do } \\
\text { aparelho em STANDBY }\end{array}$} & \multirow{2}{*}{$\begin{array}{c}\text { Período do } \\
\text { aparelho em } \\
\text { standby }\end{array}$} \\
\hline & $\begin{array}{c}\text { Total } \\
\text { amostra }\end{array}$ & $\begin{array}{l}\text { Que usam } \\
\text { o standby }\end{array}$ & $\begin{array}{c}\text { Que usam } \\
\text { o standby } \\
\text { (\%) }\end{array}$ & No mês & No ano & $\begin{array}{l}\text { média } \\
\text { mensal }\end{array}$ & No mês & No ano & $\begin{array}{l}\text { média } \\
\text { mensal }\end{array}$ & \\
\hline 0 a 80 & 130 & 1 & $0,8 \%$ & 8 & 96 & 8 & 712 & 8.544 & 712 & $98,9 \%$ \\
\hline 81 a 150 & 409 & 18 & $4,4 \%$ & 324 & 3.888 & 18 & 12.636 & 151.632 & 702 & $97,5 \%$ \\
\hline 151 a 220 & 481 & 28 & $5,8 \%$ & 428 & 5.136 & 15 & 19.732 & 236.784 & 705 & $97,9 \%$ \\
\hline 221 a 400 & 555 & 50 & $9,0 \%$ & 722 & 8.664 & 14 & 35.278 & 423.336 & 706 & $98,0 \%$ \\
\hline $400+$ & 200 & 16 & $8,0 \%$ & 424 & 5.088 & 27 & 11.096 & 133.152 & 694 & $96,3 \%$ \\
\hline Total & 1.775 & 113 & $6,4 \%$ & 1.906 & 22.872 & 17 & 79.454 & 953.448 & 703 & $97,7 \%$ \\
\hline
\end{tabular}

Tabela 17: Dados da PPH sobre a utilização do computador

\begin{tabular}{|c|c|c|c|c|c|c|c|c|c|c|}
\hline \multirow{2}{*}{$\begin{array}{c}\text { Faixa de } \\
\text { Consumo } \\
\text { (kWh) }\end{array}$} & \multicolumn{3}{|c|}{ Quantidade de aparelhos } & \multicolumn{3}{|c|}{$\begin{array}{l}\text { Quantidade de horas do } \\
\text { aparelho em UTILIZAÇÃo }\end{array}$} & \multicolumn{3}{|c|}{$\begin{array}{l}\text { Quantidade de horas do } \\
\text { aparelho em STANDBY }\end{array}$} & \multirow{2}{*}{$\begin{array}{l}\text { Período do } \\
\text { aparelho em } \\
\text { standby }\end{array}$} \\
\hline & $\begin{array}{c}\text { Total } \\
\text { amostra }\end{array}$ & $\begin{array}{l}\text { Que usam } \\
\text { o standby }\end{array}$ & $\begin{array}{c}\text { Que usam } \\
\text { o standby } \\
\text { (\%) }\end{array}$ & No mês & No ano & $\begin{array}{l}\text { média } \\
\text { mensal }\end{array}$ & No mês & No ano & $\begin{array}{l}\text { média } \\
\text { mensal }\end{array}$ & \\
\hline 0 a 80 & 42 & 5 & $11,9 \%$ & 1.990 & 23.880 & 398 & 1.610 & 19.320 & 322 & $44,7 \%$ \\
\hline 81 a 150 & 160 & 26 & $16,3 \%$ & 4.516 & 54.192 & 174 & 14.204 & 170.448 & 546 & $75,9 \%$ \\
\hline 151 a 220 & 289 & 62 & $21,5 \%$ & 14.656 & 175.872 & 236 & 29.984 & 359.808 & 484 & $67,2 \%$ \\
\hline 221 a 400 & 441 & 77 & $17,5 \%$ & 15.062 & 180.744 & 196 & 40.378 & 484.536 & 524 & $72,8 \%$ \\
\hline $400+$ & 216 & 52 & $24,1 \%$ & 13.160 & 157.920 & 253 & 24.280 & 291.360 & 467 & $64,9 \%$ \\
\hline Total & 1.148 & 222 & $19,3 \%$ & 49.384 & 592.608 & 222 & 110.456 & 1.325 .472 & 498 & $69,1 \%$ \\
\hline
\end{tabular}

Tabela 18: Dados da PPH sobre a utilização da cafeteira elétrica

\begin{tabular}{|c|c|c|c|c|c|c|c|c|c|c|}
\hline \multirow{2}{*}{$\begin{array}{c}\text { Faixa de } \\
\text { Consumo } \\
\text { (kWh) }\end{array}$} & \multicolumn{3}{|c|}{ Quantidade de aparelhos } & \multicolumn{3}{|c|}{$\begin{array}{l}\text { Quantidade de horas do } \\
\text { aparelho em UTILIZAÇÃO }\end{array}$} & \multicolumn{3}{|c|}{$\begin{array}{l}\text { Quantidade de horas do } \\
\text { aparelho em STANDBY }\end{array}$} & \multirow{2}{*}{$\begin{array}{l}\text { Período do } \\
\text { aparelho em } \\
\text { standby }\end{array}$} \\
\hline & $\begin{array}{c}\text { Total } \\
\text { amostra }\end{array}$ & $\begin{array}{l}\text { Que usam } \\
\text { o standby }\end{array}$ & $\begin{array}{c}\text { Que usam } \\
\text { o standby } \\
\text { (\%) }\end{array}$ & No mês & No ano & $\begin{array}{l}\text { média } \\
\text { mensal }\end{array}$ & No mês & No ano & $\begin{array}{l}\text { média } \\
\text { mensal }\end{array}$ & \\
\hline 0 a 80 & 41 & 4 & $9,8 \%$ & 308 & 3.696 & 77 & 2.572 & 30.864 & 643 & $89,3 \%$ \\
\hline 81 a 150 & 122 & 6 & $4,9 \%$ & 360 & 4.320 & 60 & 3.960 & 47.520 & 660 & $91,7 \%$ \\
\hline 151 a 220 & 153 & 15 & $9,8 \%$ & 580 & 6.954 & 39 & 10.221 & 122.646 & 681 & $94,6 \%$ \\
\hline 221 a 400 & 206 & 23 & $11,2 \%$ & 1.111 & 13.332 & 48 & 15.449 & 185.388 & 672 & $93,3 \%$ \\
\hline $400+$ & 96 & 4 & $4,2 \%$ & 175 & 2.100 & 44 & 2.705 & 32.460 & 676 & $93,9 \%$ \\
\hline Total & 618 & 52 & $8,4 \%$ & 2.534 & 30.402 & 49 & 34.907 & 418.878 & 671 & $93,2 \%$ \\
\hline
\end{tabular}

Tabela 19: Dados da PPH sobre a utilização do aparelho de som

\begin{tabular}{|c|c|c|c|c|c|c|c|c|c|c|}
\hline \multirow{2}{*}{$\begin{array}{c}\text { Faixa de } \\
\text { Consumo } \\
\text { (kWh) }\end{array}$} & \multicolumn{3}{|c|}{ Quantidade de aparelhos } & \multicolumn{3}{|c|}{$\begin{array}{l}\text { Quantidade de horas do } \\
\text { aparelho em UTILIZAÇÃO }\end{array}$} & \multicolumn{3}{|c|}{$\begin{array}{l}\text { Quantidade de horas do } \\
\text { aparelho em STANDBY }\end{array}$} & \multirow{2}{*}{$\begin{array}{l}\text { Período do } \\
\text { aparelho em } \\
\text { standby }\end{array}$} \\
\hline & $\begin{array}{c}\text { Total } \\
\text { amostra }\end{array}$ & $\begin{array}{l}\text { Que usam } \\
\text { o standby }\end{array}$ & $\begin{array}{c}\text { Que usam } \\
\text { o standby } \\
\text { (\%) }\end{array}$ & No mês & No ano & $\begin{array}{l}\text { média } \\
\text { mensal }\end{array}$ & No mês & No ano & $\begin{array}{l}\text { média } \\
\text { mensal }\end{array}$ & \\
\hline 0 a 80 & 114 & 56 & $49,1 \%$ & 3.360 & 40.320 & 60 & 36.960 & 443.520 & 660 & $91,7 \%$ \\
\hline 81 a 150 & 318 & 173 & $54,4 \%$ & 10.380 & 124.560 & 60 & 114.180 & 1.370 .160 & 660 & $91,7 \%$ \\
\hline 151 a 220 & 404 & 226 & $55,9 \%$ & 13.560 & 162.720 & 60 & 149.160 & 1.789 .920 & 660 & $91,7 \%$ \\
\hline 221 a 400 & 515 & 310 & $60,2 \%$ & 18.600 & 223.200 & 60 & 204.600 & 2.455 .200 & 660 & $91,7 \%$ \\
\hline $400+$ & 179 & 129 & $72,1 \%$ & 7.740 & 92.880 & 60 & 85.140 & 1.021 .680 & 660 & $91,7 \%$ \\
\hline Total & 1.530 & 894 & $58,4 \%$ & 53.640 & 643.680 & 60 & 590.040 & 7.080 .480 & 660 & $91,7 \%$ \\
\hline
\end{tabular}


Tabela 20: Dados da PPH sobre a utilização do rádio elétrico

\begin{tabular}{|c|c|c|c|c|c|c|c|c|c|c|}
\hline \multirow{2}{*}{$\begin{array}{c}\text { Faixa de } \\
\text { Consumo } \\
\text { (kWh) }\end{array}$} & \multicolumn{3}{|c|}{ Quantidade de aparelhos } & \multicolumn{3}{|c|}{$\begin{array}{l}\text { Quantidade de horas do } \\
\text { aparelho em UTILIZAÇÃOO }\end{array}$} & \multicolumn{3}{|c|}{$\begin{array}{l}\text { Quantidade de horas do } \\
\text { aparelho em STANDBY }\end{array}$} & \multirow{2}{*}{$\begin{array}{c}\text { Período do } \\
\text { aparelho em } \\
\text { standby }\end{array}$} \\
\hline & $\begin{array}{c}\text { Total } \\
\text { amostra }\end{array}$ & $\begin{array}{l}\text { Que usam } \\
\text { o standby }\end{array}$ & $\begin{array}{c}\text { Que usam } \\
\text { o standby } \\
\text { (\%) }\end{array}$ & No mês & No ano & $\begin{array}{l}\text { média } \\
\text { mensal }\end{array}$ & No mês & No ano & $\begin{array}{l}\text { média } \\
\text { mensal }\end{array}$ & \\
\hline 0 a 80 & 68 & 6 & $8,8 \%$ & 1.800 & 21.600 & 300 & 2.520 & 30.240 & 420 & $58,3 \%$ \\
\hline 81 a 150 & 175 & 24 & $13,7 \%$ & 7.200 & 86.400 & 300 & 10.080 & 120.960 & 420 & $58,3 \%$ \\
\hline 151 a 220 & 187 & 34 & $18,2 \%$ & 10.200 & 122.400 & 300 & 14.280 & 171.360 & 420 & $58,3 \%$ \\
\hline 221 a 400 & 238 & 52 & $21,8 \%$ & 15.600 & 187.200 & 300 & 21.840 & 262.080 & 420 & $58,3 \%$ \\
\hline $400+$ & 105 & 30 & $28,6 \%$ & 9.000 & 108.000 & 300 & 12.600 & 151.200 & 420 & $58,3 \%$ \\
\hline Total & 773 & 146 & $18,9 \%$ & 43.800 & 525.600 & 300 & 61.320 & 735.840 & 420 & $58,3 \%$ \\
\hline
\end{tabular}

Tabela 21: Dados da PPH sobre a utilização do vídeo cassete

\begin{tabular}{|c|c|c|c|c|c|c|c|c|c|c|}
\hline \multirow{2}{*}{$\begin{array}{c}\text { Faixa de } \\
\text { Consumo } \\
\text { (kWh) }\end{array}$} & \multicolumn{3}{|c|}{ Quantidade de aparelhos } & \multicolumn{3}{|c|}{$\begin{array}{l}\text { Quantidade de horas do } \\
\text { aparelho em UTILIZAÇÃO }\end{array}$} & \multicolumn{3}{|c|}{$\begin{array}{l}\text { Quantidade de horas do } \\
\text { aparelho em STANDBY }\end{array}$} & \multirow{2}{*}{$\begin{array}{l}\text { Período do } \\
\text { aparelho em } \\
\text { standby }\end{array}$} \\
\hline & $\begin{array}{c}\text { Total } \\
\text { amostra }\end{array}$ & $\begin{array}{l}\text { Que usam } \\
\text { o standby }\end{array}$ & $\begin{array}{c}\text { Que usam } \\
\text { o standby } \\
\text { (\%) }\end{array}$ & No mês & No ano & $\begin{array}{l}\text { média } \\
\text { mensal }\end{array}$ & No mês & No ano & $\begin{array}{l}\text { média } \\
\text { mensal }\end{array}$ & \\
\hline 0 a 80 & 7 & 2 & $28,6 \%$ & 32 & 384 & 16 & 1.408 & 16.896 & 704 & $97,8 \%$ \\
\hline 81 a 150 & 29 & 4 & $13,8 \%$ & 64 & 768 & 16 & 2.816 & 33.792 & 704 & $97,8 \%$ \\
\hline 151 a 220 & 33 & 11 & $33,3 \%$ & 176 & 2.112 & 16 & 7.744 & 92.928 & 704 & $97,8 \%$ \\
\hline 221 a 400 & 42 & 10 & $23,8 \%$ & 160 & 1.920 & 16 & 7.040 & 84.480 & 704 & $97,8 \%$ \\
\hline $400+$ & 10 & 3 & $30,0 \%$ & 48 & 576 & 16 & 2.112 & 25.344 & 704 & $97,8 \%$ \\
\hline Total & 121 & 30 & $24,8 \%$ & 480 & 5.760 & 16 & 21.120 & 253.440 & 704 & $97,8 \%$ \\
\hline
\end{tabular}

Tabela 22: Dados da PPH sobre a utilização do DVD

\begin{tabular}{|c|c|c|c|c|c|c|c|c|c|c|}
\hline \multirow{2}{*}{$\begin{array}{c}\text { Faixa de } \\
\text { Consumo } \\
\text { (kWh) }\end{array}$} & \multicolumn{3}{|c|}{ Quantidade de aparelhos } & \multicolumn{3}{|c|}{$\begin{array}{l}\text { Quantidade de horas do } \\
\text { aparelho em UTILIZAÇÃO }\end{array}$} & \multicolumn{3}{|c|}{$\begin{array}{l}\text { Quantidade de horas do } \\
\text { aparelho em STANDBY }\end{array}$} & \multirow{2}{*}{$\begin{array}{c}\text { Período do } \\
\text { aparelho em } \\
\text { standby }\end{array}$} \\
\hline & $\begin{array}{c}\text { Total } \\
\text { amostra }\end{array}$ & $\begin{array}{l}\text { Que usam } \\
\text { o standby }\end{array}$ & $\begin{array}{c}\text { Que usam } \\
\text { o standby } \\
\text { (\%) }\end{array}$ & No mês & No ano & $\begin{array}{l}\text { média } \\
\text { mensal }\end{array}$ & No mês & No ano & $\begin{array}{l}\text { média } \\
\text { mensal }\end{array}$ & \\
\hline 0 a 80 & 132 & 78 & $59,1 \%$ & 1.248 & 14.976 & 16 & 54.912 & 658.944 & 704 & $97,8 \%$ \\
\hline 81 a 150 & 406 & 263 & $64,8 \%$ & 4.208 & 50.496 & 16 & 185.152 & \begin{tabular}{|l|}
2.221 .824 \\
\end{tabular} & 704 & $97,8 \%$ \\
\hline 151 a 220 & 511 & 337 & $65,9 \%$ & 5.392 & 64.704 & 16 & 237.248 & 2.846 .976 & 704 & $97,8 \%$ \\
\hline 221 a 400 & 649 & 438 & $67,5 \%$ & 7.008 & 84.096 & 16 & 308.352 & 3.700 .224 & 704 & $97,8 \%$ \\
\hline $400+$ & 261 & 202 & $77,4 \%$ & 3.232 & 38.784 & 16 & 142.208 & 1.706 .496 & 704 & $97,8 \%$ \\
\hline Total & 1.959 & 1.318 & $67,3 \%$ & 21.088 & 253.056 & 16 & 927.872 & 11.134.464 & 704 & $97,8 \%$ \\
\hline
\end{tabular}

Tabela 23: Dados da PPH sobre a utilização da impressora

\begin{tabular}{|c|c|c|c|c|c|c|c|c|c|c|}
\hline \multirow{2}{*}{$\begin{array}{c}\text { Faixa de } \\
\text { Consumo } \\
\text { (kWh) }\end{array}$} & \multicolumn{3}{|c|}{ Quantidade de aparelhos } & \multicolumn{3}{|c|}{$\begin{array}{l}\text { Quantidade de horas do } \\
\text { aparelho em UTILIZAÇÃOO }\end{array}$} & \multicolumn{3}{|c|}{$\begin{array}{l}\text { Quantidade de horas do } \\
\text { aparelho em STANDBY }\end{array}$} & \multirow{2}{*}{$\begin{array}{l}\text { Período do } \\
\text { aparelho em } \\
\text { standby }\end{array}$} \\
\hline & $\begin{array}{c}\text { Total } \\
\text { amostra }\end{array}$ & $\begin{array}{l}\text { Que usam } \\
\text { o standby }\end{array}$ & $\begin{array}{c}\text { Que usam } \\
\text { o standby } \\
\text { (\%) }\end{array}$ & No mês & No ano & $\begin{array}{l}\text { média } \\
\text { mensal }\end{array}$ & No mês & No ano & $\begin{array}{c}\text { média } \\
\text { mensal }\end{array}$ & \\
\hline 0 a 80 & 24 & 2 & $8,3 \%$ & 60 & 720 & 30 & 1.380 & 16.560 & 690 & $95,8 \%$ \\
\hline 81 a 150 & 93 & 5 & $5,4 \%$ & 150 & 1.800 & 30 & 3.450 & 41.400 & 690 & $95,8 \%$ \\
\hline 151 a 220 & 169 & 24 & $14,2 \%$ & 720 & 8.640 & 30 & 16.560 & 198.720 & 690 & $95,8 \%$ \\
\hline 221 a 400 & 286 & 53 & $18,5 \%$ & 1.590 & 19.080 & 30 & 36.570 & 438.840 & 690 & $95,8 \%$ \\
\hline $400+$ & 141 & 26 & $18,4 \%$ & 780 & 9.360 & 30 & 17.940 & 215.280 & 690 & $95,8 \%$ \\
\hline Total & 713 & 110 & $15,4 \%$ & 3.300 & 39.600 & 30 & 75.900 & 910.800 & 690 & $95,8 \%$ \\
\hline
\end{tabular}


Tabela 24: Dados da PPH sobre a utilização do vídeo game

\begin{tabular}{|c|c|c|c|c|c|c|c|c|c|c|}
\hline \multirow{2}{*}{$\begin{array}{c}\text { Faixa de } \\
\text { Consumo } \\
\text { (kWh) }\end{array}$} & \multicolumn{3}{|c|}{ Quantidade de aparelhos } & \multicolumn{3}{|c|}{$\begin{array}{l}\text { Quantidade de horas do } \\
\text { aparelho em UTILIZAÇÃOO }\end{array}$} & \multicolumn{3}{|c|}{$\begin{array}{l}\text { Quantidade de horas do } \\
\text { aparelho em STANDBY }\end{array}$} & \multirow{2}{*}{$\begin{array}{l}\text { Período do } \\
\text { aparelho em } \\
\text { standby }\end{array}$} \\
\hline & $\begin{array}{c}\text { Total } \\
\text { amostra }\end{array}$ & $\begin{array}{l}\text { Que usam } \\
\text { o standby }\end{array}$ & $\begin{array}{c}\text { Que usam } \\
\text { o standby } \\
\text { (\%) }\end{array}$ & No mês & No ano & $\begin{array}{l}\text { média } \\
\text { mensal }\end{array}$ & No mês & No ano & $\begin{array}{l}\text { média } \\
\text { mensal }\end{array}$ & \\
\hline 0 a 80 & 23 & 4 & $17,4 \%$ & 240 & 2.880 & 60 & 2.640 & 31.680 & 660 & $91,7 \%$ \\
\hline 81 a 150 & 78 & 8 & $10,3 \%$ & 480 & 5.760 & 60 & 5.280 & 63.360 & 660 & $91,7 \%$ \\
\hline 151 a 220 & 118 & 14 & $11,9 \%$ & 840 & 10.080 & 60 & 9.240 & 110.880 & 660 & $91,7 \%$ \\
\hline 221 a 400 & 192 & 20 & $10,4 \%$ & 1.200 & 14.400 & 60 & 13.200 & 158.400 & 660 & $91,7 \%$ \\
\hline $400+$ & 75 & 11 & $14,7 \%$ & 660 & 7.920 & 60 & 7.260 & 87.120 & 660 & $91,7 \%$ \\
\hline Total & 486 & 57 & $11,7 \%$ & 3.420 & 41.040 & 60 & 37.620 & 451.440 & 660 & $91,7 \%$ \\
\hline
\end{tabular}

Tabela 25: Dados da PPH sobre a utilização do aparelho de TV por assinatura

\begin{tabular}{|c|c|c|c|c|c|c|c|c|c|c|}
\hline \multirow{2}{*}{$\begin{array}{c}\text { Faixa de } \\
\text { Consumo } \\
\text { (kWh) }\end{array}$} & \multicolumn{3}{|c|}{ Quantidade de aparelhos } & \multicolumn{3}{|c|}{$\begin{array}{l}\text { Quantidade de horas do } \\
\text { aparelho em UTILIZAÇÃo }\end{array}$} & \multicolumn{3}{|c|}{$\begin{array}{l}\text { Quantidade de horas do } \\
\text { aparelho em STANDBY }\end{array}$} & \multirow{2}{*}{$\begin{array}{l}\text { Período do } \\
\text { aparelho em } \\
\text { standby }\end{array}$} \\
\hline & $\begin{array}{c}\text { Total } \\
\text { amostra }\end{array}$ & $\begin{array}{l}\text { Que usam } \\
\text { o standby }\end{array}$ & $\begin{array}{c}\text { Que usam } \\
\text { o standby } \\
\text { (\%) }\end{array}$ & No mês & No ano & $\begin{array}{l}\text { média } \\
\text { mensal }\end{array}$ & No mês & No ano & $\begin{array}{l}\text { média } \\
\text { mensal }\end{array}$ & \\
\hline 0 a 80 & 31 & 21 & $67,7 \%$ & 3.150 & 37.800 & 150 & 11.970 & 143.640 & 570 & $79,2 \%$ \\
\hline 81 a 150 & 106 & 86 & $81,1 \%$ & 12.900 & 154.800 & 150 & 49.020 & 588.240 & 570 & $79,2 \%$ \\
\hline 151 a 220 & 150 & 114 & $76,0 \%$ & 17.100 & 205.200 & 150 & 64.980 & 779.760 & 570 & $79,2 \%$ \\
\hline 221 a 400 & 264 & 195 & $73,9 \%$ & 29.250 & 351.000 & 150 & 111.150 & 1.333 .800 & 570 & $79,2 \%$ \\
\hline $400+$ & 133 & 105 & $78,9 \%$ & 15.750 & 189.000 & 150 & 59.850 & 718.200 & 570 & $79,2 \%$ \\
\hline Total & 684 & 521 & $76,2 \%$ & 78.150 & 937.800 & 150 & 296.970 & 3.563 .640 & 570 & $79,2 \%$ \\
\hline
\end{tabular}




\section{APENDICE II - Informações sobre medição dos equipamentos elétricos}

Tabela 26: Dados de medição dos condicionadores de ar

\begin{tabular}{|c|c|c|c|c|c|c|c|c|c|}
\hline \multirow{2}{*}{ Aparelho } & \multirow{2}{*}{ Medição } & \multirow{2}{*}{ Tipo } & \multirow{2}{*}{ Tamanho } & \multirow{2}{*}{ Idade } & \multirow{2}{*}{ Marca } & \multicolumn{2}{c|}{ Consumo em 1 hora (kWh) } & \multicolumn{2}{c|}{$\begin{array}{c}\text { Consumo equivalente em 1 } \\
\text { hora (kWh) }\end{array}$} \\
\cline { 7 - 11 } & & & & & em utilização & em standby & em utilização & em standby \\
\hline 1 & 2 & Janela & 19000 & 2 & Springer & 0,5436 & 0,0009 & 0,11062 & 0,00073 \\
\hline 2 & 25 & Split & 18000 & 4 & Comfee & 1,2968 & 0,0032 & 0,26388 & 0,00255 \\
\hline 3 & 75 & janela & 10000 & 5 & Consul & 0,7741 & 0,0014 & 0,15753 & 0,00108 \\
\hline \multicolumn{3}{|c|}{ Valores médios do consumo } & & 0,8715 & 0,0018 & 0,17734 & 0,00145 \\
\hline
\end{tabular}

Tabela 27: Dados de medição dos televisores de LED

\begin{tabular}{|c|c|c|c|c|c|c|c|c|c|}
\hline \multirow{2}{*}{ Aparelho } & \multirow{2}{*}{ Medição } & \multirow{2}{*}{ Tipo } & \multirow{2}{*}{ Tamanho } & \multirow{2}{*}{ Idade } & \multirow{2}{*}{ Marca } & \multicolumn{2}{|c|}{ Consumo em 1 hora (kWh) } & \multicolumn{2}{|c|}{$\begin{array}{c}\begin{array}{c}\text { Consumo equivalente em } 1 \\
\text { hora }(\mathrm{kWh})\end{array} \\
\end{array}$} \\
\hline & & & & & & em utilização & em standby & em utilização & em standby \\
\hline 1 & 4 & LED & $55^{\prime}$ & 3 & LG & 0,1422 & 0,0003 & 0,03654 & 0,00022 \\
\hline 2 & 16 & LED & $40^{\prime}$ & 2 & Samsung & 0,0602 & 0,0002 & 0,01547 & 0,00018 \\
\hline 3 & 27 & LED & $40^{\prime}$ & 0,2 & Samsung & 0,0624 & 0,0003 & 0,01602 & 0,00021 \\
\hline 4 & 42 & LED & $40^{\prime}$ & 1 & STi & 0,0903 & 0,0006 & 0,02321 & 0,00043 \\
\hline 5 & 65 & LED & $32^{\prime}$ & 1 & Hbuster & 0,0333 & 0,0004 & 0,00855 & 0,00031 \\
\hline 6 & 76 & LED & $55^{\prime}$ & 1 & Samsung & 0,0967 & 0,0010 & 0,02484 & 0,00077 \\
\hline \multicolumn{6}{|c|}{ Valores médios do consumo } & 0,0809 & 0,0005 & 0,02077 & 0,00035 \\
\hline
\end{tabular}

Tabela 28: Dados de medição dos televisores de LCD

\begin{tabular}{|c|c|c|c|c|c|c|c|c|c|}
\hline \multirow{2}{*}{ Aparelho } & \multirow{2}{*}{ Medição } & \multirow{2}{*}{ Tipo } & \multirow{2}{*}{ Tamanho } & \multirow{2}{*}{ Idade } & \multirow{2}{*}{ Marca } & \multicolumn{2}{|c|}{ Consumo em 1 hora (kWh) } & \multicolumn{2}{|c|}{\begin{tabular}{|c}
$\begin{array}{c}\text { Consumo equivalente em } 1 \\
\text { hora (kWh) }\end{array}$ \\
\end{tabular}} \\
\hline & & & & & & em utilização & em standby & em utilização & em standby \\
\hline 1 & 11 & LCD & $26^{\prime}$ & 3 & Semp & 0,0611 & 0,0009 & 0,01569 & 0,00066 \\
\hline 2 & 23 & LCD & $32^{\prime}$ & 8 & Philips & 0,1024 & 0,0006 & 0,02630 & 0,00045 \\
\hline 3 & 35 & LCD & $32^{\prime}$ & 3 & Philips & 0,0776 & 0,0002 & 0,01994 & 0,00016 \\
\hline 4 & 45 & LCD & $32^{\prime}$ & 3 & Semp & 0,0949 & 0,0009 & 0,02437 & 0,00071 \\
\hline 5 & 55 & LCD & $32^{\prime}$ & 3 & Toshiba & 0,1141 & 0,0004 & 0,02933 & 0,00029 \\
\hline 6 & 56 & LCD & $32^{\prime}$ & 5 & Semp & 0,0907 & 0,0004 & 0,02330 & 0,00032 \\
\hline 7 & 57 & LCD & $42^{\prime}$ & 1 & LG & 0,1603 & 0,0002 & 0,04118 & 0,00018 \\
\hline 8 & 58 & LCD & $26^{\prime}$ & 7 & LG & 0,0780 & 0,0006 & 0,02003 & 0,00043 \\
\hline \multicolumn{6}{|c|}{ Valores médios do consumo } & 0,0974 & 0,0005 & 0,02502 & 0,00040 \\
\hline
\end{tabular}


Tabela 29: Dados de medição dos televisores CRT

\begin{tabular}{|c|c|c|c|c|c|c|c|c|c|}
\hline \multirow{2}{*}{ Aparelho } & \multirow{2}{*}{ Medição } & \multirow{2}{*}{ Tipo } & \multirow{2}{*}{ Tamanho } & \multirow{2}{*}{ Idade } & \multirow{2}{*}{ Marca } & \multicolumn{2}{|c|}{ Consumo em 1 hora (kWh) } & \multicolumn{2}{|c|}{$\begin{array}{c}\text { Consumo equivalente em } 1 \\
\text { hora (kWh) }\end{array}$} \\
\hline & & & & & & em utilização & em standby & em utilização & em standby \\
\hline 1 & 1 & Tubo & $14^{\prime}$ & 12 & Gradiente & 0,0427 & 0,0046 & 0,01096 & 0,00344 \\
\hline 2 & 14 & Tubo & $21^{\prime}$ & 6 & Sony & 0,0698 & 0,0007 & 0,01792 & 0,00055 \\
\hline 3 & 34 & Tubo & $14^{\prime}$ & 6 & LG & 0,0416 & 0,0010 & 0,01068 & 0,00076 \\
\hline 4 & 39 & Tubo & $21^{\prime}$ & 6 & CCE & 0,0457 & 0,0052 & 0,01173 & 0,00387 \\
\hline 5 & 40 & Tubo & $29^{\prime}$ & 23 & CCE & 0,0411 & 0,0008 & 0,01056 & 0,00059 \\
\hline \multicolumn{6}{|c|}{ Valores médios do consumo } & 0,0481 & 0,0025 & 0,01237 & 0,00184 \\
\hline
\end{tabular}

Tabela 30: Dados de medição dos fornos de micro-ondas

\begin{tabular}{|c|c|c|c|c|c|c|c|c|c|}
\hline \multirow{2}{*}{ Aparelho } & \multirow{2}{*}{ Medição } & \multirow{2}{*}{ Tipo } & \multirow{2}{*}{ Tamanho } & \multirow{2}{*}{ Idade } & \multirow{2}{*}{ Marca } & \multicolumn{2}{|c|}{ Consumo em 1 hora (kWh) } & \multicolumn{2}{|c|}{$\begin{array}{c}\text { Consumo equivalente em } 1 \\
\text { hora (kWh) }\end{array}$} \\
\hline & & & & & & em utilização & em standby & em utilização & em standby \\
\hline 1 & 6 & - & $30 \mathrm{~L}$ & 8 & Brastemp & 1,4613 & 0,0015 & 0,01000 & 0,00148 \\
\hline 2 & 26 & - & $28 \mathrm{~L}$ & 2 & Panasonic & 1,5404 & 0,0018 & 0,01054 & 0,00175 \\
\hline 3 & 31 & - & $20 \mathrm{~L}$ & 0,9 & Consul & 1,1220 & 0,0014 & 0,00768 & 0,00136 \\
\hline 4 & 41 & - & $30 \mathrm{~L}$ & 20 & Philco & 1,4557 & 0,0037 & 0,00996 & 0,00369 \\
\hline 5 & 44 & - & $18 \mathrm{~L}$ & 1 & Electrolux & 1,1865 & 0,0013 & 0,00812 & 0,00124 \\
\hline 6 & 52 & - & $31 \mathrm{~L}$ & 7 & GE & 1,5704 & 0,0014 & 0,01075 & 0,00144 \\
\hline \multicolumn{6}{|c|}{ Valores médios do consumo } & 1,3894 & 0,0018 & 0,00951 & 0,00183 \\
\hline
\end{tabular}

Tabela 31: Dados de medição das lavadoras de roupas

\begin{tabular}{|c|c|c|c|c|c|c|c|c|c|}
\hline \multirow{2}{*}{ Aparelho } & \multirow{2}{*}{ Medição } & \multirow{2}{*}{ Tipo } & \multirow{2}{*}{ Tamanho } & \multirow{2}{*}{ Idade } & \multirow{2}{*}{ Marca } & \multicolumn{2}{|c|}{ Consumo em 1 hora (kWh) } & \multicolumn{2}{|c|}{$\begin{array}{c}\text { Consumo equivalente em } 1 \\
\text { hora (kWh) }\end{array}$} \\
\hline & & & & & & em utilização & em standby & em utilização & em standby \\
\hline 1 & 53 & - & $12 \mathrm{~kg}$ & 2 & Electrolux & 0,0821 & 0,0002 & 0,00192 & 0,00021 \\
\hline 2 & 61 & - & $8 \mathrm{~kg}$ & 4 & Brastemp & 0,1487 & 0,0004 & 0,00348 & 0,00044 \\
\hline 3 & 62 & - & $7 \mathrm{~kg}$ & 5 & Electrolux & 0,0716 & 0,0005 & 0,00168 & 0,00044 \\
\hline 4 & 67 & - & $7 \mathrm{~kg}$ & 2 & Electrolux & 0,1299 & 0,0006 & 0,00304 & 0,00058 \\
\hline \multicolumn{6}{|c|}{ Valores médios do consumo } & 0,1081 & 0,0004 & 0,00253 & 0,00042 \\
\hline
\end{tabular}

Tabela 32: Dados de medição dos computadores

\begin{tabular}{|c|c|c|c|c|c|c|c|c|c|}
\hline \multirow[t]{2}{*}{ Aparelho } & \multirow[t]{2}{*}{ Medição } & \multirow{2}{*}{ Tipo } & \multirow{2}{*}{ Tamanho } & \multirow{2}{*}{ Idade } & \multirow{2}{*}{ Marca } & \multicolumn{2}{|c|}{ Consumo em 1 hora (kWh) } & \multicolumn{2}{|c|}{$\begin{array}{c}\text { Consumo equivalente em } 1 \\
\text { hora (kWh) }\end{array}$} \\
\hline & & & & & & em utilização & em standby & em utilização & em standby \\
\hline 1 & 19 & Desktop & $21^{\prime}$ & 2 & Dell & 0,0663 & 0,0043 & 0,02049 & 0,00299 \\
\hline 2 & 20 & Desktop & $21^{\prime}$ & 2 & Dell & 0,0481 & 0,0012 & 0,01485 & 0,00081 \\
\hline 3 & 32 & Desktop & $21^{\prime}$ & 4 & $\mathrm{AOC}$ & 0,0641 & 0,0063 & 0,01980 & 0,00433 \\
\hline 4 & 38 & Notebook & $14^{\prime}$ & 4 & Sony Vaio & 0,0157 & 0,0009 & 0,00485 & 0,00060 \\
\hline 5 & 47 & Notebook & $14^{\prime}$ & 5 & Acer & 0,0321 & 0,0004 & 0,00990 & 0,00025 \\
\hline \multicolumn{6}{|c|}{ Valores médios do consumo } & 0,0452 & 0,0026 & 0,01398 & 0,00180 \\
\hline
\end{tabular}


Tabela 33: Dados de medição das cafeteiras elétricas

\begin{tabular}{|c|c|c|c|c|c|c|c|c|c|}
\hline \multirow{2}{*}{ Aparelho } & \multirow{2}{*}{ Medição } & \multirow{2}{*}{ Tipo } & \multirow{2}{*}{ Tamanho } & \multirow{2}{*}{ Idade } & \multirow{2}{*}{ Marca } & \multicolumn{2}{|c|}{ Consumo em 1 hora (kWh) } & \multicolumn{2}{|c|}{$\begin{array}{c}\text { Consumo equivalente em } 1 \\
\text { hora (kWh) }\end{array}$} \\
\hline & & & & & & em utilização & em standby & em utilização & em standby \\
\hline 1 & 22 & - & - & 1 & Nespresso & 0,0425 & 0,0003 & 0,00287 & 0,00027 \\
\hline 2 & 71 & - & - & 2 & Faet & 0,1179 & 0,0001 & 0,00798 & 0,00013 \\
\hline 3 & 78 & - & - & 3 & Arno & 0,0578 & 0,0001 & 0,00391 & 0,00008 \\
\hline \multicolumn{6}{|c|}{ Valores médios do consumo } & 0,0727 & 0,0002 & 0,00492 & 0,00016 \\
\hline
\end{tabular}

Tabela 34: Dados de medição dos aparelhos de som

\begin{tabular}{|c|c|c|c|c|c|c|c|c|c|}
\hline \multirow{2}{*}{ Aparelho } & \multirow{2}{*}{ Medição } & \multirow{2}{*}{ Tipo } & \multirow{2}{*}{ Tamanho } & \multirow{2}{*}{ Idade } & \multirow{2}{*}{ Marca } & \multicolumn{2}{|c|}{ Consumo em 1 hora (kWh) } & \multicolumn{2}{|c|}{$\begin{array}{c}\text { Consumo equivalente em } 1 \\
\text { hora (kWh) }\end{array}$} \\
\hline & & & & & & em utilização & em standby & em utilização & em standby \\
\hline 1 & 10 & - & 3 em 1 & 23 & Gradiente & 0,0222 & 0,0003 & 0,00185 & 0,00023 \\
\hline 2 & 51 & - & 3 em 1 & 16 & Gradiente & 0,0147 & 0,0090 & 0,00123 & 0,00827 \\
\hline 3 & 64 & - & 3 em 1 & 3 & Philco & 0,0084 & 0,0007 & 0,00070 & 0,00065 \\
\hline 4 & 70 & - & 3 em 1 & 7 & Hyunday & 0,0044 & 0,0016 & 0,00036 & 0,00144 \\
\hline 5 & 77 & - & 4 em 1 & 5 & Samsung & 0,0238 & 0,0019 & 0,00198 & 0,00173 \\
\hline \multicolumn{6}{|c|}{ res médios do cons } & 0,0147 & 0,0027 & 0,00122 & 0,00247 \\
\hline
\end{tabular}

Tabela 35: Dados de medição dos rádios elétricos

\begin{tabular}{|c|c|c|c|c|c|c|c|c|c|}
\hline \multirow{2}{*}{ Aparelho } & \multirow{2}{*}{ Medição } & \multirow{2}{*}{ Tipo } & \multirow{2}{*}{ Tamanho } & \multirow{2}{*}{ Idade } & \multirow{2}{*}{ Marca } & \multicolumn{2}{|c|}{ Consumo em 1 hora (kWh) } & \multicolumn{2}{|c|}{$\begin{array}{c}\text { Consumo equivalente em } 1 \\
\text { hora (kWh) }\end{array}$} \\
\hline & & & & & & em utilização & em standby & em utilização & em standby \\
\hline 1 & 63 & - & rádio/relógio & 10 & Sony & 0,0011 & 0,0010 & 0,00044 & 0,00058 \\
\hline 2 & 79 & - & rádio/relógio & 0 & Sony & 0,0015 & 0,0014 & 0,00061 & 0,00080 \\
\hline \multicolumn{6}{|c|}{ Valores médios do consumo } & 0,0013 & 0,0012 & 0,00053 & 0,00069 \\
\hline
\end{tabular}

Tabela 36: Dados de medição dos aparelhos de vídeo cassete

\begin{tabular}{|c|c|c|c|c|c|c|c|c|c|}
\hline \multirow{2}{*}{ Aparelho } & \multirow{2}{*}{ Medição } & \multirow{2}{*}{ Tipo } & \multirow{2}{*}{ Tamanho } & \multirow{2}{*}{ Idade } & \multirow{2}{*}{ Marca } & \multicolumn{2}{|c|}{ Consumo em 1 hora (kWh) } & \multicolumn{2}{|c|}{$\begin{array}{c}\text { Consumo equivalente em } 1 \\
\text { hora (kWh) }\end{array}$} \\
\hline & & & & & & em utilização & em standby & em utilização & em standby \\
\hline 1 & 49 & - & - & 18 & Sharp & 0,0082 & 0,0049 & 0,00018 & 0,00477 \\
\hline 2 & 59 & - & - & 0 & 0 & 0,0065 & 0,0064 & 0,00014 & 0,00622 \\
\hline 3 & 60 & - & - & 23 & JVC & 0,0113 & 0,0034 & 0,00025 & 0,00337 \\
\hline \multicolumn{6}{|c|}{ Valores médios do consumo } & 0,0087 & 0,0049 & 0,00019 & 0,00479 \\
\hline
\end{tabular}

Tabela 37: Informações de medição dos aparelhos de DVD

\begin{tabular}{|c|c|c|c|c|c|c|c|c|c|}
\hline \multirow{2}{*}{ Aparelho } & \multirow{2}{*}{ Medição } & \multirow{2}{*}{ Tipo } & \multirow{2}{*}{ Tamanho } & \multirow{2}{*}{ Idade } & \multirow{2}{*}{ Marca } & \multicolumn{2}{|c|}{ Consumo em 1 hora (kWh) } & \multicolumn{2}{|c|}{$\begin{array}{c}\text { Consumo equivalente em } 1 \\
\text { hora (kWh) }\end{array}$} \\
\hline & & & & & & em utilização & em standby & em utilização & em standby \\
\hline 1 & 13 & H. Theater & - & 6 & Philips & 0,0256 & 0,0010 & 0,00057 & 0,00101 \\
\hline 2 & 29 & 3D & - & 0,2 & Samsung & 0,0048 & 0,0004 & 0,00011 & 0,00035 \\
\hline 3 & 43 & karaoke & - & 3 & Philips & 0,0065 & 0,0007 & 0,00014 & 0,00068 \\
\hline 4 & 50 & karaoke & - & 10 & Gradiente & 0,0069 & 0,0014 & 0,00015 & 0,00132 \\
\hline 5 & 72 & karaoke & - & 12 & Aistar & 0,0056 & 0,0040 & 0,00012 & 0,00391 \\
\hline \multicolumn{6}{|c|}{ Valores médios do consumo } & 0,0099 & 0,0015 & 0,00022 & 0,00145 \\
\hline
\end{tabular}


Tabela 38: Dados de medição das impressoras

\begin{tabular}{|c|c|c|c|c|c|c|c|c|c|}
\hline \multirow{2}{*}{ Aparelho } & \multirow{2}{*}{ Medição } & \multirow{2}{*}{ Tipo } & \multirow{2}{*}{ Tamanho } & \multirow{2}{*}{ Idade } & \multirow{2}{*}{ Marca } & \multicolumn{2}{|c|}{ Consumo em 1 hora (kWh) } & \multicolumn{2}{|c|}{$\begin{array}{c}\text { Consumo equivalente em } 1 \\
\text { hora (kWh) }\end{array}$} \\
\hline & & & & & & em utilização & em standby & em utilização & em standby \\
\hline 1 & 3 & laser & Multifuncional & 6 & HP & 0,6666 & 0,0114 & 0,02778 & 0,01090 \\
\hline 2 & 33 & J. tinta & Multifuncional & 4 & Epson & 0,0155 & 0,0015 & 0,00065 & 0,00142 \\
\hline 3 & 48 & J. tinta & Só Impressora & 10 & Canon & 0,0153 & 0,0037 & 0,00064 & 0,00352 \\
\hline 4 & 54 & J. tinta & Só Impressora & 2 & HP & 0,0096 & 0,0023 & 0,00040 & 0,00217 \\
\hline 5 & 66 & J. tinta & Multifuncional & 1 & $\mathrm{HP}$ & 0,0111 & 0,0003 & 0,00046 & 0,00028 \\
\hline \multicolumn{6}{|c|}{ Valores médios do consumo } & 0,1436 & 0,0038 & 0,00598 & 0,00366 \\
\hline
\end{tabular}

Tabela 39: Dados de medição dos aparelhos de vídeo game

\begin{tabular}{|c|c|c|c|c|c|c|c|c|c|}
\hline \multirow{2}{*}{ Aparelho } & \multirow{2}{*}{ Medição } & \multirow{2}{*}{ Tipo } & \multirow{2}{*}{ Tamanho } & \multirow{2}{*}{ Idade } & \multirow{2}{*}{ Marca } & \multicolumn{2}{|c|}{ Consumo em 1 hora (kWh) } & \multicolumn{2}{|c|}{$\begin{array}{c}\text { Consumo equivalente em } 1 \\
\text { hora (kWh) }\end{array}$} \\
\hline & & & & & & em utilização & em standby & em utilização & em standby \\
\hline 1 & 21 & - & - & 1 & Nintendo & 0,0331 & 0,0005 & 0,00276 & 0,00044 \\
\hline 2 & 36 & - & - & 1 & ps3 & 0,0813 & 0,0004 & 0,00678 & 0,00036 \\
\hline \multicolumn{6}{|c|}{ Valores médios do consumo } & 0,0572 & 0,0004 & 0,00477 & 0,00040 \\
\hline
\end{tabular}

Tabela 40: Dados de medição dos aparelhos de TV por assinatura

\begin{tabular}{|c|c|c|c|c|c|c|c|c|c|}
\hline \multirow{2}{*}{ Aparelho } & \multirow{2}{*}{ Medição } & \multirow{2}{*}{ Tipo } & \multirow{2}{*}{ Modelo } & \multirow{2}{*}{ Idade } & \multirow{2}{*}{ Marca } & \multicolumn{2}{|c|}{ Consumo em 1 hora (kWh) } & \multicolumn{2}{|c|}{$\begin{array}{c}\text { Consumo equivalente em } 1 \\
\text { hora }(\mathrm{kWh})\end{array}$} \\
\hline & & & & & & em utilização & em standby & em utilização & em standby \\
\hline 1 & 5 & $\mathrm{HD}$ & HDC74X1 & 3 & NET & 0,0100 & 0,0100 & 0,00209 & 0,00790 \\
\hline 2 & 7 & $\mathrm{HD}$ & DCR7121 & 2 & NET & 0,0117 & 0,0105 & 0,00243 & 0,00831 \\
\hline 3 & 12 & $\mathrm{HD}$ & DCR7121 & 3 & NET & 0,0113 & 0,0101 & 0,00235 & 0,00796 \\
\hline 4 & 15 & não HD & $\mathrm{NA}$ & 5 & NET & 0,0080 & 0,0072 & 0,00167 & 0,00573 \\
\hline 5 & 17 & $\mathrm{HD}$ & HDC74X1 & 2 & NET & 0,0102 & 0,0095 & 0,00213 & 0,00751 \\
\hline 6 & 28 & $\mathrm{HD}$ & DSI83 & 0,2 & $\mathrm{Oi}$ & 0,0081 & 0,0078 & 0,00168 & 0,00617 \\
\hline 7 & 37 & não HD & DCR2231 & 1 & NET & 0,0042 & 0,0040 & 0,00087 & 0,00321 \\
\hline 8 & 46 & não HD & DCl106A & 1 & NET & 0,0040 & 0,0040 & 0,00084 & 0,00313 \\
\hline 9 & 68 & não HD & DS222 & 1 & Claro & 0,0083 & 0,0061 & 0,00172 & 0,00483 \\
\hline \multicolumn{6}{|c|}{ Valores médios do consumo } & 0,0084 & 0,0077 & 0,00175 & 0,00608 \\
\hline
\end{tabular}




\section{ANEXO I - Instrumento de coleta de dados para classe residencial AMPLA(PPH)}

\section{PESQUISA DE POSSE DE ELETRODOMESTICOS E HIBITOS DE CONSUMO QUESTIONARIO RESIDENCIAL - BT}

Bom dia (tarde/noite), meu nome é e sou um pesquisador da PUC do Rio de Janeiro e estamos realizando uma pesquisa de campo para um projeto desenvolvido pelo IEPUC (Instituto de Energia da PUC), sobre o perfil e habitos de consumo de energia dos clientes da AMPLA/COELCE. Gostaria de saber se você teria disponibilidade para uma entrevista, que deve durar cerca de 45 minutos.

O objetivo do projeto é ceder informações que possam melhorar os serviços prestados pelas concessionárias de Energia Elétrica.

Posso entrevistá-lo(a)?

HORA DE INICIO DA ENTREVISTA

CONCESSIONARIA: 1. A AMPLA 2. 7 COELCE

NUMERO DO CLIENTE: MUNICIPIO:

FAIXA DE CONSUMO DO CLIENTE (kWh):
1. $\square 0$ a 80
2. 780 a 150
3. 150 a 220
4. 220 a 400
5. $700+$

\section{CARACTERIZAÇÃo DO DOMICÍlIO}

1.1 - QUANTIDADE DE PESSOAS QUE MORAM NO DOMICILIO:

1.2 - O RELOGIO (MEDIDOR) SERVE SO A ESTE DOMICILIO?

1. [ SIM 2.] NÃ̃o 99. [ NÂO SABE / NR

1.3 - QUANTO TEMPO VOCÉS (FAMILIA) MORAM NESTE DOMICILIO? $\square$ ANOS $\square$ MESES

1.4 - QUAL O TEMPO APROXIMADO DE CONSTRUÇĂO DO IMÓVEL? $\square$ ANOS $\square$ NSNR

1.5 - ITENS DE CONFORTO FAMILIAR:

\begin{tabular}{|l|l|}
\hline \multicolumn{1}{|c|}{ ITENS } & QUANTIDADE \\
\hline 1.5 .1 - BANHEIRO & \\
\hline 1.5 .2 - AUTONOVEL & \\
\hline 1.5 .3 - EMPREGADA $(O)$ DOMESTICA(O) MENSALISTA & \\
\hline
\end{tabular}




\section{POSSES E HÁBITOS DE USO DE LÂMPADAS}

2.1 - CARACTERISTICAS E HABITOS DE USO:

\begin{tabular}{|c|c|c|c|c|c|c|c|c|c|c|c|c|c|c|c|c|c|c|c|c|c|c|c|c|c|c|c|}
\hline \multirow{2}{*}{$\begin{array}{c}\text { TIPO DE } \\
\text { COMODO }\end{array}$} & \multicolumn{2}{|c|}{ LĀMPADAS } & \multicolumn{25}{|c|}{$\begin{array}{l}\text { QUANTIDADE DE LAMPADAS ACESAS POR PERIODO } \\
\text { "marcar com o número de lâmpadas acesas" }\end{array}$} \\
\hline & $\begin{array}{c}\text { Tipo } \\
\text { (1) }\end{array}$ & Total & E & $\circ$ & 1 & 2 & 3 & 4 & $s$ & 6 & 3 & 8 & 8 & to & u & 12 & 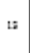 & s & is & 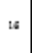 & 17 & 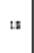 & 5 & $n$ & 2 & 2 & $2=$ \\
\hline \multirow{2}{*}{\multicolumn{28}{|c|}{$\begin{array}{l}\text { Sala de estar, } \\
\text { Jantar e TV }\end{array}$}} \\
\hline & & & & & & & & & & & & & & & & & & & & & & & & & & & \\
\hline \multicolumn{28}{|l|}{ Quarto 1} \\
\hline Q nut & & & & & & & & & & & & & & & & & & & & & & & & & & & \\
\hline \multicolumn{28}{|l|}{ Quarto 2} \\
\hline Quallo 2 & & & & & & & & & & & & & & & & & & & & & & & & & & & \\
\hline \multicolumn{28}{|l|}{ Quarto 3} \\
\hline Q & & & & & & & & & & & & & & & & & & & & & & & & & & & \\
\hline \multicolumn{28}{|l|}{ Quarto 4} \\
\hline Q uarto & & & & & & & & & & & & & & & & & & & & & & & & & & & \\
\hline \multicolumn{28}{|l|}{ Banheiro 1} \\
\hline Бенсто & & & & & & & & & & & & & & & & & & & & & & & & & & & \\
\hline \multirow{2}{*}{\multicolumn{28}{|c|}{ Banheiro 2}} \\
\hline & & & & & & & & & & & & & & & & & & & & & & & & & & & \\
\hline \multicolumn{28}{|l|}{ Banheiro 3} \\
\hline Danmello & & & & & & & & & & & & & & & & & & & & & & & & & & & \\
\hline \multicolumn{28}{|l|}{ Corredores } \\
\hline Worientito & & & & & & & & & & & & & & & & & & & & & & & & & & & \\
\hline \multicolumn{28}{|l|}{ Copa/Cozinha } \\
\hline F & & & & & & & & & & & & & & & & & & & & & & & & & & & \\
\hline \multirow{2}{*}{\multicolumn{28}{|c|}{$\begin{array}{l}\text { Area de } \\
\text { Serviço }\end{array}$}} \\
\hline & & & & & & & & & & & & & & & & & & & & & & & & & & & \\
\hline \multirow{2}{*}{\multicolumn{28}{|c|}{ Garagem }} \\
\hline & & & & & & & & & & & & & & & & & & & & & & & & & & & \\
\hline \multirow{2}{*}{\multicolumn{28}{|c|}{ Area Externa }} \\
\hline & & & & & & & & & & & & & & & & & & & & & & & & & & & \\
\hline \multirow{2}{*}{ Outras } & & & & & & & & & & & & & & & & & & & & & & & & & & & \\
\hline & & & & & & & & & & & & & & & & & & & & & & & & & & & \\
\hline
\end{tabular}

CHAMADA: (1)

(1) INCANDESCENTE 25W (7) FLUORESCENTE TUBULAR 40W

(3) INCANDESCENTT $60 \mathrm{~W}$ (8) FLURESCENTE COMPACTA $3 W$

(4) INCANDESCENTE 100W

(5) INCANDESCENTE $150 \mathrm{~W}$ (11) FLUORESCENTE COMPACTA $13 \mathrm{~W}$

(13) FLUORESCENTE COMPACTA 2OW

(14) FLUORESCENTE COMPACTA 25 W OUMAIS

(11) FLUORESCENTE COMPACTA $13 \mathrm{~W}$

(15) FLUORESCENTE CIRCUL.AR 22W

FLORESCENIE TUBULAR 2OW

(17) DICROICA

NOTA: (1) Na sala e na copa/cozinha deve ser verificada a potência na própria lâmpada, nos demais cômodos essa medida pode ser feita por

(2) Se não for possivel identificar um horário habitual de uso marque o nímero de lâmpadas na columa referente a uso eventual " $\mathrm{E}$ ". 


\section{POSSES E HẢBITOS DE USO DOS PRINCIPAIS ELETRODOMÉSTICOS}

3.1 - QUANTIDADE DE REFRIGERADORES (GELADEIRAS) NO DOMCILIO

3.2 - SELECIONE OS 3 PRINCIPAIS REFRIGERADORES DO DOMICILIO E PREENCHA AS CARACTERISTICAS DE CADA UM, NA TABELA ABAIXO:

\begin{tabular}{|c|c|c|c|c|c|c|c|c|c|c|c|c|c|c|}
\hline \multirow[t]{2}{*}{ REF. } & $\begin{array}{c}3.21 \\
\text { TIPO DE } \\
\text { APARELHO } \\
\text { (VER CARTAO 1) }\end{array}$ & \multirow{2}{*}{\multicolumn{2}{|c|}{$\begin{array}{c}3.22 \\
\text { UTIIZAÇÄO } \\
\text { 1-uso } \\
\text { permanente } \\
\text { 2-desligado }\end{array}$}} & \multirow{2}{*}{\multicolumn{3}{|c|}{$\begin{array}{c}3.2 .3 \\
\text { POSIÇĀO DO } \\
\text { TERMOSTATO } \\
\text { 1-mínimo } \\
\text { 2-médio } \\
\text { 3-máximo }\end{array}$}} & \multirow{3}{*}{$\begin{array}{c}3.2 .4 \\
\text { IDADE } \\
\text { DO } \\
\text { APARELHO } \\
\text { (em anos) }\end{array}$} & \multirow{2}{*}{\multicolumn{5}{|c|}{$\begin{array}{c}3.2 .5 \\
\text { PROBLEMAS } \\
\text { OCORRIDOS } \\
\text { NOS ULTIMOS } \\
12 \text { MESES } \\
\text { (*) }\end{array}$}} & \multirow{2}{*}{\multicolumn{2}{|c|}{$\begin{array}{l}\text { Pode ser } \\
\text { marcado } \\
\text { mais de } 1 \\
\text { problema } \\
\text { ocorrido }\end{array}$}} \\
\hline & CODIGO & & & & & & & & & & & & & \\
\hline 1 & & 1 & 2 & 1 & 2 & 3 & & 1 & 2 & 3 & 4 & 5 & 99 & \\
\hline 2 & & 1 & 2 & 1 & 2 & 3 & & 1 & 2 & 3 & 4 & 5 & 99 & \\
\hline 3 & & 1 & 2 & 1 & 2 & 3 & & 1 & 2 & 3 & 4 & 5 & 99 & \\
\hline CHAII & $\begin{array}{l}\text { (1) } \mathrm{MO} \\
\text { (3) } \mathrm{POB} \\
\text { (5) } \mathrm{NAC}\end{array}$ & & tu & $\mathrm{BI}$ & & & $\begin{array}{l}\text { (2) CONG } \\
\text { (4) OUIR } \\
\text { (99) NAO }\end{array}$ & & & & & & & tos \\
\hline
\end{tabular}

- tabela PARA PREENCHIMENTO DO TIPO dO APARELHO CASO O ENTREVISTADO NÃO TENHA ENCONTRADO O REFRIGERADOR NO CARTÄO

\begin{tabular}{|c|c|c|c|c|c|c|}
\hline REF. & $\begin{array}{c}3.211 \\
\text { MARCA }\end{array}$ & $\begin{array}{c}3.212 \\
\text { MODELO }\end{array}$ & $\begin{array}{c}3.213 \\
\text { QTD } \\
\text { PORTAS }\end{array}$ & $\begin{array}{c}3.214 \\
\text { QTD } \\
\text { LITROS }\end{array}$ & $\begin{array}{c}3.215 \\
\text { CONSUMO } \\
\text { MEDIO }\end{array}$ & $\begin{array}{c}3.2 .16 \\
\text { POTENCIA }\end{array}$ \\
\hline 1 & & & & & & \\
\hline 2 & & & & & & \\
\hline 3 & & & & & & \\
\hline
\end{tabular}

3.3 - QUANTIDADE DE FREEZERS NO DOMICILIO:

3.4 - SELECIONE OS 3 PRINCIPAIS FREEZERS DO DOMICILIO E PREENCHA AS CARACTERISTICAS DE \# CADA UM, NA TABELA ABAIXO.

\begin{tabular}{|c|c|c|c|c|c|c|}
\hline \multirow[t]{2}{*}{ REF. } & $\begin{array}{c}3.4 .1 \\
\text { TIPO DE } \\
\text { APARELHO } \\
\text { (VER CARTAO 2) }\end{array}$ & \multirow{2}{*}{\multicolumn{4}{|c|}{$\begin{array}{c}3.4 .2 \\
\text { UTILIZAÇǞO } \\
\text { 1-uso permanente } \\
\text { 2-uso parte do dia } \\
\text { 3-ligo eventualmente } \\
\text { 4-desligado }\end{array}$}} & \multirow[t]{2}{*}{$\begin{array}{l}3.4 .3 \\
\text { IDADE } \\
\text { DO } \\
\text { APARELHO } \\
\text { (em anos) }\end{array}$} \\
\hline & CODIGO & & & & & \\
\hline 1 & & 1 & 2 & 3 & 4 & \\
\hline 2 & & 1 & 2 & 3 & 4 & \\
\hline 3 & & 1 & 2 & 3 & 4 & \\
\hline
\end{tabular}

- tabela PARA PREENCHIMENTO DO TIPO DO APARELHO CASO O ENTREVISTADO NÃO TENHA ENCONTRADO O FREEZER NO CARTÄO

\begin{tabular}{|c|c|c|c|c|c|c|c|}
\hline REF. & $\begin{array}{c}3.4 .11 \\
\text { MARCA }\end{array}$ & $\begin{array}{l}3.4 .12 \\
\text { MODELO }\end{array}$ & \multicolumn{2}{|c|}{$\begin{array}{c}3.4 .13 \\
\text { TIPO } \\
\text { 1-vertical } \\
\text { 2-horizontal }\end{array}$} & $\begin{array}{c}3.4 .14 \\
\text { QTD } \\
\text { LITROS }\end{array}$ & $\begin{array}{c}3.4 .15 \\
\text { CONSUMO } \\
\text { MEDIO }\end{array}$ & $\begin{array}{l}3.4 .16 \\
\text { POTENCIA }\end{array}$ \\
\hline 1 & & & 1 & 2 & & & \\
\hline 2 & & & 1 & 2 & & & \\
\hline 3 & & & 1 & 2 & & & \\
\hline
\end{tabular}


3.5 - QUANTIDADE DE CONDICIONADORES DE AR NO DOMICILIO:

3.6 - SELECIONE OS 4 PRINCIPAIS CONDICIONADORES DE AR DO DOMICILIO E PREENCHA AS CARACTERISTICAS DE CADA UM, NA TABELA ABAIXO:

\begin{tabular}{|c|c|c|c|c|c|c|c|c|c|c|c|c|}
\hline \multirow{2}{*}{ REF. } & \multirow{2}{*}{$\begin{array}{c}3.6 .1 \\
\begin{array}{c}\text { TIPO DE } \\
\text { APAREL HO } \\
\text { (VER C.ARTAO3) }\end{array} \\
\begin{array}{c}3.6 .1 \\
\text { CODIGO }\end{array}\end{array}$} & \multirow{2}{*}{\multicolumn{3}{|c|}{$\begin{array}{c}\text { 3.6.2 } \\
\text { TIPO } \\
\text { 1-janela } \\
\text { 2-split } \\
\text { 3-portátil }\end{array}$}} & \multirow{2}{*}{$\begin{array}{c}3.6 .3 \\
\text { IDADE } \\
\text { DO } \\
\text { APARELHO } \\
\text { (em anos) }\end{array}$} & \multicolumn{3}{|c|}{$\begin{array}{c}3.64 \\
\text { O COMMODO } \\
\text { RECEBE SOL? }\end{array}$} & \multicolumn{2}{|c|}{$\begin{array}{c}3.6 .5 \\
\text { CONTROLE } \\
\text { REMOTO }\end{array}$} & \multicolumn{2}{|c|}{$\begin{array}{c}3.6 .6 \\
\text { STAND-BY }\end{array}$} \\
\hline & & & & & & $\mathrm{M}$ & $\mathrm{T}$ & NÄO & SIM & $\mathrm{NABO}$ & SIM & NÄO \\
\hline 1 & & 1 & 2 & 3 & & & & & & & & \\
\hline 2 & & 1 & 2 & 3 & & & & & & & & \\
\hline 3 & & 1 & 2 & 3 & & & & & & & & \\
\hline 4 & & 1 & 2 & 3 & & & & & & & & \\
\hline
\end{tabular}

- tabela PARA PREENCHIMENTO do TIPO do APARELHO CASO O ENTREVISTADO NÃO TENHA ENCONTRADO O AR CONDICIONADO NO CARTÁO

\begin{tabular}{|c|c|c|c|c|c|}
\hline REF. & $\begin{array}{c}3.611 \\
\text { MARCA }\end{array}$ & $\begin{array}{c}3.612 \\
\text { MODELO }\end{array}$ & $\begin{array}{c}3.613 \\
\text { QTD BTU'S }\end{array}$ & $\begin{array}{c}3.614 \\
\text { CONSUMO } \\
\text { MEDIO }\end{array}$ & $\begin{array}{c}3.615 \\
\text { POTENCIA }\end{array}$ \\
\hline 1 & & & & & \\
\hline 2 & & & & & \\
\hline 3 & & & & & \\
\hline 4 & & & & & \\
\hline
\end{tabular}

3.7 - HÁBITOS DE USO DE ACORDO COM O CLIMA NOS DIAS DE SEMANA E FINAIS DE SEMANA.

\begin{tabular}{|c|c|c|c|c|c|c|c|c|c|c|c|c|c|c|c|c|c|c|c|c|c|c|c|c|c|c|}
\hline \multirow{2}{*}{$\begin{array}{l}N^{0} \\
\text { Do } \\
\text { AP. }\end{array}$} & \multirow{2}{*}{$\begin{array}{c}3.7 .1 \\
\text { USAO } \\
\text { APARELHO } \\
\text { NOSMESES } \\
\text { DE. } \\
\text { (MARQUE LM } \\
\text { "X") }\end{array}$} & \multirow{2}{*}{$\begin{array}{c}3.7 .2 \\
\text { GRAU } \\
\text { DE } \\
\text { UTII } \\
(1)\end{array}$} & \multicolumn{24}{|c|}{$\begin{array}{c}3.7 .3 \\
\text { TEMPO DE USO POR PERIODO } \\
\text { (marque um " } \mathrm{X} ")\end{array}$} \\
\hline & & & $=$ & 0 & & 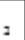 & $:$ & 4 & 3 & $\approx$ & , & : & & 18 & $18:$ & 1: & $\because$ & 12 & 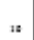 & י & $: 3$ & & $: p$ & & & \\
\hline \multirow{3}{*}{1} & VERÄO () & & & & & & & & & & & & & & & & & & & & & & & & & \\
\hline & PRIOUT ( ) & & & & & & & & & & & & & & & & & & & & & & & & & \\
\hline & INVERNO ( ) & & & & & & & & & & & & & & & & & & & & & & & & & \\
\hline \multirow{3}{*}{2} & VERÃO ( ) & & & & & & & & & & & & & & & & & & & & & & & & & \\
\hline & PRIOUT ( ) & & & & & & & & & & & & & & & & & & & & & & & & & \\
\hline & INVERNO ( ) & & & & & & & & & & & & & & & & & & & & & & & & & \\
\hline \multirow{3}{*}{3} & VERÃO () & & & & & & & & & & & & & & & & & & & & & & & & & \\
\hline & PRIOUT ( ) & & & & & & & & & & & & & & & & & & & & & & & & & \\
\hline & INVERNO ( ) & & & & & & & & & & & & & & & & & & & & & & & & & \\
\hline \multirow{3}{*}{4} & VERÃO ( ) & & & & & & & & & & & & & & & & & & & & & & & & & \\
\hline & PRIOUT ( ) & & & & & & & & & & & & & & & & & & & & & & & & & \\
\hline & INERNNO ( ) & & & & & & & & & & & & & & & & & & & & & & & & & \\
\hline
\end{tabular}


3.8 - QUANTIDADE DE TELEVISORES NO DOMICILIO:

3.9 - SELECIONE OS 5 PRINCIPAIS TELEVISORES DO DOMICILIO E PREENCHA AS CARACTERISTICAS DE CADA UMNA TABELA ABALXO

\begin{tabular}{|c|c|c|c|c|c|c|c|c|c|}
\hline \multirow[t]{2}{*}{ REF. } & \multirow{2}{*}{$\begin{array}{c}3.9 .1 \\
\text { TIPO DE } \\
\text { APARELHO } \\
\text { (VER CARTAO 4) } \\
\begin{array}{c}3.1 \\
\text { CODIGO }\end{array}\end{array}$} & \multirow{2}{*}{$\begin{array}{c}3.9 .2 \\
\text { ESTIMATIVA } \\
\text { DE IDADE } \\
\text { DO } \\
\text { APARELHO } \\
\text { (em anos) }\end{array}$} & \multirow{2}{*}{\multicolumn{5}{|c|}{$\begin{array}{c}39.3 \\
\text { GRAU DE } \\
\text { UTILIZACCÃo } \\
\text { 1-usa mais de 4x na semana } \\
\text { 2-usa de l a 4x na semana } \\
\text { 3-usa de l a 3x no mês } \\
\text { 4-usa menos de lx no mês } \\
\text { 5-não utiliza }\end{array}$}} & \multicolumn{2}{|c|}{$\begin{array}{c}3.9 .4 \\
\text { STAND BY }\end{array}$} \\
\hline & & & & & & & & SIM & $\mathrm{NÄO}$ \\
\hline 1 & & & 1 & 2 & 3 & 4 & 5 & & \\
\hline 2 & & & 1 & 2 & 3 & 4 & 5 & & \\
\hline 3 & & & 1 & 2 & 3 & 4 & 5 & & \\
\hline 4 & & & 1 & 2 & 3 & 4 & 5 & & \\
\hline 5 & & & 1 & 2 & 3 & 4 & 5 & & \\
\hline
\end{tabular}

- TABELA PARA PREENCHIMENTO DO TIPO DO APARELHO CASO O ENTREVISTADO NÃ̃ TENHA ENCONTRADO A TELEVISÄO NO CARTÄO

\begin{tabular}{|c|c|c|c|c|c|c|c|c|}
\hline \multirow{2}{*}{$\begin{array}{c}\text { REF. } \\
\\
1 \\
\end{array}$} & \multirow[t]{2}{*}{$\begin{array}{c}3.9 .11 \\
\text { MARCA }\end{array}$} & \multirow{2}{*}{$\begin{array}{l}3.9 .12 \\
\text { POLEGADAS }\end{array}$} & \multicolumn{4}{|c|}{$\begin{array}{c}3.9 .13 \\
\text { TIPO } \\
\text { 1-convencional } \\
\text { 2-LCD } \\
\text { 3-Plasma } \\
\text { 4-LED }\end{array}$} & \multirow[t]{2}{*}{$\begin{array}{c}3.9 .14 \\
\text { CONSUMO } \\
\text { MEDIO }\end{array}$} & \multirow[t]{2}{*}{$\begin{array}{c}3.9 .15 \\
\text { POTENCIA }\end{array}$} \\
\hline & & & 1 & 2 & 3 & 4 & & \\
\hline 2 & & & 1 & 2 & 3 & 4 & & \\
\hline 3 & & & 1 & 2 & 3 & 4 & & \\
\hline 4 & & & 1 & 2 & 3 & 4 & & \\
\hline 5 & & & 1 & 2 & 3 & 4 & & \\
\hline
\end{tabular}

3.10 - HORARIOS DE USO DOS APARELHOS DE TV DE ACORDO COM O DIA DA SEMANA.

\begin{tabular}{|c|c|c|c|c|c|c|c|c|c|c|c|c|c|c|c|c|c|c|c|c|c|c|c|c|c|}
\hline \multirow{2}{*}{ DIAS } & \multirow{2}{*}{$\underset{\text { REF }}{\mathbf{N}^{\circ}}$} & \multicolumn{24}{|c|}{ HORARTOS DE USO DOS APAREL HOS DE TV (marove um " $\mathrm{X}$ ") } \\
\hline & & $E$ & 0 & 1 & & 3 & 4 & 5 & 6 & \begin{tabular}{l|l}
7 & 8 \\
\end{tabular} & 9 & 10 & 11 & 12 & 13 & 14 & 15 & 16 & 17 & 18 & 19 & 20 & 21 & 22 & 23 \\
\hline \multirow{5}{*}{$\begin{array}{l}\text { DIAS DE } \\
\text { SEMANA }\end{array}$} & 1 & & & & & & & & & & & & & & & & & & & & & & & & \\
\hline & 2 & & & & & & & & & & & & & & & & & & & & & & & & \\
\hline & 3 & & & & & & & & & & & & & & 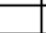 & & & & & & & & 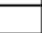 & & \\
\hline & 4 & & & & & & & & & & & & & & & & & & & & & & & & \\
\hline & 5 & & & & & & & & & & & & & & & & & & & & & & & & \\
\hline \multirow{5}{*}{ SABADO } & 1 & & & & & & & & & & & & & & & & & & & & & & & & \\
\hline & 2 & & & & & & & & & & & & & & & & & & & & & & & & \\
\hline & 3 & & & & & & & & & & & & & & & & & & & & & & & & \\
\hline & 4 & & & & & & & & & & & & & & & & & & & & & 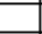 & & & \\
\hline & 5 & & & & & & & & & & & & & & & & & & & & & & & & \\
\hline \multirow{4}{*}{ DOMINGO } & 1 & & & & & & & & & & & & & & & & & & & & & & & & \\
\hline & $\frac{2}{3}$ & & & & & & & & & & & & & & & & & & & & & & & & \\
\hline & 4 & & & & & & & & & & & & & & & & & & & & & & & & \\
\hline & 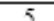 & & & & & & & & & & & & & & & & & & & & & & & & \\
\hline
\end{tabular}


3.11 - QUANTIDADE DE CHUVEIROS ELÉTRICOS NO DOMCILIO:

3.12 - SELECIONE OS 3 PRINCTPAIS CHUVIEIROS ELETRICOS DO DOMICILIO E PREENCHA AS CARACTERISTICAS DE CADA UMNA TABELA ABAIXO

\begin{tabular}{|c|c|c|c|c|c|c|c|c|}
\hline \multirow[t]{2}{*}{ REF. } & \multirow{2}{*}{$\begin{array}{c}3.12 .1 \\
\text { TIPO DE } \\
\text { APARELHO } \\
(\text { (ERR CARTAO 5) }\end{array}$} & \multirow[t]{2}{*}{$\begin{array}{c}3.12 .2 \\
N^{0} \mathrm{DE} \\
\text { BANHOS } \\
\text { POR DIA }\end{array}$} & \multicolumn{3}{|c|}{$\begin{array}{c}3.12 .3 \\
\text { NUMERO DE BANHOS POR } \\
\text { DIA POR POSIÇÄO DA } \\
\text { CHAVE DO CHUVEIRO }\end{array}$} & \multicolumn{3}{|c|}{$\begin{array}{l}3.12 .4 \\
\text { NUMERO DE BANHOS POR } \\
\text { DIA POR POSICCAOO DA } \\
\text { CHAVE DO CHUVEIRO } \\
\text { DURANIE OS MESES DE } \\
\text { INVERNO }\end{array}$} \\
\hline & & & VERAO & $\begin{array}{c}\text { INVER- } \\
\text { No }\end{array}$ & $\begin{array}{l}\text { DESLI- }- \\
\text { GADA }\end{array}$ & VERAO & $\begin{array}{c}\text { INVER- } \\
\text { NO }\end{array}$ & $\begin{array}{l}\text { DESLI- } \\
\text { GADA }\end{array}$ \\
\hline 1 & & & & & & & & \\
\hline 2 & & & & & & & & \\
\hline 3 & & & & & & & & \\
\hline
\end{tabular}

- tabela PARA PREENCHIMENTO dO TIPO DO APARELHO CASO O ENTREVISTADO NÃO TENHA ENCONTRADO O CHUVEIRO NO CARTÄO

\begin{tabular}{|c|c|c|c|c|}
\hline REF. & $\begin{array}{c}3.1211 \\
\text { MARCA }\end{array}$ & $\begin{array}{c}3.1212 \\
\text { MODELO }\end{array}$ & $\begin{array}{c}3.12 .13 \\
\text { CONSUMO } \\
\text { MEDIO }\end{array}$ & $\begin{array}{c}3.12 .14 \\
\text { POTENCIA }\end{array}$ \\
\hline 1 & & & & \\
\hline 2 & & & & \\
\hline 3 & & & & \\
\hline
\end{tabular}

3.13 - HABITOS DE USO DO CHUVEIRO ELETRICO NOS DIAS DE SEMANA.

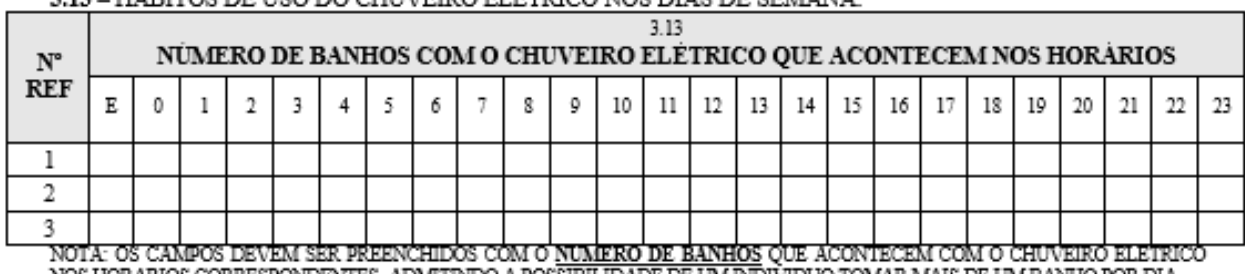

NOS HORARIOS CORPESPONDENTES, ADMTTNDO A POSSIBILDADE DE UNINDIVIDUO TOMAR. MAIS DE UM BANHO POR DIA

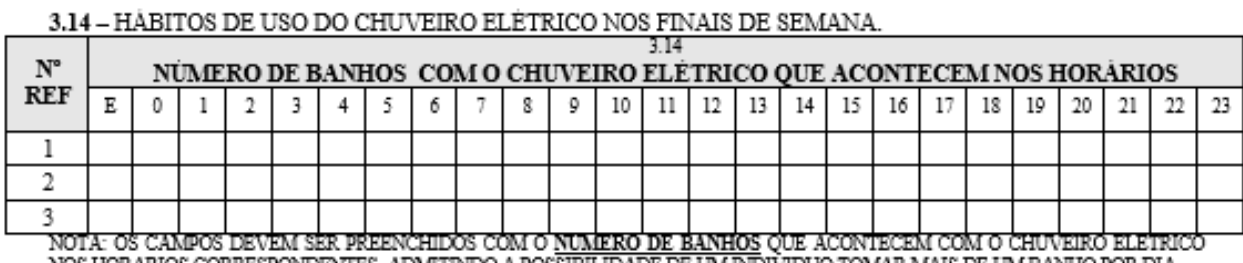
1.] ATE $10 \mathrm{MGN}$
2. $10 \mathrm{~A} 20 \mathrm{MIN}$
3. $\square$ MAIS DE $20 \mathrm{MIN}$
99.] NÃO SABE / NR 
3.16 - SE O PREÇO DA ENERGIA FOSSE O DOBRO NO HORARIO DAS 18:00 AS 21:00, VOCË ACHA QUE A SUA FAMIII IA EVITARIA TOMAR BANHO NESSE PERIODO?

1. $\square$ SIM $2 . \square$ NÃO $99 . \square$ NÃO SABE / NR $\quad 4 . \square$ UNS SIM, OUTROS NÃO

\section{POSSES E HABBITOS DE USO DE OUTROS ELETRODOMESTICOS}

\begin{tabular}{|c|c|c|c|c|c|c|c|c|c|c|c|}
\hline \multirow[t]{2}{*}{ APARELHO } & \multirow[t]{2}{*}{$\begin{array}{l}4.1 .1 \\
\text { QTD }\end{array}$} & \multicolumn{2}{|c|}{$\begin{array}{c}4.1 .2 \\
\text { STAND } \\
\text { BY }\end{array}$} & \multirow[t]{2}{*}{ APARELHO } & \multirow[t]{2}{*}{$\begin{array}{l}4.1 .1 \\
\text { QTD }\end{array}$} & \multicolumn{2}{|c|}{$\begin{array}{c}41.2 \\
\text { STAND } \\
\text { BY }\end{array}$} & \multirow[t]{2}{*}{ APARELHO } & \multirow[t]{2}{*}{$\begin{array}{l}4.1 .1 \\
\text { QTD }\end{array}$} & \multicolumn{2}{|c|}{$\begin{array}{l}4.1 .2 \\
\text { STAND } \\
\text { BY }\end{array}$} \\
\hline & & \begin{tabular}{c|c|} 
\\
\end{tabular} & $\mathrm{N}$ & & & \begin{tabular}{l|l} 
\\
$\mathrm{s}$
\end{tabular} & $\mathrm{N}$ & & & & $\mathrm{N}$ \\
\hline 1. APARELHO DE SOM & & & & 6. VDEO GAME & & & & 14. ASPIRADOR DE PO & & & \\
\hline 2.RADIO ELETRICO & & & & 7.LLQUIDIFICADOR & & & & 15. HIDROMASSAGEM & & & \\
\hline 3. VIDEO CASSETE & & & & 8. BATEDEIRA & & & & 16. TV POR ASSNATURA & & & \\
\hline 4.DVD & & & & 9. EXAUSTOR & & & & 17. TV PARABOLICA & & & \\
\hline 5. IMPRESSORA & & & & 13. ENCERADERRA & & & & 18. OUIROS & & & \\
\hline
\end{tabular}

4.2 - POSSES E HABITOS DE USO DE OUTROS APARELHOS:

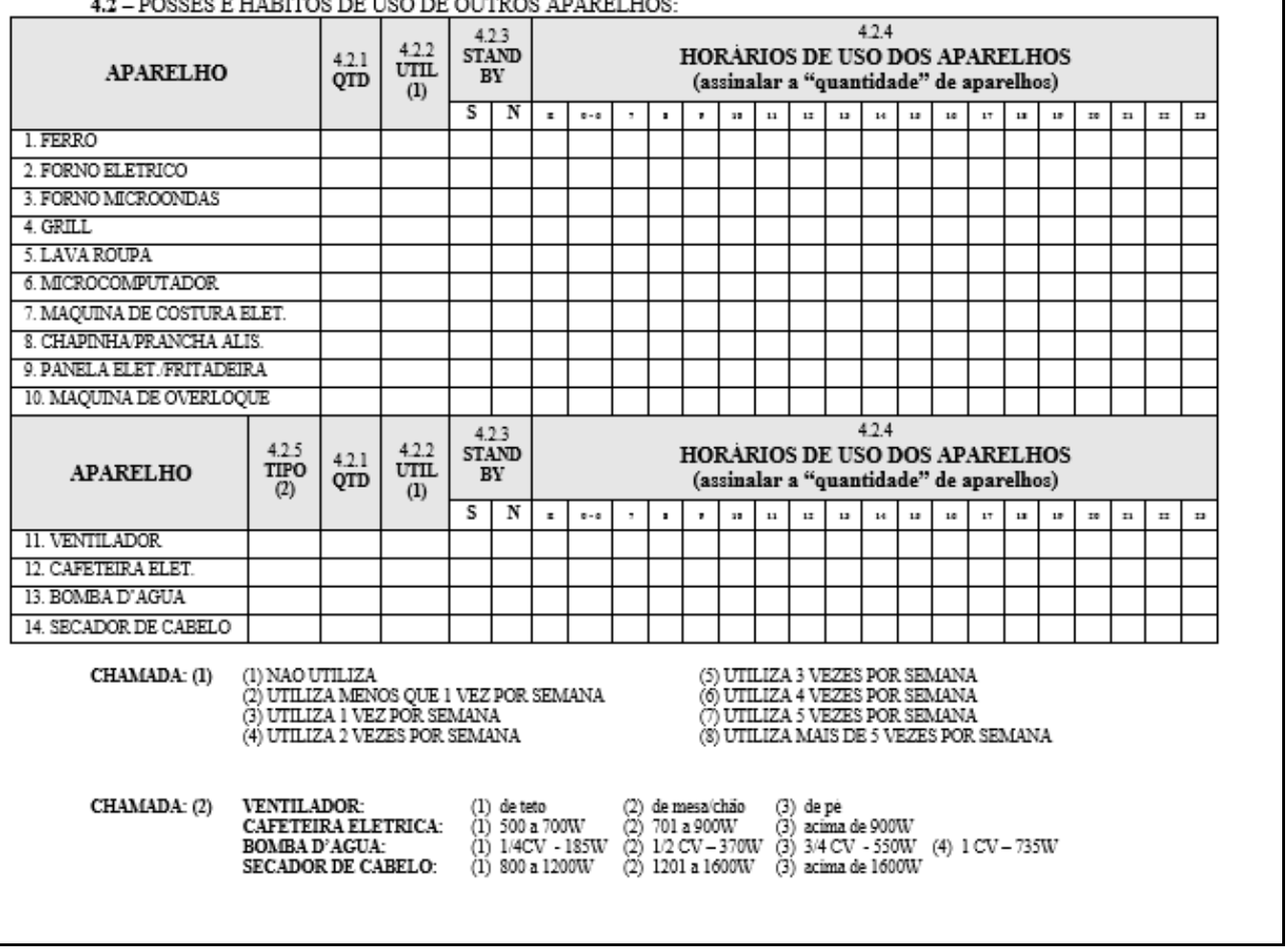




\section{OUTRAS INFORMAÇỎES SOBRE EQUIPAMENTOS ELĖTRICOS}

5.1 - PRETENDE COMPRAR ALGUM ELETRODOMESTICO NOS PROXIMOS SEIS MESES, PARA ESTE DOMICILIO?

1. 7 SIM - (PREENCHA TABELA ABAIXO IDENTIFICANDO NO CARTÃO 6)

2. \ NÃO $99 . \square$ NÃO SABE/NR

\begin{tabular}{|l|l|l|l|l|l|l|l|l|l|l|}
\hline & & & & & & & & & & \\
\hline
\end{tabular}

5.2 - NESTE DOMICILIO E FEITO ALGUM TIPO DE TRABALHO PARA SER COMERCIALIZADO? (VEJA NO CARTÄO 7

CASO NAOO SEJA FEITO NENHUM TIPO DE TRABALHO COM FIM COMERCIAL, VA PARA O ITEM 5.5.

5.3 - QUAIS SÄO OS EQUIPAMENTOS ELETRICOS UTILIZADOS NESTE(S) TRABALHO(S)? (IDENTIFIQUE OS EQUIPAMENTOS NO CARTAOO 6

5.4 - EM QUE FAIXA VOCE CLASSIFICARIA A RENDA TOTAL DO SEU DOMICILIO (em salários mínimos)?

1. $\square$ ( RS 510)

2. 1 a 2 (R\$ 511 a 1.020)

5.74 a 5 (R $\$ 2.041$ a 2.550$)$

8. $\square 10$ a 15 (R\$ 5.101 a 7.650)

11. 30 a 40 (R\$ 15.301 a 20.400)

10. $\square 20$ a $30(\mathrm{R} \$ 10.201$ a 15.300$)$

99. [ NÃO SABE/NR
3. 2 a 3 (RS 1.021 a 1.530)

6. 5 a 7 (RS 2.551 a 3.570 )

9. 15 a 20 (R\$ 7.650 a 10.200$)$

12. $] 40$ (R\$ 20.401) 
5.5 - LISTE AS PESSOAS QUE MORAM NESTE DOMICILIO, ESPECIFICANDO GRAU DE PARENTESCO OU RELAÇÄO COM O(A) CHEFE DA FAMIILIA, IDADE, SEXO, NIVEL DE INSTRUÇÄO E PERIODO HABITUAL DE PERMANENCIA NO DOMICILIO

\begin{tabular}{|c|c|c|c|c|c|c|c|c|}
\hline \multirow[t]{2}{*}{$\begin{array}{c}5.5 .1 \\
\text { NOME DO MORADOR }\end{array}$} & \multirow{2}{*}{$\begin{array}{l}5.5 .2 \\
\text { CONDIÇÄO } \\
\text { No } \\
\text { DOMICILIO } \\
\text { (1) }\end{array}$} & \multirow[t]{2}{*}{$\begin{array}{c}5.3 .3 \\
\text { IDADE }\end{array}$} & \multirow{2}{*}{$\begin{array}{c}5.5 .4 \\
\text { SEXO } \\
M=1 \\
\mathrm{~F}=2\end{array}$} & \multirow{2}{*}{$\begin{array}{l}5.5 .5 \\
\text { NIVEL DE } \\
\text { INSTRUÇÄO } \\
\text { (2) }\end{array}$} & \multicolumn{4}{|c|}{$\begin{array}{c}5.2 .0 \\
\text { EM QUE PARTE DO DIA O } \\
\text { MORADOR PERMANECE NO } \\
\text { DOMICILIO? }\end{array}$} \\
\hline & & & & & Manhä & Tarde & Noite & Madrugada \\
\hline \multicolumn{9}{|l|}{ 1) } \\
\hline \multicolumn{9}{|l|}{ 2) } \\
\hline \multicolumn{9}{|l|}{ 3) } \\
\hline \multicolumn{9}{|l|}{ 4) } \\
\hline \multicolumn{9}{|l|}{ 5) } \\
\hline \multicolumn{9}{|l|}{ 6) } \\
\hline \multicolumn{9}{|l|}{ 7) } \\
\hline \multicolumn{9}{|l|}{ 8) } \\
\hline \multicolumn{9}{|l|}{ 9) } \\
\hline 10) & & & & & & & & \\
\hline
\end{tabular}

CHAMADA: (1)
(1) CHEFE DA FAMILIA
(2) CONJUGE COMPANHEIRO(A)
(4) OUTRO PARENIE
(5) AGRBGADO
CHAMADA- (2)
(1) ANALFABETO
(3) ATE GNASIAL INCOMPLETO
(4) ATE COLEGLAL NCOMPLETO
(5) ATE SUPERIOR NCOMPLETO
(6) CURSO SUPERIOR COMPLETO
(99) NS/NR

(7) EMPREGADO DOMESTICO

(8) HOARENIE

OBS.1: Hoje a terminologia é ensino fundamental $\left(1^{x}\right.$ a $9^{x}$ série) e ensino médio ( $1^{x}$ a $3^{x}$ gérie do $2^{\circ}$ grau)

OBS.2: Criança de até 7 anos, é considerada no nivel de instrução, como primário incompleto

\section{IDENTIFICAC̣Á:}

6.1 - ENTREVISTADOR

6.2 - ENTREVISTADO:

6.3 - ENDEREÇO

6.4 - BAIRRO: 6.5 - TELEFONE

6.6 - DATA DA ENTREVISTA.

6.7 - ESSA PESQUISA FOI CONTRATADA PELA SUA CONCESSIONARIA DE ENERGIA. O SR.(A) ACEITARIA A INSTALACẢO DE UM MEDIDOR DE ENERGIA POR 1 SEMANA AQUT NO SEU DOMICILIO PARA QUE POSSAMOS INTENSIFICAR AS NOSSAS ANALISES?

1. 7 SIM, RUBRICAR DE ACORDO

2. \ NÃO 


\section{ANEXO II - Tabela de estimativa de consumo médio mensal de eletrodomésticos}

\begin{tabular}{|c|c|c|c|}
\hline \multicolumn{4}{|c|}{ 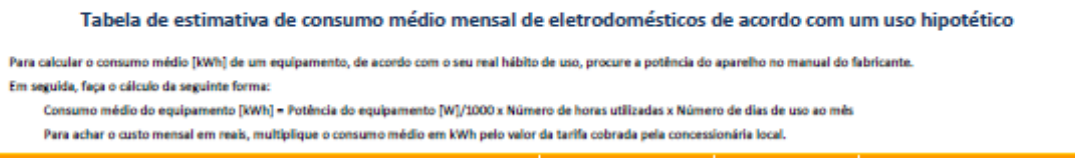 } \\
\hline \multirow{2}{*}{ NoARELHos ELETracos } & DIAS EsTIMLOOS & mtou & consumo Mtoro MENSAL \\
\hline & Usa/mes & Untracho/Des & $(\mathrm{aWh})$ \\
\hline APACELHO DE BL RAY & 8 & $2 \mathrm{~h}$ & 0,192 \\
\hline APANELHO DE DVD & 8 & $2 \mathrm{~h}$ & 0,240 \\
\hline APARELHO DE SOM 3 EM 1 & 20 & $3 \mathrm{~h}$ & 6,600 \\
\hline AQUECEDOR DE AMEIIENTE & 15 & $8 \mathrm{~h}$ & 193,440 \\
\hline AQUECEDOR DE MAMADEIRA & 30 & $15 \mathrm{mb}$ & 0,750 \\
\hline AQUECEDOR DE MARMTIA & 20 & $30 \mathrm{mb}$ & 0,600 \\
\hline AR CONDICOONADO THO IANELA MENOR OU IGUAL A 9.000 BTU & 30 & $8 \mathrm{~h}$ & 128,800 \\
\hline AR CONOICIONADO THO JANELA DE 9.001 A 14.000 BTU & 30 & $8 \mathrm{~h}$ & 181,600 \\
\hline AR CONDICDONADO TIPO IANELA MAJORR QUE $14.000 \mathrm{BTU}$ & 30 & $8 \mathrm{~h}$ & 374,000 \\
\hline AR CONDICIONADO TINO SRIT MENOR OU ICUAL A 10.000 BTU & 30 & $8 \mathrm{~h}$ & 142,288 \\
\hline AR CONOICOOMADO THO SRLT DE 10.001 A 15.000 BTU & 30 & $8 \mathrm{~h}$ & 193,760 \\
\hline AR CONOICONADO THO SRLT DE 15.001 A 20.000 BTU & 30 & $8 \mathrm{~h}$ & 203,680 \\
\hline AR CONOICONADO TINO SALT DE 20.001 A 30.000 BTU & 30 & $8 \mathrm{~h}$ & 439,200 \\
\hline AR CONOICOONADO THNO SMLT MNIOR QUE 30.000 BTU & 30 & $8 \mathrm{~h}$ & 679,200 \\
\hline ASMRADOR DE PÓ & 30 & $20 \mathrm{mb}$ & 7,170 \\
\hline BATEDEVIRA & 8 & $20 \mathrm{mh}$ & 0,400 \\
\hline BOILER ELÉTRCO DE $200 \mathrm{~L}$ & 30 & $24 \mathrm{~h}$ & 346,750 \\
\hline BOMEA O'ÁGUA $1 / 2 \mathrm{QV}$ & 30 & $30 \mathrm{mb}$ & 7,200 \\
\hline BOMBA D'ÁGUA $1 / 3 \mathrm{CV}$ & 30 & $30 \mathrm{mk}$ & 6,150 \\
\hline CAFETERRA ELÉtRUCA & 30 & $1 \mathrm{~h}$ & 6,565 \\
\hline CAFETEIRA EXPRESSO & 30 & $1 \mathrm{~h}$ & 23,820 \\
\hline CHALEREA ELETIRTA & 30 & $1 \mathrm{~h}$ & 28,230 \\
\hline OHURSASQUERA ELETRICA & 5 & $4 \mathrm{~h}$ & 76,000 \\
\hline CHUVELRO ELETRUCO - $4500 \mathrm{~W}$ & 30 & $32 \mathrm{mb}$ & 72,000 \\
\hline OHUVELRO ELETRUCO - $5500 \mathrm{~W}$ & 30 & $32 \mathrm{mb}$ & 88,000 \\
\hline COMNUTADOR & 30 & $8 \mathrm{~h}$ & 15,120 \\
\hline ENCERADEIRA & 2 & $2 \mathrm{~h}$ & 1,800 \\
\hline ESPRENEDOR DE FRUTAS & 20 & $10 \mathrm{mb}$ & 0,187 \\
\hline EXEUSTOR FOCäO & 30 & $2 \mathrm{~h}$ & 9,960 \\
\hline FAX MODEN EM STAND BY & 30 & $24 \mathrm{~h}$ & 2,160 \\
\hline FERRO ELÉTRUCO AUTOMÁTCO A SECO - $1050 \mathrm{~W}$ & 12 & $1 \mathrm{~h}$ & 2,400 \\
\hline FERRO ELETRUCO AUTOMÁTICO A VAPOR - $1200 \mathrm{~W}$ & 12 & $1 \mathrm{~h}$ & 7,200 \\
\hline ROCAO ELETRUCO - COOK TOP (POR QUEMMADOR) & 30 & $1 \mathrm{~h}$ & 68,550 \\
\hline FORNO ELÉTRUCO & 30 & $1 \mathrm{~h}$ & 15,000 \\
\hline RORNO MIORO-ONDAS - $25 \mathrm{~L}$ & 30 & $20 \mathrm{mh}$ & 13,960 \\
\hline FREEZER VERTCAL/MORLZONTAL & 30 & $24 \mathrm{~h}$ & 47,550 \\
\hline FREEZER VERTCAL FROST FREE & 30 & $24 \mathrm{~h}$ & 54,000 \\
\hline frloobar & 30 & $24 \mathrm{~h}$ & 18,900 \\
\hline FRTTADEIRA ELÉTRUCA & 15 & $30 \mathrm{mb}$ & 6,810 \\
\hline PURADEIRA & 4 & $1 \mathrm{~h}$ & 0,944 \\
\hline GELADEIRA I MORTA & 30 & $24 \mathrm{~h}$ & 25,200 \\
\hline GELADERA 1 MORTA FROST FREF & 30 & $24 \mathrm{~h}$ & 39,600 \\
\hline GELADEIRA 2 MORTAS & 30 & $24 \mathrm{~h}$ & 48,240 \\
\hline GELADEIRA 2 MORTAS FROST FREE & 30 & $24 \mathrm{~h}$ & 56,800 \\
\hline GRац & 10 & $30 \mathrm{mb}$ & 3,205 \\
\hline HOME THEATER - $350 \mathrm{~W}$ & 8 & $2 \mathrm{~h}$ & 5,600 \\
\hline
\end{tabular}

Página 1 de 2

Fonte: PROCEL/ELETROBRAS 


\begin{tabular}{|c|c|c|c|}
\hline \multirow{2}{*}{ NARELHOS ELETRICOS } & DIN EsTIENoos & metora & CONSUMO MtDHO MENSML \\
\hline & Usa/mes & Uthacho/Da & (aWh) \\
\hline IMPRESSORA & 30 & $1 \mathrm{~h}$ & 0,450 \\
\hline LAMPADA FWORESCENTE COMEACTA - $11 \mathrm{~W}$ & 30 & $5 \mathrm{~h}$ & 1,650 \\
\hline LAMPADA FWORESCENTE COMEACTA - $15 \mathrm{~W}$ & 30 & $5 \mathrm{~h}$ & 2,250 \\
\hline LAMPADA FUORESCENTE CONPACTA - $23 \mathrm{~W}$ & 30 & $5 \mathrm{~h}$ & 3,450 \\
\hline LAMPADA INCANDESCENTE - $40 \mathrm{~W}$ & 30 & $5 \mathrm{~h}$ & 6,000 \\
\hline LAMPAQDA INCANDESCENTE - $60 \mathrm{~W}$ & 30 & $5 \mathrm{~h}$ & 9,000 \\
\hline LAMPADA INCANDESCENTE - $100 \mathrm{~W}$ & 30 & $5 \mathrm{~h}$ & 15,000 \\
\hline LAVADORA DE LOUCAS & 30 & $40 \mathrm{mb}$ & 30,860 \\
\hline LAVADORA DE ROUPAS & 12 & $1 \mathrm{~h}$ & 1,764 \\
\hline UQUUDIFICADOR & 15 & $15 \mathrm{mb}$ & 0,806 \\
\hline Maquisa de COSTURA & 10 & $3 \mathrm{~h}$ & 3,000 \\
\hline MOOEM DE INTERAET & 30 & $8 \mathrm{~h}$ & 1,920 \\
\hline MONITOR & 30 & $8 \mathrm{~h}$ & 13,200 \\
\hline MONITOR LCD & 30 & $8 \mathrm{~h}$ & 8,160 \\
\hline MULTPROCESSADOR & 20 & $1 \mathrm{~h}$ & 8,560 \\
\hline NEBULEZADOR & 16 & $2,5 \mathrm{~h}$ & 1,680 \\
\hline NOTEBOOKK & 30 & $8 \mathrm{~h}$ & 4,800 \\
\hline PANELA Eletruca & 20 & $1 \mathrm{~h}$ & 22,000 \\
\hline PraNOHA (CHAPINHA) & 20 & $30 \mathrm{mb}$ & 0,330 \\
\hline PROJETOR & 20 & 1h & 4,780 \\
\hline RéDIO ELETRTCO PEQUENO & 30 & $10 \mathrm{~h}$ & 1,500 \\
\hline REDIO RELOCIO & 30 & $24 \mathrm{~h}$ & 3,600 \\
\hline ROTEADOR & 30 & $8 \mathrm{~h}$ & 1,440 \\
\hline SANOUICHELRA & 30 & $10 \mathrm{mb}$ & 3,348 \\
\hline SCANNER & 30 & $1 \mathrm{~h}$ & 0,270 \\
\hline SECADOR DE CABELO - $1000 \mathrm{~W}$ & 30 & $10 \mathrm{mb}$ & 5,215 \\
\hline SECADORA DE ROUPA & 8 & $1 \mathrm{~h}$ & 14,920 \\
\hline TANQUinHo & 12 & $1 \mathrm{~h}$ & 0,840 \\
\hline TELEFONE SEM FIO & 30 & $24 \mathrm{~h}$ & 2,160 \\
\hline TORNEDEA ELETROCA - $3250 \mathrm{~W}$ & 30 & $30 \mathrm{mb}$ & 48,750 \\
\hline TORREDEIRA & 30 & $10 \mathrm{mb}$ & 4,000 \\
\hline TV EM CORES - 14" (TUBO) & 30 & $5 \mathrm{~h}$ & 6,300 \\
\hline TV EM CORES - 20 (TUBO) & 30 & $5 \mathrm{~h}$ & 15,150 \\
\hline TV EM CORES - 32 (LCD) & 30 & $5 \mathrm{~h}$ & 14,250 \\
\hline TV EM CORES - 40" (LED) & 30 & $5 \mathrm{~h}$ & 12,450 \\
\hline TV EM CORES - 42 (LCD) & 30 & $5 \mathrm{~h}$ & 30,450 \\
\hline TV PORTÁTLL & 30 & $5 \mathrm{~h}$ & 7,060 \\
\hline VENTLADOR DE MESA & 30 & $8 \mathrm{~h}$ & 17,280 \\
\hline VENTLADOR DE TETO & 30 & $8 \mathrm{n}$ & 17520 \\
\hline VDDEOGAME & 15 & $4 \mathrm{~h}$ & 1,449 \\
\hline
\end{tabular}

Fonte: PROCEL/ELETROBRAS 


\section{ANEXO III - Relatório anual de Demonstrações Financeiras da AMPLA (2012) - Número de consumidores}

DESEMPENHO OPERACIONAL

NÚMERO DE CONSUMIDORES (UNID.)

\begin{tabular}{lr} 
& 2012 \\
\hline Mercado Cativo & $\mathbf{2 . 3 9 8 . 2 8 9}$ \\
\hline Residencial - Convencional & 1.899 .196 \\
Residencial - Baixa Renda & 269.357 \\
Industrial & 4.682 \\
Comercial & 145.784 \\
Rural & 63.088 \\
$\quad$ Setor Público & 16.182 \\
\hline Clientes Livres & 39 \\
\hline Industrial & 28 \\
$\quad$ Comercial & 11 \\
\hline Revenda & 13 \\
\hline Subtotal - Consumidores Efetivos & 2.398 .341 \\
\hline Consumo Próprio & 365 \\
Consumidores Ativos sem Fornecimento & 313.653 \\
\hline Total - Número de Consumidores & $\mathbf{2 . 7 1 2 . 3 5 9}$ \\
\hline
\end{tabular}

Fonte: AMPLA 


\section{ANEXO IV - Relatório anual de Demonstrações Financeiras}

da AMPLA(2012) - Volume de vendas

\begin{tabular}{lr} 
& 2012 \\
\hline Residencial - Convencional & 3.915 \\
Residencial - Baixa Renda & 417 \\
Industrial & 1.058 \\
Comercial & 2.052 \\
Rural & 234 \\
Setor Público & 1.292 \\
\hline Total - Venda de Energia no Mercado Cativo & 8.968 \\
\hline
\end{tabular}

Fonte: AMPLA 
ANEXO V - Anuário Estatístico de Energia Elétrica 2011:

Consumo por classe

Tabela 3.24 Consumo da classe residencial por região geográfica e tensão de fornecimento (GWh)

\begin{tabular}{lrrrrrrrr} 
& 2006 & 2007 & 2008 & 2009 & 2010 & $\begin{array}{r}\Delta \% \\
(2010 / 09)\end{array}$ & $\begin{array}{r}\text { Part. \% } \\
\text { (2010) }\end{array}$ \\
\hline Total & 85.784 & 89.885 & 94.746 & 100.776 & 107.215 & 6,4 & 100,0 \\
A - Alta Tensão & 190 & 183 & 160 & 160 & 159 & $-0,8$ & 0,1 \\
B - Baixa Tensão & 85.593 & 89.703 & 94.586 & 100.616 & 107.056 & 6,4 & 99,9
\end{tabular}

Fonte: EPE 


\section{ANEXO VI - Anuário Estatístico de Energia Elétrica 2011: Consumidores por classe}

Tabela 3.34 Número total de consumidores por classe

\begin{tabular}{lrrrrrrrr} 
& 2006 & 2007 & 2008 & 2009 & 2010 & $\begin{array}{c}\Delta \% \\
(2010 / 09)\end{array}$ & $\begin{array}{r}\text { Part. \% } \\
(2010)\end{array}$ \\
\hline Brasil & 58.979 .698 & 61.072 .066 & 63.367 .452 & 65.528 .441 & 67.906 .964 & 3,6 & 100,0 \\
\hline Residencial & 50.318 .859 & 52.057 .460 & 54.156 .879 & 55.949 .403 & 58.006 .079 & 3,7 & 85,4 \\
Industrial & 515.618 & 525.504 & 528.953 & 536.545 & 553.589 & 3,2 & 0,8 \\
Comercial & 4.431 .013 & 4.528 .838 & 4.635 .006 & 4.794 .546 & 4.901 .920 & 2,2 & 7,2 \\
Rural & 3.163 .016 & 3.385 .448 & 3.439 .007 & 3.613 .254 & 3.784 .428 & 4,7 & 5,6 \\
Poder público & 435.944 & 451.633 & 471.086 & 490.520 & 507.455 & 3,5 & 0,7 \\
Iluminação pública & 52.048 & 57.337 & 65.130 & 69.858 & 73.947 & 5,9 & 0,1 \\
Serviço público & 51.982 & 54.586 & 60.079 & 63.016 & 68.017 & 7,9 & 0,1 \\
Próprio & 11.218 & 11.260 & 11.312 & 11.299 & 11.529 & 2,0 & 0,0 \\
\hline
\end{tabular}

Nota: dezembro de cada ano

Fonte: EPE

Fonte: EPE 


\section{ANEXO VII - Anuário Estatístico de Energia Elétrica 2013: Tarifa média por classe}

Tabela 3.93 Tarifa média por classe ( $\mathrm{R} \$ \mathbf{M W h})$

\begin{tabular}{lrrrrrrr} 
& 2008 & 2009 & 2010 & 2011 & 2012 & $\begin{array}{r}\Delta \% \\
(2012 / 11)\end{array}$ & $\Delta \%$ médio \\
& $28012 / 08)$ \\
\hline Residencial & 282,02 & 293,48 & 300,14 & 324,07 & 333,47 & 2,9 & 4,3 \\
Industrial & 216,41 & 230,31 & 236,58 & 218,11 & 262,32 & 20,3 & 4,9 \\
Comercial & 273,26 & 281,96 & 286,97 & 286,40 & 309,80 & 8,2 & 3,2 \\
Rural & 178,95 & 189,48 & 198,22 & 202,29 & 220,25 & 8,9 & 5,3 \\
Poder Público & 296,09 & 308,11 & 311,51 & 315,16 & 336,51 & 6,8 & 3,3 \\
Iluminação Pública & 158,66 & 163,66 & 166,79 & 172,24 & 182,53 & 6,0 & 3,6 \\
Serviço Público & 195,07 & 204,58 & 207,13 & 194,94 & 221,52 & 13,6 & 3,2 \\
Consumo Próprio & 276,33 & 296,14 & 305,04 & 306,09 & 323,87 & 5,8 & 4,0 \\
\hline
\end{tabular}

Fonte: Agência Nacional de Energia Elétrica (ANEEL): Sistema de Apoio à Decisão (SAD) última atualização em 16/04/2013

Fonte: ANEEL 